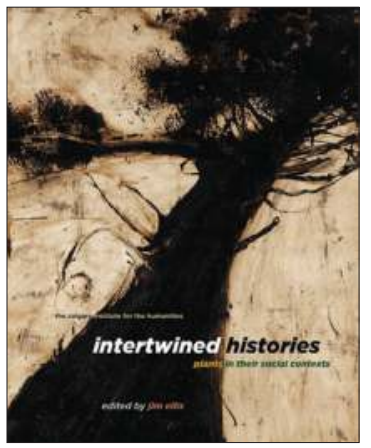

\title{
INTERTWINED HISTORIES: Plants in their Social Contexts
}

\section{Edited by Jim Ellis}

ISBN 978-1-77385-091-7

THIS BOOK IS AN OPEN ACCESS E-BOOK. It is an electronic version of a book that can be purchased in physical form through any bookseller or on-line retailer, or from our distributors. Please support this open access publication by requesting that your university purchase a print copy of this book, or by purchasing a copy yourself. If you have any questions, please contact us at ucpress@ucalgary.ca

Cover Art: The artwork on the cover of this book is not open access and falls under traditional copyright provisions; it cannot be reproduced in any way without written permission of the artists and their agents. The cover can be displayed as a complete cover image for the purposes of publicizing this work, but the artwork cannot be extracted from the context of the cover of this specific work without breaching the artist's copyright.

COPYRIGHT NOTICE: This open-access work is published under a Creative Commons licence. This means that you are free to copy, distribute, display or perform the work as long as you clearly attribute the work to its authors and publisher, that you do not use this work for any commercial gain in any form, and that you in no way alter, transform, or build on the work outside of its use in normal academic scholarship without our express permission. If you want to reuse or distribute the work, you must inform its new audience of the licence terms of this work. For more information, see details of the Creative Commons licence at: http://creativecommons.org/licenses/by-nc-nd/4.0/

UNDER THE CREATIVE COMMONS LICENCE YOU MAY:

- read and store this document free of charge;

- distribute it for personal use free of charge;

- print sections of the work for personal use;

- read or perform parts of the work in a context where no financial transactions take place.
UNDER THE CREATIVE COMMONS LICENCE YOU MAY NOT:

- gain financially from the work in any way;

- sell the work or seek monies in relation to the distribution of the work;

- use the work in any commercial activity of any kind;

- profit a third party indirectly via use or distribution of the work;

- distribute in or through a commercial body (with the exception of academic usage within educational institutions such as schools and universities);

- reproduce, distribute, or store the cover image outside of its function as a cover of this work;

- alter or build on the work outside of normal academic scholarship.

Acknowledgement: We acknowledge the wording around open access used by Australian publisher, re.press, and thank them for giving us permission to adapt their wording to our policy http://www.re-press.org 


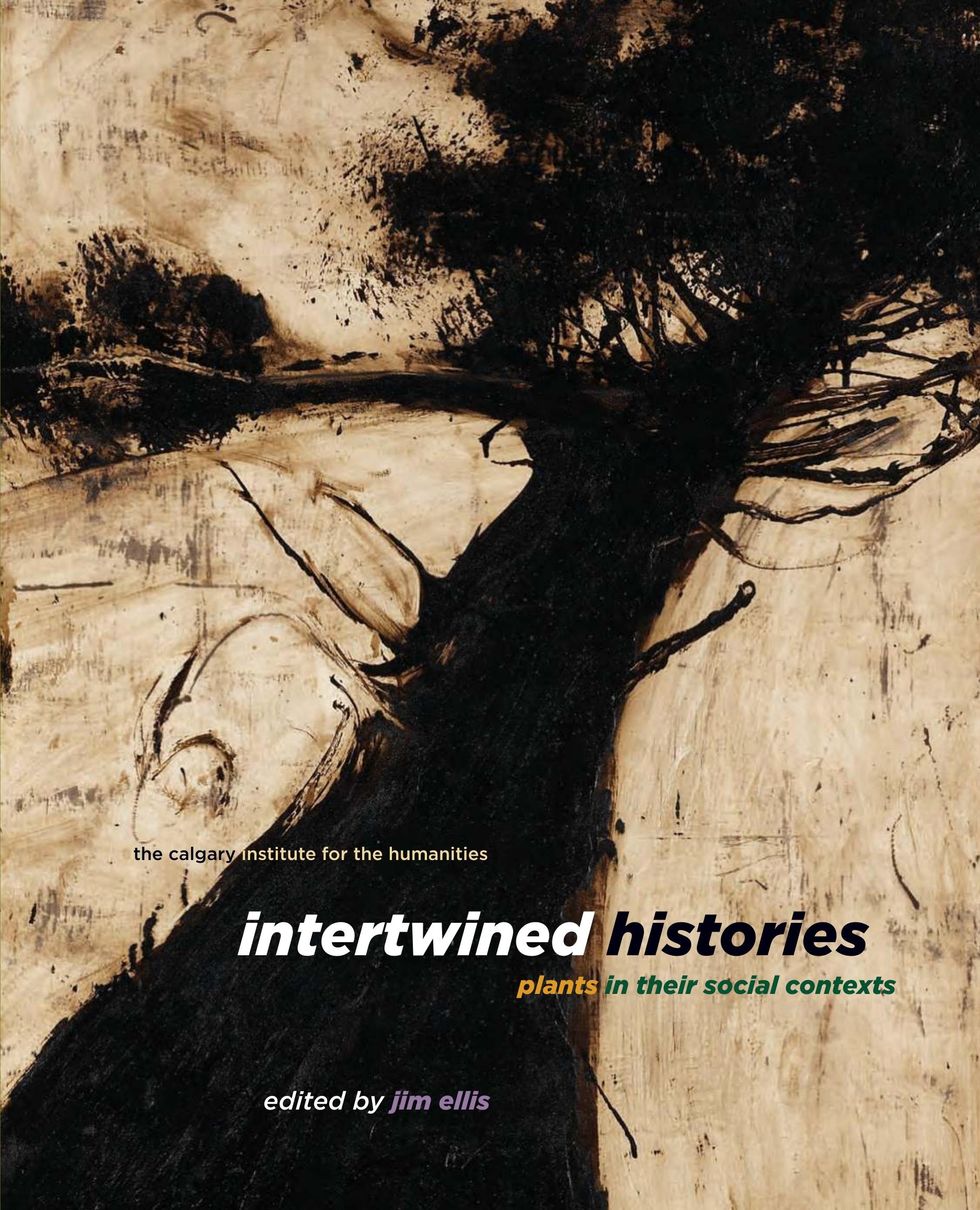




\section{intertwined histories \\ plants in their social contexts}




\section{UMVERSTTY OF CALGARY \\ FACULTY OF ARTS \\ Calgary institute for the Humanities}

\section{Calgary Institute for the Humanities Series}

Co-published with the Calgary Institute for the Humanities

ISSN 2560-6883 (Print) ISSN 2560-6891 (Online)

The humanities help us to understand who we are and where we came from; they help us to understand and respectfully engage with those who are different from us; and they encourage a curiosity and imagination that allows us to bring older ideas to the new worlds in which we find ourselves. Books in this series embody this spirit of inquiry.

No. 1 Calgary: City of Animals, edited by Jim Ellis

No. 2 Water Rites: Reimagining Water in the West, edited by Jim Ellis

No. 3 Intertwined Histories: Plants in Their Social Contexts, edited by Jim Ellis 


\title{
intertwined histories
}

plants in their social contexts

\author{
edited by jim ellis
}

a special publication of the university of calgary press

in co-operation with the calgary institute for the humanities 
University of Calgary Press

2500 University Drive NW

Calgary, Alberta

Canada $\mathrm{T} 2 \mathrm{~N} 1 \mathrm{~N} 4$

press.ucalgary.ca

This book is available as an ebook which is licensed under a Creative Commons license.

The publisher should be contacted for any commercial use which falls outside the terms of that license.

Library and Archives Canada Cataloguing in Publication

Title: Intertwined histories : plants in their social contexts / edited by Jim Ellis.

Names: Ellis, Jim, 1964- editor. | Calgary Institute for the Humanities, publisher.

Series: Calgary Institute for the Humanities series ; no. 3

Description: Series statement: Calgary Institute for the Humanities series, 2560-6883 ; no. 3 |

This book has its origins in the Calgary Institute for the Humanities' 38th Annual Community Seminar, which took place in May 2018. I Includes bibliographical references.

Identifiers: Canadiana (print) 20190073446 | Canadiana (ebook) 2019007342X | ISBN

9781773850900 (softcover) | ISBN 9781773850917 (Open Access PDF) | ISBN

9781773850924 (PDF) | ISBN 9781773850931 (EPUB) | ISBN 9781773850948 (Kindle)

Subjects: LCSH: Plants. | LCSH: Plants-History. | LCSH: Plants-Social aspects. | LCSH:

Plants in art.

Classification: LCC QK50 .158 2019 | DDC 580-dc23

The University of Calgary Press acknowledges the support of the Government of Alberta through the Alberta Media Fund for our publications. We acknowledge the financial support of the Government of Canada. We acknowledge the financial support of the Canada Council for the Arts for our publishing program.

\section{Albertar Canadilä}

Copyediting by Peter Enman

Front \& Back flap image: A cultivar of garden pea (Pisum sativum) and of variegated kale (Brassica oleracea acephala). Chromolithograph, c. 1890. Credit: Wellcome Collection. (CC BY 4.0). Cover art: Attila Richard Lukacs, Arbour Vitae 6, 2002, bitumen and oil on canvas, private collection, photograph courtesy Glenbow Museum

Cover design, page design, and typesetting by glenn mielke

OPPOSITE: An 'everlasting' pea plant (Lathyrus latifolius): flowers and leaf Chromolithograph, c. 1879, after F. Hulme. Wellcome Collection (CC BY 4.0). 


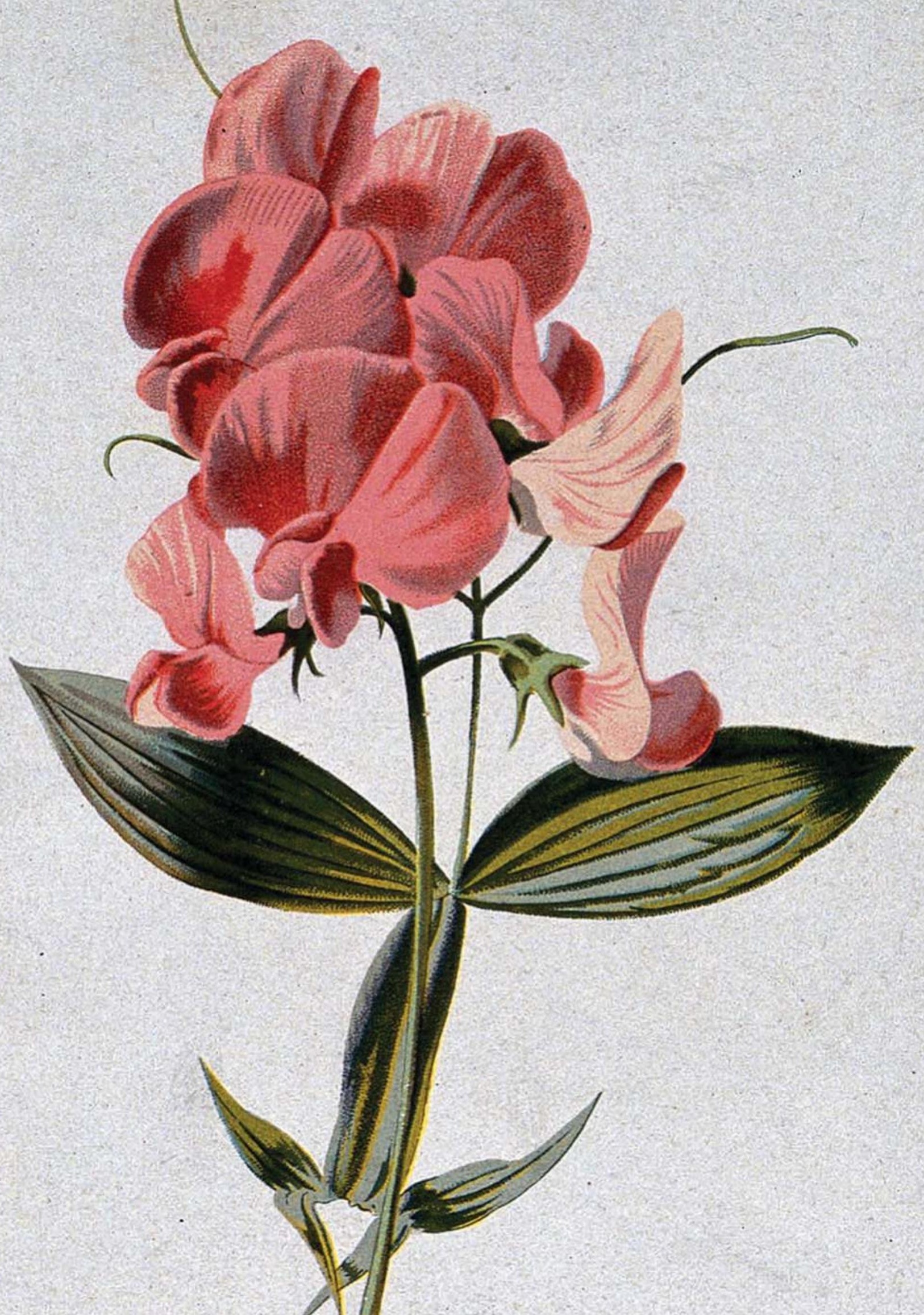





\section{contents}

xi acknowledgements

xiff introduction

jim ellis

1 the nature of plants: how different scientific perspectives shape our understanding of what plants are

james f. cahill jr., megan k. ljubotina, \& habba f. mahal

12 phytognosis: learning from plants

patrícia vieira

20 historia plantarum: from persphone's abecedarium

erina harris

36 periculum: artist's statement \& portfolio

jennifer wanner

46 spectral garden: artist's statement \& portfolio

laura st. pierre

54 mike macdonald's butterfly garden: the little garden that could katherine ylitalo 

66 an ancient partnership: prairie grass, bison, \& First Nations wes olson

76 big stone

m. n. hutchinson

78 gone today, here tomorrow:

an interview with mia rushton \& eric moschopedis

ciara mckeown

88 the city of calgary's urban forest: past, present, \& future nikki anguish

92 make the waste places fruitful gardens: the calgary vacant lots garden club, 1914-1952 jim ellis

102 coming into noticing: on being called to account by ancient trees andrew s. mathews

112 leila sujir's forest of pixels nancy tousley

125 contributors 


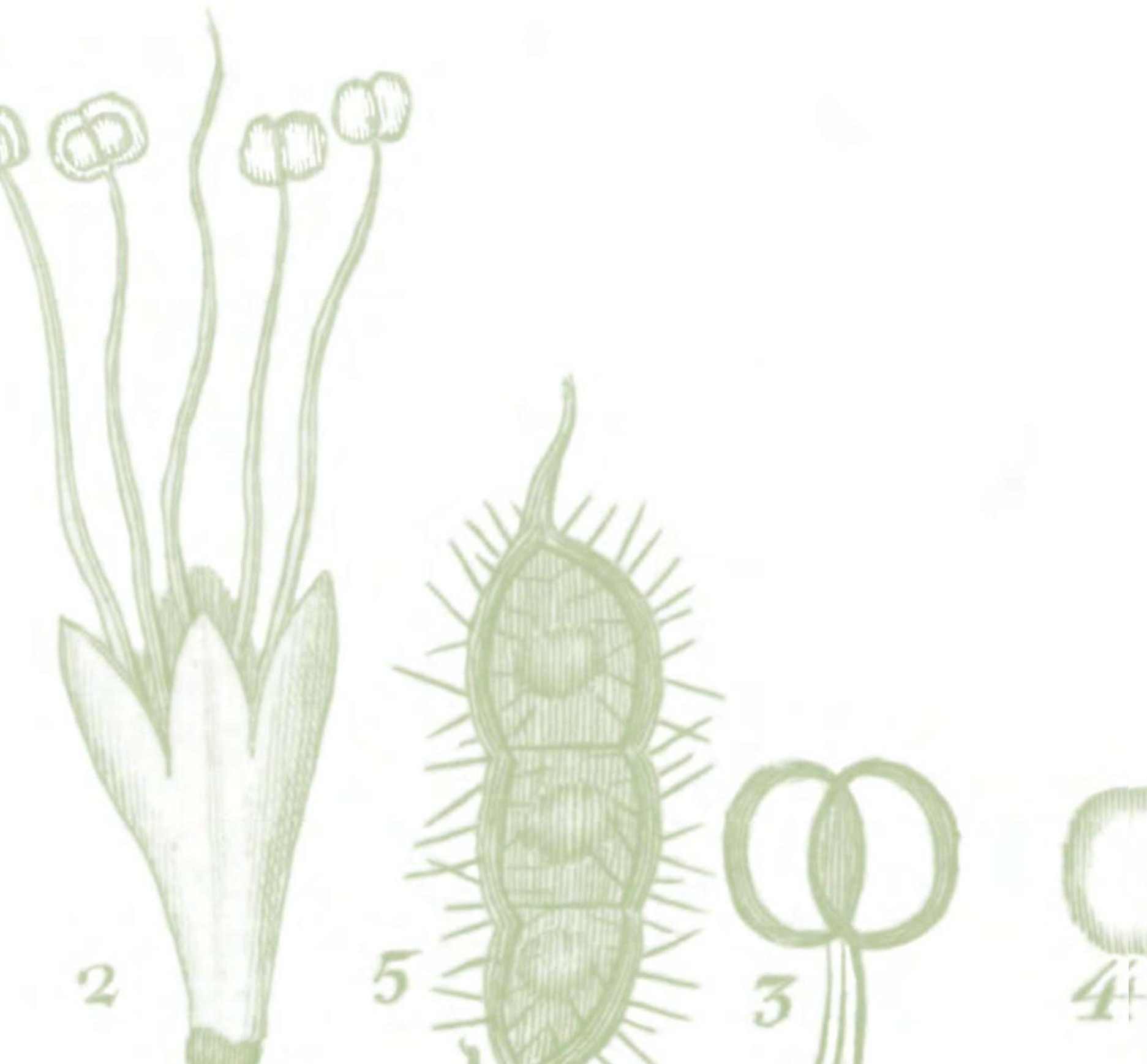




\section{acknowledgements}

This book originated in the Calgary Institute for the Humanities' Annual Community Seminar for 2018, which had the theme Living with Plants. The idea for the seminar came from the ClH's Advisory Council, which included Jackie Flanagan, Fran Jamison, Murray Laverty, Donna Livingstone, Judy MacLachlan, Micheline Maylor, Bill Ptacek, Valerie Seaman, Nancy Tousley, and Rod Wade. Many thanks are due for their guidance and support of the project from beginning to end; I am particularly grateful to Nancy Tousley for her advice on art and artists.

At the University of Calgary Press, Brian Scrivener, Helen Hajnoczky, Alison Cobra, and Melina Cusano have all been very supportive of the project and our vision for the book; thanks to glenn mielke for the beautiful design.

Carol Stokes, Archivist at the City of Calgary Corporate Records, Archives very helpfully compiled information about the Calgary Vacant Lots Garden Club. Thanks as well to the staff at the Glenbow for assistance with archival images and objects.

$\mathrm{ClH}$ Coordinator Sean Lindsay provided research assistance and organizational support for the community seminar and at all stages of book production. I am grateful to the four original speakers at the seminar, and to all of the other contributors to the book, for being co-operative and patient with our many requests as the outlines of the book came into shape. A heartfelt thank you to all of the writers, artists, and organizations who allowed their work to be included. Special thanks to Katherine Ylitalo for her enthusiasm and advice, and for her invaluable assistance in securing the beautiful cover image; I am grateful to Attila Richard Lukacs for giving us permission to use his work for the cover.

-jim ellis 
IMAGE pp x - xi: (Detail) Sensitive plant, Mimosa pudica, native to central and south America. Handcoloured copperplate stipple engraving from Jussieu's Dictionary of Natural Science, Florence, Italy, 1837. Engraved by Corsi, drawn by Pierre Jean-Francois Turpin, and published by Batelli e Figli. Credit: Album / Florilegius. 


\section{Thitroduction jim ellis \\ director, calgary institute for the humanities}

Plants were the first to colonize the planet, and they created the soil and the atmosphere that made life possible for the animals. The largest and oldest life forms currently inhabiting our earth are plants. In spite of their primacy, Western cultures have traditionally regarded plants as the lowest of life forms, lacking mobility, language, and sensation. However, recent research by botanists, anthropologists, philosophers, historians, and ecocritics has challenged these older views of plants, shedding new light on how plants have shaped and continue to shape life on earth, and how intimately plants are intertwined with human history.

Scholars, writers, and scientists such as Suzanne Simard, Monica Gagliano, Stefano Mancuso, and Peter Wohlleben have argued that plants move, respond to their environment, communicate with each other, and form mutually beneficial partnerships with other species.' These thinkers explore the connections to be found in the "Wood Wide Web," where mycorrhizal fungi facilitate forms of community that we traditionally associate with animals. ${ }^{2}$ These new studies not only shift our view of plants themselves as largely inert beings but also alter the way we understand the borders or boundaries of individual creatures and the systems of interdependency that bind all living things together. This leads philosophers like Matthew Hall to consider the moral standing of plants, echoing certain Indigenous ways of knowing that see plants as fellow creatures. ${ }^{3}$ 


\section{xiv introduction}

Moving in a related direction, Anna Lowenhaupt Tsing's The Mushroom at the End of the World is a breathtaking exploration of the world of the matsutake mushroom, which grows in human-disturbed forests, nurturing new growth and supporting cultures of itinerant harvesters in a globalized economy; in Tsing's telling, the mushroom offers lessons for life in the Anthropocene era. ${ }^{4}$

Here in western Canada, human habitation has always been intricately intertwined with the lives of plants. As Wes Olson demonstrates in his essay in this book, prairie grasslands co-evolved with Indigenous cultures and the buffalo. Calgary is located on land where the Bow River meets the Elbow River; the traditional Blackfoot name of this place is "Mohkinstsis." Another name for this region is "Old Man's Garden," according to Annora Brown. Brown was an Alberta artist and amateur botanist born in Red Deer in 1899; she heard the name "Old Man's Garden" in the sacred stories told to her by First Nations friends about the first man and the planting of the Earth. These stories portray a world in which plants are fellow creatures, with which we have relations and reciprocal responsibilities. In her book Old Man's Garden, Brown categorizes the plants of the foothills of Alberta largely by the uses that the First Nations people made of them: whether for food or medicine or dye, or for something else. Whenever she can, she gives the names that the First Nations people use for the plants, but she also notes the names that the European visitors gave them, and their reasons for the names, which offers an insight into the different relations that different groups have had with plants. ${ }^{5}$ As Katherine Ylitalo notes, whereas Europeans generally give plants one name, First Nations people might have three different names for different parts of the same plant.

When discussing plants, Brown writes about the methods by which the First Nations people harvested and processed them for food, whether by boiling, drying, pounding, or roasting, and how they also produced food for trade, either with other neighbouring nations or with the European visitors who came onto their territories. For the European explorers, it is clear that they could not have survived without the plant products they traded for or the knowledge of edible plants that they slowly gained. These visitors sent plants, seeds, and roots back to European collections and gardens, and brought others here. Plants are often thought of as immobile, but they do in fact get around, often by manipulating others: they manage to get insects to move their pollen, birds and animals to carry their seeds, and humans to transport them to various parts of the world.

The potato, for example, which is now one of the biggest crops in Alberta, is indigenous to the Andes and was domesticated by the Inca sometime between 8000 and 5000 
BCE; it moved to Europe in the sixteenth century, via the Spanish, before coming back across the Atlantic in the seventeenth century. In North America there were already varieties of wild potato; the sixteenth-century English botanist John Gerard in his Herball includes the Virginia potato, and notes that some called Jerusalem artichokes Battatas de Canada, or Potatoes of Canada. Wheat, our other big Alberta crop, was first domesticated about ten thousand years ago in southeastern Turkey; through cultivation, it began to move outward from Turkey around 8000 BCE.

Plants, then, have from the beginning been intertwined with the lives of humans here in the West and with the European settlement of the West. It was the prospect of farming and farmland that brought most European settlers west and, a bit later, Maritime boys like my grandfather, who came out on special trains to help harvest the grain in the 1920 s before going back to work in the logging camps of New Brunswick in the winter. What has brought others, more recently, is the fossil fuel industry, which is dependent upon the fossils not of dinosaurs but of ancient forests that grew a much longer time ago. And the burning of those fuels is causing warming trends that affect our contemporary forests, increasing the length of the forest fire season and thus diminishing the watershed's ability to hold water.

This book has its origins in the Calgary Institute for the Humanities' 38th Annual Community Seminar, which took place in May 2018. The seminar, with the title of Living with Plants, was the third in a trilogy of seminars that concerned topics from the environmental humanities. The first, in 2016, was Calgary: City of Animals, and the second, in 2017, was Water Rites: Reimagining Water in the West. The Calgary Institute for the Humanities $(\mathrm{CIH})$ is Canada's oldest humanities institute, founded in 1976 to support high-level research in the humanities at the University of Calgary and to engage the Calgary community with humanities research and questions. The contributions in this book by Patrícia Vieira, Andrew S. Mathews, James F. Cahill, and Jennifer Wanner all began as presentations in the seminar. Cahill discusses his laboratory's experiments on plant behaviour, a relatively recent and still controversial area of plant biology. His experiments are designed to test and challenge conventional notions of plants as essentially organic factories that process inputs and expend energy; instead, his lab's experiments often demonstrate that plants respond to their environments in manners similar to those of animals, taking in information about their surroundings and modifying their behaviour accordingly. 


\section{xvi introduction}

Patrícia Vieira uses the work of plant behaviourists as a starting point for a philosophical challenge to ways of thinking about human behaviour. Her essay on phytognosis asks what we can learn from the behaviour of plants, particularly in the era of the Anthropocene. Erina Harris draws on the work of Vieira and her collaborator Monica Gagliano in her poem "Historia Plantarum." This is an excerpt from a book manuscript that reimagines the ancient Homeric hymn to Demeter, the only Homeric hymn devoted to a mother and daughter. In this case, the mother is the goddess of the harvest, whose daughter Kore, the goddess of grain, is abducted by the god of the underworld. This startling revision of the myth rests on the latest philosophical speculations about plants as beings, using the language of botany to rewrite the girlhood of a plant deity.

Two of the artists included in this volume take their starting place from botanical illustration and specimen collection to produce dystopic reflections on the Anthropocene era. Jennifer Wanner presented work from her series Periculum at the 2018 Community Seminar, showing collages made from endangered plant species along with surreal animations of plants that draw on French nature documentaries of the 1930s. Wanner's project is a satiric modest proposal, grafting together the endangered plants of each Canadian province into one single entity that can be more easily preserved. In her installation "Fruits and Flowers of the Spectral Garden," Laura St. Pierre collects and preserves specimens from Saskatchewan's boreal forest. The resulting displays conjure up the melancholy of vitrines in a natural history museum, where fading and disintegrating specimens document life while simultaneously evoking death. The title of her 2018 exhibition in Regina's Sherwood Gallery, Museum of Future History, points to a possible future where these now-common plants will have disappeared from the landscape.

The cover image of this book similarly documents loss, in its sumptuous depiction of a giant tree. The painting, "Arbor Vitae (6)," is by celebrated Calgary artist Attila Richard Lukacs. What appears to be the disorienting perspective of looking up into a tree is in fact part of a series of portraits of trees in Vancouver's Stanley Park that were downed in a violent storm. These extraordinarily vibrant and active paintings, painted in gold on tar, bring an epic quality to these fallen gods, evoking the mythical dimensions of plants that Erina Harris explores in her poetry. Anthropologist Andrew S. Mathews documents the lives of other long-lived giants. His work details the mutually beneficial relations between chestnut trees and peasant farmers in Tuscany. The different time scales of lives means that individual trees depend on the labours and attentions of generations of farmers, who in turn must develop an acute sensitivity to the life cycles of trees. Mathews urges an attentiveness to the plants that surround us, an attentiveness that includes an awareness of these different time scales. 
Like the peasant farmers of Tuscany, Nikki Anguish has a professional connection to trees: she works for the City of Calgary's Urban Forestry program. Anguish attended the ClH's community seminar, and her contribution below reflects on the particular challenges faced by urban trees. She starts by noting the ambitions of city official William Pearce to make Calgary a "City of Trees"; Pearce was also involved in another early civic endeavour, the Calgary Vacant Lots Garden Club. This club started early in the city's history and was designed to help with the high cost of produce by giving city dwellers the opportunity to have gardens in vacant lots. Like other such programs in the United States, and the early twentieth-century back to the land movement, it was informed by a belief in the morally and socially uplifting experience of working with plants. The vacant lots clubs are thus important precursors to contemporary progressive programs to address food deserts in underserved city neighbourhoods, as well as to post-humanist ideas that see a moral imperative in reconsidering our relation to plants and reclaiming earlier modes of being-in-the-world.

Two pieces about artists illuminate contemporary reclamation projects. Katherine Ylitalo discusses the work of Indigenous artist Mike MacDonald, who planted a series of butterfly gardens in disused spaces around art galleries in the 1990s. The original impulse for this work was a period of illness, when an elder told MacDonald to follow the butterflies, who would lead him to medicine. Ylitalo describes the process of maintaining the garden MacDonald planted at the Banff Centre for the Arts, which is the last surviving example. Calgary artists Mia Rushton and Eric Moschopedis took up a three-month residency at the Lougheed House, a local history museum in the heart of Calgary. As they discuss in an interview with Ciara McKeown, they undertook a work of reclamation by replanting indigenous plant species in the garden outside the house and bringing examples into the house, installing them on the mantelpieces. This act of bringing the weed, a plant which is by definition "out of place," into the centre of the home, challenges our ideas of what belongs where.

The earlier history of the native plant species is discussed in Wes Olson's essay on the intertwined histories of prairie grasses, bison, and Indigenous people. Olson explores some of the complexities of the co-evolution and mutual dependency of plants, humans, and animals, as they remade the landscape of the Great Plains. Relics of the subsequent phase of that history, when the West was being homesteaded by European settlers, are represented in the work of Calgary photographer M. N. Hutchinson. Hutchinson returned to Big Stone, in southern Alberta, to visit the place where his great-grandmother briefly settled with her five daughters, having moved northward from the United States in the 


\section{xvili introduction}

course of a long migration that began in Norway. Hutchinson's long-format photographs, captured with a custom-built camera, beautifully evoke the scope of the grasslands and the melancholy of an abandoned farm.

Moving westward, Leila Sujir takes us from prairie grasslands to the old-growth forests of British Columbia. Drawing on the latest photographic and projection technology, Sujir constructs an immersive experience of a space that is increasingly threatened by logging. Nancy Tousley's discussion of Sujir's work highlights the collaborative nature of the forest project, which draws in artists, community activists, and plant researchers like Suzanne Simard.

Sujir's multi-disciplinary approach matches that of this current volume. In combining art, philosophy, poetry, history, botany, and activism, the aim is to bring together a multiplicity of approaches that will illuminate an interconnected series of stories. One recurring story is of the plants of western Canada, and their role in the long history of human habitation. This is part of a larger story about our dependence on plants, and what we can learn from them for our own survival. Plants are the foundation of life on the planet, the source of energy for human and non-human animals and the air that we breathe. In habitually overlooking plants, we miss the myriad benefits they offer to us and, perhaps, the keys to our continued co-existence. 
introduction xix

\section{notes}

1. Simard, "The Mother Tree"; Wohlleben, The Hidden Life of Trees; Gagliano, Thus Spoke the Plant; Mancuso and Viola, Brilliant Green; Gagliano, Ryan, and Vieira, The Language of Plants.

2. Macfarlane, "The Secrets of the Wood Wide Web."

3. Hall, Plants as Persons; see also Nealon, Plant Theory.

4. Tsing, The Mushroom at the End of the World.

5. Brown, O/d Man's Garden; on the relations between plants and First Nations of southern Alberta, see also Johnston, Plants and the Blackfoot.

\section{bibliography}

Brown, Annora. Old Man's Garden. Sidney, BC: Gray's Publishing, 1970.

Gagliano, Monica. Thus Spoke the Plant: A Remarkable Journey of Groundbreaking Scientific Discoveries and Personal Encounters with Plants. Berkeley, CA: North Atlantic Books, 2018.

Gagliano, Monica, John C. Ryan, and Patricia Vieira, eds. The Language of Plants. Minneapolis: University of Minnesota Press, 2017.

Hall, Matthew. Plants as Persons: A Philosophical Botany. Albany, NY: SUNY Press, 2011.

Johnston, Alex. Plants and the Blackfoot. Lethbridge, AB: Lethbridge Historical Society, 1987.

Macfarlane, Robert. "The Secrets of the Wood Wide Web." New Yorker, August 7, 2016.

Mancuso, Stefano, and Alessandro Viola. Brilliant Green: The Surprising History and Science of Plant Intelligence. Washington, DC: Island Press, 2015.

Nealon, Jeffrey T. Plant Theory: Biopower and Vegetable Life. Stanford, CA: Stanford University Press, 2016.

Simard, Suzanne. "The Mother Tree." In The Word for World is Still Forest, edited by Anna-Sophie Springer and Etienne Turpin. Berlin: K. Verlag, 2017.

Tsing, Anna Lowenhaupt. The Mushroom at the End of the World. Princeton, NJ: Princeton University Press, 2015.

Wohlleben, Peter. The Hidden Life of Trees. Vancouver, BC: Greystone Books, 2016. 



\title{
how different scientific perspectives shape our understanding of what plants are
}

\author{
james f. cahill jr. \\ megan k. ljubotina \\ habba f. mahal
}

\section{prologue}

There exists a perspective both in popular culture and in some scientific contexts that plants are inactive and insensitive organisms not capable of perceiving and responding to their environments. This perception of plants is based partly on the fact that the lives of plants are so profoundly and obviously different from our own, yet ample evidence exists demonstrating that plants are highly capable of responding to their environments. In part because of the social politics of publishing, even the use of terms such as "plant behaviour" was historically discouraged in the scientific literature. However, in the past 20-25 years there has been a marked shift in the language surrounding plant biology that has accompanied an analogous shift in our philosophical and empirical approaches to understanding plants. In science, sometimes it is challenging to move forward in a given field until the underlying philosophy of what we are trying to figure out is better understood. Until there were advances in our philosophical approach to studying plants, we were not properly equipped to understand which questions to ask. We believe that as a field, plant behaviour continues to be limited more by philosophy than the ability to do the natural science research, though there is much progress on both fronts. 


\section{2 intertwined histories plants in their social contexts}

In this essay, we discuss different scientific perspectives on plants and how this affects the questions and answers we come to in plant biological research. We also discuss some of the research being done in our lab ${ }^{1}$ and why we can comfortably discuss plant behaviour based on the data rather than personal opinion. Finally, we end on some thoughts about where our current ideas and research may lead us.

\section{on being a plant}

There are multiple scientific perspectives about what a plant is. For example, if we were interested in understanding the plants in our home garden, one way we could think of the plants therein would be through the use of descriptive terms. We could describe the garden in terms of what species are present and in what quantities-cucumbers (Cucumis sativus), sunflowers (Helianthus annuus), and tomatoes (Solanum lycopersicum), for example. We could alternatively eschew species boundaries (which tend to be especially blurry for plants) and describe the plants in terms of the characteristics that they have: the different shapes of their body parts, for example. We could note that the fruits of our cucumber plants are a very different shape from those of our tomatoes, or that our sunflowers tend to be much taller than our cucumber plants, which might allow them to thrive under different circumstances. These are widely used and useful approaches to answering questions about plant ecology: For example, what characteristics in plants tend to be found in different environments, and why? But the information we obtain from understanding differences in species compositions and physical traits does not necessarily tell us about what individual plants are, or what they are capable of.

The more dominant perspective in research, and certainly in agriculture, is that a plant is a factory. Plants convert raw materials into usable products such as food and building materials. We can take this factory, put it in a specific location, give it supplies, and then collect the products. There is a great deal of funding available for researchers working in agroforestry to work toward "improvement" of plants in this context, where improvement does not mean making a better organism but making a better factory. In returning to our garden, we could predict that adding more nutrients into the soil would allow the plants to produce more product. However, we might not necessarily understand what individual plants are doing in response to the enrichment. If we broadcast nutrients across the entire system, we also would not have very much control over where those nutrients ended up. Conservation biologists sometimes also seem to consider a plant to be a kind of factory that gives us ecological goods and services. It stores our carbon, produces oxygen, and provides food and habitats for other organisms. 


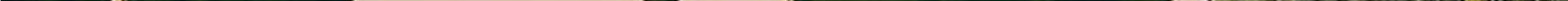




\section{4 intertwined histories plants in their social contexts}

Though the dominant paradigm in plant biology is the idea of maximizing the products we can attain from plants, we are beginning to show that this has been a problem for attaining a broader understanding of what plants are. We tend to describe plants in terms of the species that are present in a given location, and what these species tend to look like or could be used for. However, in a natural system, species do not interact with each other. Species may not even be real, since dividing organisms into species is an artificial construct that is useful only in certain contexts. Individual organisms, on the hand, are real, and these individuals do interact; individuals interact with each other, the natural world, resources, their enemies, and their allies. Many perspectives about what a plant is ignore the individuality of the organism; they are focused on plants as a whole but not as individuals who operate in their environment.

How can we learn about nature without knowing who is in nature? In our lab, we seek to ask questions so that we understand the natural world by understanding the individuals that live in it. To return to our garden, what if we shifted our focus to try to understand what individuals in this environment were doing? For example, will our cucumber plant grow differently if placed next to our tall sunflower? Or how will its roots respond if we change where we put the fertilizer? What will happen if it is presented with both of these changes? Our lab is moving more and more toward taking an approach to understanding plants based on what they are capable of and how they act under certain conditions. We are taking a very traditional scientific, experimental approach to a very non-traditional set of questions.

Though the questions we are asking are non-traditional, there is a historical context to the study of plant behaviour dating at least as far back as Charles Darwin. Darwin published The Power of Movement in Plants in 1880. In it, he states that "it is hardly an exaggeration to say that the tip of the radicle, thus endowed [with sensitivity] and having the power of directing the movements of the adjoining parts, acts like the brain of one of the lower animals." ${ }^{2}$ By making this comparison, Darwin recognized that plants could take in information about their environments and respond to it. Almost thirty years ago, the first paper synthesizing the concept of plant behaviour was published, ${ }^{3}$ and the field is continuing to expand. 


\section{using behavioural ecology to understand plants}

Although the amount of research being done in plant behaviour is small compared to other fields in plant biology, there have been many studies demonstrating interesting behaviour in plants, particularly in the last ten years. For the purposes of this essay, we want to focus on research done in our home lab because we can speak more intimately to the way that the research was done, but we would be remiss not to acknowledge that this work is part of a larger context, including scientists such as Stefano Mancuso at the University of Florence (plant communication), Monica Gagliano at the University of Western Australia (plant learning and memory), Suzanne Simard at the University of British Columbia (communication and resource sharing in plants), and Susan Dudley at McMaster University (kin recognition in plants).

One plant with a behavioural response unusually obvious to human eyes is Mimosa pudica, the sensitive plant. When touched, it responds by closing its leaves. This is widely thought to be a defensive strategy, a way of hiding from or otherwise deterring leaf herbivores such as insects and grazing mammals. However, this strategy has costs for the plant.

The plant's ability to photosynthesize and produce food is greatly reduced when the leaves are closed, since the plant is hiding from the sun as much as it is hiding from herbivores. We knew that the amount of time that individual Mimosa plants take to reopen their leaves varies, so we wanted to ask under what circumstances the leaves would stay hidden for longer. In studies of animal behaviour, we know that many animals frequently accept more risk of being eaten if they are starving. If an organism is starving, it will go where the predators are if the food is there. Conversely, organisms that are well fed will be more likely to avoid the risk of predation. If we view Mimosa pudica leaf-closing behaviour as avoiding predation risk, we can use theory from animal behavioural ecology to make predictions about when they should hide for longer. Since plants obtain energy from light, we could make the behavioural prediction that if a plant is very "well fed" under high light conditions, it will hide for longer. If the plant is "starving" in low light conditions, however, it would reopen quickly since it has greater energy requirements.

Besides the reduction in photosynthesis, there is another cost to the plant of this behaviour, which is that reopening the leaves after closure requires energy. A more conventional prediction based on plant physiology would be that since reopening the leaves 


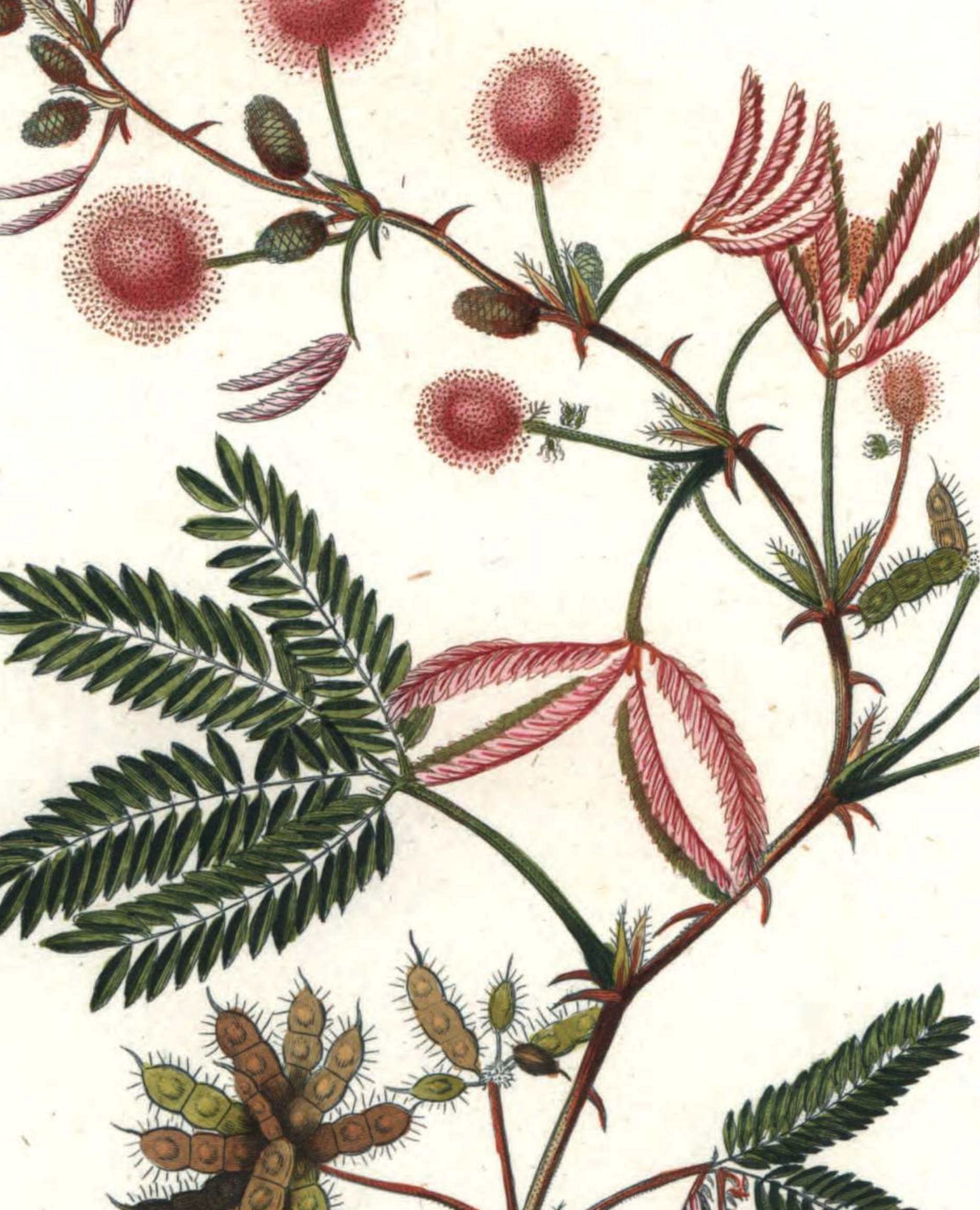


takes energy, plants would be able to reopen leaves faster under high light conditions because there is more energy available to do so. This illustrates an interesting case where using two different general approaches to understanding plants results in two very different, testable hypotheses.

To test this, we created high and low light environments and measured how long leaves took to reopen in these different environments. Our results showed that under high light, leaves reopened more slowly, therefore hiding for longer, as was predicted by behavioural theory. ${ }^{4}$ Our findings were consistent with behavioural theory and inconsistent with more traditional understandings of plant biology. This is a prime example of why we, as plant scientists, are moving away from pure physiological predictions and approaches. This has led to a need for frameworks that allow us to incorporate both behaviour and physiology into our understandings of how plants work.

Most of the behavioural work we do in the lab looks at root systems. We want to understand what drives plants to place their roots in particular locations, because plants are capable of altering the distribution of their roots in response to their environments. Roots are essential for acquiring resources from the soil, so their placement has big consequences for plants, and there are obvious analogies to be made between how plants forage for resources and how animals search for food.

Studying root behaviour comes with a unique set of challenges: for one, dirt is dark, and it obscures the roots, so observing roots requires unique solutions. For another, a lot of behavioural theory is based on the idea of an organism with a single body and a single mouth. For plants, roots are the location of tens of thousands if not millions of root tips, all of which can acquire resources from their environments, and so act as "mouths" for the plant. They also serve as sensory organs, so while they are acquiring resources from the environment they are also detecting the environment. The roots also serve an essential structural purpose, anchoring the plant. The environments roots grow into are complex and contain other plant roots, enemies (such as predators and parasites), and potential allies (such as mycorrhizal fungi that may aid in nutrient uptake), as well as nutrients and other factors. Plants are unique organisms, and so we need to create new theories to understand them, but we can also borrow some pre-existing aspects of behavioural theory.

Many behavioural ecologists use the concept of "optimal foraging" as a framework for understanding animal foraging behaviour. The essential idea is that in acquiring food, animals make foraging decisions consistent with fitness outcomes. On a very basic level, 
we could predict that animals that are actively foraging should concentrate their efforts in areas where food is available, rather than where it is not. This concept also appears to hold true for how plants place their roots in soil. If we were to observe the roots of different individual plants in our garden and see how they responded to heterogeneity in nutrient concentrations in the soil, we would find a common thread: most plants put more of their roots where the food is (i.e., where nutrient concentrations are high) than in areas where nutrient concentrations are lower. ${ }^{5}$ This makes sense from an evolutionary perspective, since plants that are better equipped to capture resources from their environment should be at an advantage. Like animals, given a choice, plants usually go where the resources are, although they usually accomplish this by changing the way they grow rather than by moving.

Behavioural theory also makes predictions about how animals should move around in an environment with patches of food. One prediction that comes from behavioural theory is that animals should spend more time in good patches with more resources than in lower-quality patches with fewer resources. This allows the animal to fully exploit the patch before moving on. This prediction is based on a mathematical model called the marginal value theorem, ${ }^{6}$ but it also makes intuitive sense. We wanted to apply this concept to plants and ask what happens when a plant encounters a goodquality patch belowground: Do plants, like animals and humans, stop "looking" once they have found something?

We grew plants (a species named Achillea millefolium, or yarrow, which can be found distributed across the northern hemisphere) next to either a high-quality patch of soil or a low-quality patch. When we looked at how the roots grew over time, we found that plants in these two environments behaved consistently with animal behavioural theory. Plants grown next to high-quality patches did not grow their roots very far, while plants grown next to low-quality patches grew roots that extended far past the patch. In other words, plants that found food stopped exploring. ${ }^{7}$ A more traditional concept of how plants grow would have predicted the opposite responses: with more resources, plants should have been able to grow more. As in the case with the leaf-closing behaviour in Mimosa pudica, this behavioural approach lent a different perspective that allowed us to better understand what was happening in these different environments. The animalderived behavioural models are useful because they assume a rational player: natural selection. And natural selection has shaped plants as much as it has shaped the organisms that are more traditionally considered in the framework of behavioural ecology. 
So far, we have discussed how plants behave when they are grown alone in the soil, but if our goal is to better understand the individuals in our garden, it is essential to understand the interactions between individuals-the social context that the plants make decisions in. Like us, plants can take multiple factors into account when they make decisions, and as with us, social interactions dictate much of their behaviour. This can be demonstrated by the way plants use information about both nutrients and neighbours to decide where to place their roots in the soil. ${ }^{8}$

In another experiment, we grew plants (Abutilon theophrasti, or velvetleaf, a common agricultural weed) in environments that either had a high-quality patch or homogenous soil, and with or without another plant in this soil. We found that this species did not respond to the high-quality patch in the same way as the yarrow plants did in the previous experiment. When grown alone, they grew their roots to the same spatial extent regardless of whether their roots encountered a good patch, effectively ignoring the patch. When we added a second plant to the homogenous soil environment, the plants responded by shortening the breadth of the root system and avoiding the other plant. What was striking was what happened when the plants were grown in environments with a high-quality patch and a neighbour. They displayed an entirely new foraging strategy wherein they grew roots into the patch and no longer avoided their neighbours to the same extent as when there was no patch between the two plants. We found that plants can integrate information about different aspects of their environment into new strategies, which implies a level of complexity in how plants perceive their environment and make decisions.

We conceptualize the way that plants place their roots in soil as the result of a decision-making process, which does not imply any cognitive abilities, but rather the ability to take in information about the environment and respond accordingly. We know that in human psychology and animal behaviour stressful events disrupt the ability to make good decisions-something most of us have learned from personal experience. Right now, we are asking whether this is true for plants too: Can stress disrupt the ability to make decisions in plants? We are using a stressful event (clipping the leaves of plants to simulate herbivory, which is a common stressor encountered by plants in nature) and observing the foraging behaviour of plants afterward to determine how stress affects these decisions. The results thus far indicate that these stressful events impact plants much like they do other organisms, including ourselves. Early evidence is suggesting that stress negatively affects the ability to make good foraging decisions in plants, a finding difficult to explain within the framework of traditional plant biology but with obvious parallels to animal psychology that should be explored further. 


\section{epillogue}

What happens if we understand plants as individual organisms rather than factories? If we could understand how they find their food, could we modify our agricultural approach to take advantage of this knowledge? Could we be smarter in our fertilizer application so that there are less wasted resources, less run-off, less cost? Could we better understand how these behaviours impact larger patterns in biodiversity and other aspects of natural systems that we are interested in preserving?

And when we adjust our preconceptions about what plants are capable of, can we come to better understand these organisms that are so ubiquitous and so essential to our own success on this planet?

It is an exciting time to be a plant biologist, with a world of questions to answer, and so we want to end on a note of acknowledgement. Many people contributed to the work we discussed in this paper, but first and foremost, we want to thank the funding agencies that allow us to do this research. Because our lab is funded by federal agencies and conservation groups, the money comes from Canadian taxpayers, and we are profoundly grateful for the opportunity this provides us to explore these questions. Thank you very much. 


\section{notes}

1. Cahill Lab of Experimental Plant Ecology: https://grad.biology.ualberta.ca/labs/cahill/. James F. Cahill Jr. is a professor at the University of Alberta. Megan K. Ljubotina and Habba F. Mahal are graduate students in his lab.

2. Darwin, Power of Movement in Plants, 573.

3. Silvertown and Gordon, "Framework for Plant Behavior."

4. Jensen, Dill, and Cahill, "Applying Behavioral-Ecological Theory to Plant Defense."

5. Kembel and Cahill, "Plant Phenotypic Plasticity Belowground."

6. Charnov, "Optimal Foraging."

7. McNickle and Cahill, "Plant Root Growth and the Marginal Value Theorem."

8. Cahill et al., "Plants Integrate Information."

\section{bibliography}

Cahill, James F., Jr., Gordon G. McNickle, Joshua J. Haag, Eric G. Lamb, Samson M. Nyanumba, and Colleen Cassady St. Clair. "Plants Integrate Information about Nutrients and Neighbors." Science 328, no. 5986 (2010): 1657. https://doi.org/10.1126/science.1189736.

Charnov, Eric L. "Optimal Foraging, the Marginal Value Theorem.” Theoretical Population Biology 9, no. 2 (1976): $129-36$.

Darwin, Charles. The Power of Movement in Plants. London: John Murray, 1880.

Jensen, Evelyn L., Lawrence M. Dill, and James F. Cahill Jr. "Applying Behavioral-Ecological Theory to Plant Defense: Light-Dependent Movement in Mimosa Pudica Suggests a Trade-off between Predation Risk and Energetic Reward.” The American Naturalist 177, no. 3 (2011): 377-81. https://doi.org/10.1086/658343.

Kembel, Steven W., and James F. Cahill Jr. "Plant Phenotypic Plasticity Belowground: A Phylogenetic Perspective on Root Foraging Trade-offs." The American Naturalist 166, no. 2 (2005): 216-30.

https://doi.org/10.1086/431287.

McNickle, Gordon G., and James F. Cahill Jr. "Plant Root Growth and the Marginal Value Theorem." Proceedings of the National Academy of Sciences 106, no. 12 (2009): 4747-51. https://doi.org/10.1073/pnas.0807971106.

Silvertown, Jonathan, and Deborah M. Gordon. "A Framework for Plant Behavior." Annual Review of Ecology and Systematics 20 (1989): 349-66. 


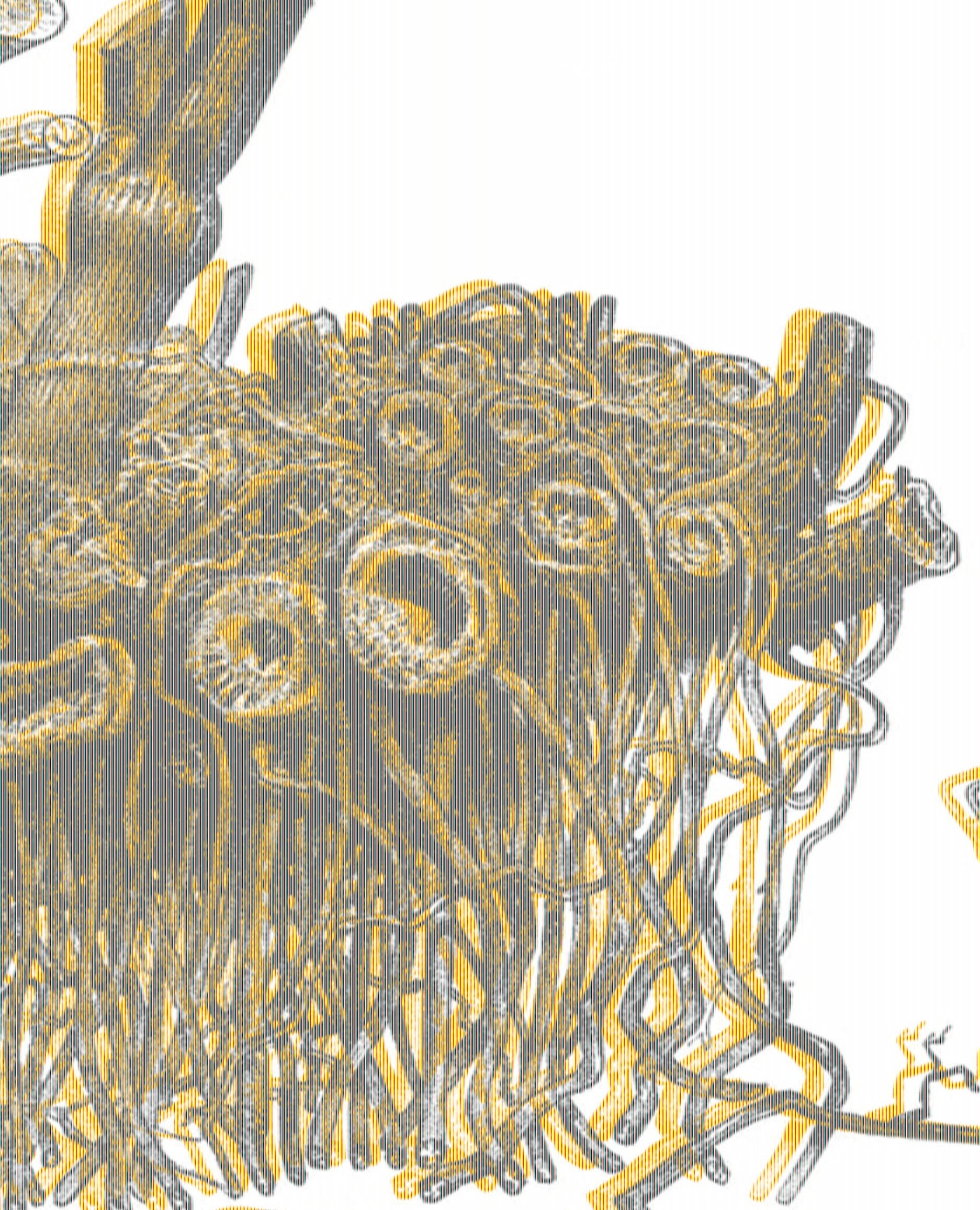




\section{ohytognosís learning from plants patrícia vieira}

Can plants learn? What knowledge do they have and which new insights do they strive to acquire? Imagine you are a run-of-the-mill garden pea plant worried about getting enough light to produce food and nourish yourself. Obviously, you will be on the lookout for signs that indicate where sunlight comes from. If, judging by past experience, you figure out that light and wind tend to come from the same place, you will be conditioned to grow in the direction from which the wind is blowing, even if there has been no light originating from that area for a while. Or will you? This is what biologist Monica Gagliano and her colleagues investigated in an experiment published in the journal Nature a couple of years ago.' They showed that, like animals, plants can associate a neutral stimulus-the blowing of air, in this case-with a biological reward-getting plenty of light to enable photosynthesis-replicating the so-called Pavlovian conditioning already widely established in animals. In the study, plants learned something they did not previously know-that wind and light come from the same area-and started to behave accordingly, growing in the direction of the air flow in the absence of light.

This experiment adds to a growing body of scientific work showing that, even though plants do not have a brain, the organ seen as responsible for intelligence in the animal kingdom, they can learn from past experience and behave intelligently. They are able to adjust their conduct to changing environmental conditions and store knowledge so as to maximize their chances to survive and reproduce. ${ }^{2}$ They communicate with other plants and animals and even signal distress when under attack by predators or when facing extreme environmental conditions, such as a situation of drought. ${ }^{3}$ This research 
on plant learning has been complemented by recent philosophical takes on flora that extend categories previously employed to discuss human beings and, at most, some our closest evolutionary relatives, to the realm of plant life. Notions like "plant soul" and "plant-thinking," developed by Michael Marder, or Matthew Hall's theorization of plant subjectivity, push the boundaries of what we used to conceive of as plant behaviour and open the door to a cognitive approach to the vegetal kingdom. ${ }^{4}$ That a pea plant can learn from where the light shines and make an informed decision to grow in that direction is taken for granted in these new philosophical inquiries.

The reconceptualization of the relation between plants and humans that is currently underway in the sciences and in some branches of the humanities should not simply result in adopting a more mindful, respectful take on flora. It entails a radical recognition of our indebtedness to vegetal life on different levels: from the physiological reality of our reliance upon plants for breathing and nourishment to the realization that many of our cultural constructs, ranging from aesthetics to ontological, ethical, and even political conceptions, can be traced back to our understanding of vegetal beings. The recent attention afforded to plants in scientific and philosophical inquiries, as well as in literary and cultural studies with the rise of ecocriticism, should prompt us to look at flora anew and draw the consequences from the fact that vegetal entities, which represent 82 per cent of all living matter, are the basis for all life on earth, including the existence and thought of us humans. ${ }^{5}$

It is in the context of this turn to plants that I put forth the idea of phytognosis-a compound word that combines the ancient Greek terms for plant (phyton) and knowledge (gnosis). Taking as a point of departure the notion that plants can and do indeed learn and have their own forms of knowledge, phytognosis goes a step further and turns the onus of learning back onto humans. It refers to two separate but related forms of knowing. On the one hand, it signifies an effort to expand our knowledge of plants in a variety of fields. Whether to distance ourselves from plant life and assert the superiority of our species-we regard ourselves as active and agential, as opposed to the passive, "vegative" state of plants, which has negative connotations in most human cultures-or perhaps even to repress the knowledge of Homo sapiens' and most other animals' dependence upon plants, we have long relegated them to the margins of our thoughts, as beings that are simply there, part of the background and barely distinguishable from the landscape. Phytognosis requires us to struggle against the zoocentric bias present in many disciplines that has led scientific inquiries to privilege the study of animals. As Gagliano has found in a survey of the scientific literature of the last five years, on average, only one paper is published on plants for every two published on animals. ${ }^{6}$ Similar 
to science, the humanities have historically focused on the study of human beings and of our closest evolutionary relatives, foregrounding what distinguishes us from other mammals. Phytognosis would thus require us to move beyond what some have called a "plant blindness,"" beyond our privileging of ourselves and other animals in our studies. As I pointed out above, this kind of phytognosis is already well underway in some branches of science, as well as in the humanities, in philosophy, literary studies, and cinema, for instance. Plant studies has developed in the context of this re-evaluation of flora, its representation, and human-plant interactions, similar to the rise of animal studies in the 1990s in response to the animal ethics debates that took place in the last quarter of the past century.

Leaving aside the sciences, there are many questions we should aim to address in the humanities when talking about phytognosis. In philosophy, for example, we could ask: ${ }^{8}$ What is the specific ontology of plants, their mode of being-in-the-world? Which epistemological questions are raised by our study of plants? What are the ethical consequences of the recent "turn" to plants? Should the socio-political status of plants change in light of new discoveries in plant science? If plants feel distress, have memory, can communicate, can learn, and are able to make their own decisions, should they not be granted some of the privileges previously reserved for humans and animals? Should plants have rights, for instance, and, if so, which form would these take? Is a tree's right not to be cut down upon a whim the same as the right of a blade of glass growing in your backyard not to be mowed?' Is it acceptable to instrumentalize plants for economic gain and to destroy them for human pleasure? Should we be allowed to cut down a pine to use it as a Christmas tree?

In literary and film studies, another set of issues is raised when we approach plants from a phytognostic point of view. How have plants been represented in literary and cinematic works, and how do these depictions reflect cultural biases about the vegetal world? In which ways do plants inscribe themselves in human cultural productions? Are plants a mere background for human action-as in portrayals of the landscape-or can they play an active role in the development of a plot? What are the stylistic implications of having plants as main characters, as in Ursula K. Le Guin's short story "Vaster than Empires and More Slow" (1971) or in M. Night Shyamalan's film The Happening (2008)?

But phytognosis entails more than transforming our anthropocentric and zoocentric fields of research, so as to learn about the plant world. Phytognosis is both our knowledge of plants and the knowledge of the plants themselves. It recognizes that plants learn and that, in turn, we can learn from the plant world. A phytognostic approach to 


\section{6 intertwined histories plants in their social contexts}

flora, then, is one that takes into consideration what vegetal beings know and that tries to learn not only about but also from them.

A caveat to phytognosis precludes the facile idealization of plants as benign beings, the other side of picturing humans as sinister creatures who malevolently destroy flora's habitats and those of other animals. Plants, like all other forms of life, strive to adapt to their environment and use all physiological means at their disposal to nourish themselves, reproduce, and thrive. Regarding plants as angelical, abnegating entities whose actions are aimed solely at furthering the well-being of others, including us humans, would be as erroneous as seeing them as passive, quasi-inert life forms. Phytognosis is not about promoting a Manichean view of reality whereby plants are the good and Homo sapiens the bad guys in the theatre of life on earth. Still, a phytognostic take on plant-human relations acknowledges that humanity has a lot to learn from flora's forms of existence and can draw valuable lessons from the plants' specific mode of being-in-the-world.

One significant difference that separates plants from animals, including humans, is that vegetal life is able to create its own organic sources of nourishment, namely the sugars produced from carbon dioxide and water in the process of photosynthesis. Plants are self-sufficient and enable the existence of most other life forms, which use the energy harnessed by flora for sustenance. While humans cannot aspire to emulate vegetal photosynthesis, phytognosis teaches us a lesson in sustainability. Instead of preying on other beings-both the ones now living and those long dead, by using fossil fuels, which are the bodies of dead plants-we should emulate plants and, as far as possible, produce our own energy using renewable sources, in the same way that plants utilize solar energy. What would our world look like if, instead of depending on energy produced by other entities, we would direct our efforts into producing our own, synthesizing it from the elements, such as sunlight, wind, and the movement of water? Global warming would be much less of a problem, as would air pollution in major cities across the globe. Furthermore, the by-product of the vegetal production of energy is not a polluting substance but oxygen, which is central for life on earth. To be sure, oxygen was not always needed for life; ancient microbes existed in an anaerobic environment before photosynthesis changed the composition of our planet's atmosphere. Still, most creatures now alive are the result of plant colonization of the globe, and therefore plant-produced oxygen is key to their metabolism. Again, phytognosis would teach us to exist on earth, while enabling and even furthering the flourishing of all other entities that share the planet with us, a lesson sorely needed in our era of environmental devastation. 
A second major difference between plants and animals is that plants have a capacity to regenerate that far surpasses that of other living beings. A plant can lose up to 90 per cent of its body without being killed: a tree can be pruned, have most of its branches cut and trimmed, and then flourish again, sprouting new branches the following spring. This capacity has often been used to denigrate flora. Because of their modular structure, basically reproducing the same elements again and again-in the Metamorphosis of Plants (1790), for instance, Goethe was convinced that all parts of a plant are modifications of the same basic structure, namely, the leaf-plants' organs are not as individuated as those of animals. They do not have an intestine, lungs, or a mouth, for example. The plants' ability to regenerate has served as an excuse for human destruction of the natural world. We see plants as emblems for the whole of the environment and assume that, no matter how much we devastate it, it will be able to bounce back and regrow. But were we to take a cue from plants, we would learn the boundaries of regeneration. Phytognosis makes us aware of the point up to which we are able to use a given part of nature without damaging the ecosystem as a whole. Even though plants are hugely pliable and able to regrow after large parts of them are cut, they do have bounds beyond which they will be unable to recover. Phytognosis would imply identifying these thresholds so as to work around them. It would mean, for instance, learning how to harvest timber without destroying a forest, how to fish without endangering the reproducibility of certain species, and so on. In other words, phytognosis teaches us to respect environmental limits.

Humans can also take the plants' decentred physical structure as a blueprint for progressive forms of social and political organization. As philosophers Gilles Deleuze and Félix Guattari have pointed out in A Thousand Plateaus, the rhizomatic structure of some plants points us in the direction of a non-hierarchical socio-political and economic structure, one where there is no "head" but, rather, a multiplicity of communicating parts. ${ }^{10}$ What if, instead of thinking of the state as a leviathan, a large animal, as political philosopher Thomas Hobbes suggested in his eponymous book, we thought of it as a plant, as grass, for instance? What would be the consequences of this horizontal view of society for our institutional organization? We would certainly live in more egalitarian communities, with strong political participation and a more just distribution of resources across the body politic.

A third substantial difference between plants and animals is that, apart from some exceptions, plants are sessile beings, that is to say, they are rooted to a specific location, while animals are mobile, going from place to place in search of food and shelter. True, plants release their seeds to the elements in such a way that they often traverse large distances, but a place where a seed falls owes as much to chance as to the ingenuity of the plant 
and, once it takes root, it can rarely move to a different spot. The sessile nature of flora has historically been regarded as a sign of deficiency, with vegetal beings deemed inferior to animals because they are unable to choose where they grow. However, humans could gather valuable insights from the rootedness of plants. Being tied to a place, plants need to cherish and nurture that particular area, lest it become unsuitable to support life. Instead of depleting and rendering barren a given region, and then moving on to exploit the next one, as some animals, including humans, often do, plants nourish their environment, the bodies of dead vegetal matter providing the soil with the nutrients needed for the growth of other plants. A phytognostic approach to plant life would learn from its attachment to a given place. At a time when humans are already looking for other planets as a possible replacement for the earth once we have used up all of its resources, completely destroyed the planet's ecosystems, or made it unlivable because of a nuclear catastrophe-as in Christopher Nolan's film Interstellar (2014) or in more concrete plans to colonize Mars by entrepreneurs such as Elon Musk-plants teach us to care for and preserve the environment that allows for our existence. They are a constant reminder of how reckless it is to dirty, devastate, and deplete one's own home.

A final example of phytognosis, in terms of what we can learn from plants, takes as a point of departure the recent scientific studies that highlight the plants' various forms of communication, decision making, language, "vision"-through their photosensitivity to sunrays-and so on. The recognition that much of what we thought were exclusively human or, at the very least, animal features are shared by all living beings shows that, far from being the pinnacle of creation, Homo sapiens is not all that exceptional. Our lives are neither more complex nor superior to those of animals or plants, many of which have existed on earth long before we came along and will surely live on long after our disappearance. Plants teach us that the human mode of existence should not be seen as the measure of all life, and that the idea of all other beings existing exclusively for our use is nothing but a phantasy created by our anthropocentric arrogance. Perhaps more important than anything else, plants teach us humility.

Phytognosis is a pressing task in light of the current environmental destruction. Turning to plants, learning about and from them, paves the way for a less instrumental approach not only to the environment, to the way we behave toward other vegetal and animal beings, but also to social relations, to our interactions with our fellow humans. Phytognosis teaches us to cherish the place we inhabit, as well as to be mindful of the lives and needs of other humans and non-humans-in other words, to be good guests in the home we share with all other beings on this planet. 


\section{notes}

1. Gagliano et al., "Learning by Association in Plants."

2. See, for instance, Trewavas, "Aspects of Plant Intelligence”; Brenner et al., "Plant Neurobiology"; or Gagliano et al., "Experience Teaches Plants."

3. See, for instance, Karban, "Language of Plant Communication."

4. Marder, Plant-Thinking; Hall, Plants as Persons.

5 Carrigton, "Humans just $0.01 \%$ of all life."

6. Gagliano, Ryan, and Vieira, "Introduction," viii.

7. Ibid.

8. For a review of how flora's mode of being leads us to question established philosophical ways of thinking, see Marder, "Vegetal Anti-Metaphysics."

9. For instance, the government-appointed Swiss Federal Ethics Committee on Non-Human Biotechnology $(\mathrm{ECNH})$ considered in a 2008 report that interfering with plants without a valid reason is morally inadmissible.

10. Deleuze and Guattari, $A$ Thousand Plateaus. To be sure, Deleuze and Guattari contrast the rhizomatic structures to arborescent ones, i.e., those that are tree-like and hierarchically structured. Still, one could argue that all plants are, to a certain extent, rhizomatic, especially when compared to animals.

\section{bibliography}

Brenner, Eric, Rainer Stahlberg, Stefano Mancuso, Jorge M. Vivanco, František Baluška, and Elizabeth Van Volkenburgh. "Plant Neurobiology: An Integrated View of Plant Signaling." Trends in Plant Science 11, no. 8 (2006): 413-19.

Carrigton, Damian. "Humans just $0.01 \%$ of all life but have destroyed $83 \%$ of wild mammals-study." The Guardian, May 21, 2018. https://www.theguardian.com/environment/2018/may/21/human-race-just-001-of-all-lifebut-has-destroyed-over-80-of-wild-mammals-study.

Deleuze, Gilles, and Félix Guattari. A Thousand Plateaus: Capitalism and Schizophrenia, trans. and foreword Brian Massumi (Minneapolis: University of Minnesota Press, 1987).

Gagliano, Monica, Michael Renton, Martial Depczynski, and Stefano Mancuso. "Experience Teaches Plants to Learn Faster and Forget Slower in Environments Where It Matters." Oecologia 175, no. 1 (2014): 63-72. https://doi.org/10.1007/s00442-013-2873-7.

Gagliano, Monica, John Ryan, and Patrícia Vieira. “Introduction.” In The Language of Plants: Science, Philosophy, Literature, edited by Monica Gagliano, John Ryan, and Patricia Vieira. Minneapolis: University of Minnesota Press, 2017.

Gagliano, Monica, Vladyslav Vyazovskiy, Alexander A. Borbély, Mavra Grimonprez, and Martial Depczynski. "Learning by Association in Plants." Scientific Reports 6, art. 38427 (2016). https://doi.org/10.1038/ srep38427.

Hall, Matthew. Plants as Persons: A Philosophical Botany. Albany, NY: SUNY Press, 2011.

Karban, Richard. "The Language of Plant Communication (and How it Compares to Animal Communication).” In The Language of Plants: Science, Philosophy, Literature, edited by Monica Gagliano, John Ryan, and Patricia Vieira, 3-26. Minneapolis: University of Minnesota Press, 2017.

Marder, Michael. "Vegetal Anti-Metaphysics: Learning from Plants." Continental Philosophy Review 44 (2011): 469-89.

. Plant-Thinking: A Philosophy of Vegetal Life. New York: Columbia University Press, 2013.

Trewavas, Anthony. "Aspects of Plant Intelligence." Annals of Botany 92, no. 1 (July 2003): 1-20.

https://doi.org/10.1093/aob/mcg101. 

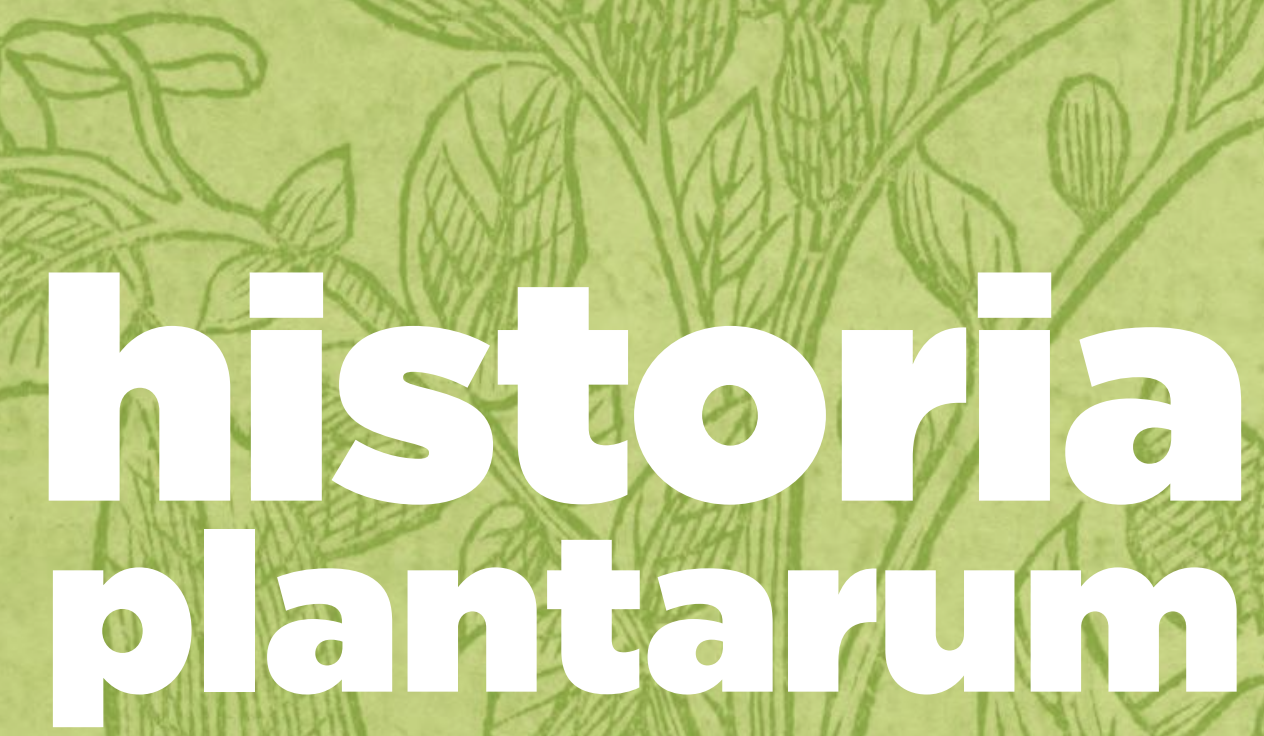

\section{hecate prepares instructions for demeter and kore in hell}

NHE STORY OF THEN=U I F $H$,

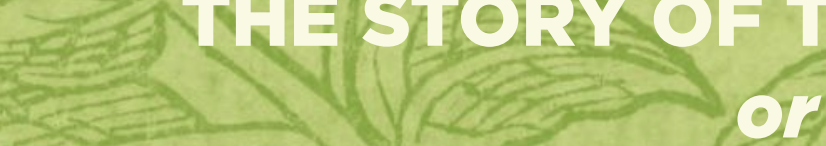

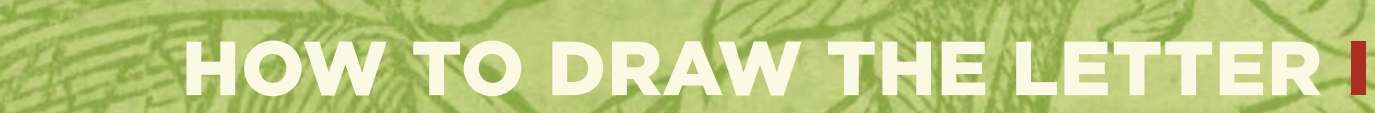
a metaphysics,

$$
\text { 206. notes on }
$$

anatomy, conception, reproduction and the daughter erina harris 
This poem is an excerpt from the poetry manuscript

Persephone's Abecedarium: An Alphabet Play

An Ecopoetical Adaptation of the Homeric "Hymn to Demeter"

This work builds on the interpretation of the ancient poem ( $6^{\text {th }}$ or $5^{\text {th }}$ Century B.C.E.), already an adaptation of an oral tale, as a proto-feminist mother-daughter narrative. Its anonymous and possibly female author deployed poetic language in a fashion that models an ethos of compassionate interconnectivity among humans and ecological others such as flora and fauna: an early meditation on ecological ethics, I propose.

In the tale, the deity Hecate is the first to inform Demeter (Goddess of Harvest) of her daughter Kore's (Goddess of Grain) abduction to the Underworld, of their immanent separation, and possible individuation.

Hecate was a liminal goddess of crossroads, and a keeper of plant lore - especially plants' healing, poisonous, and metaphysical properties. The Historia Plantarum or Enquiry Into Plants by Theophrastus (somewhere between 350 and $287 \mathrm{BCE}$ ) is among the earliest written accounts of how plants reproduce. It included detailed studies of plant anatomy, individuation, and classifications. Patricia Vieira and Michael Marder report that "Aristotle's student Theophrastus was excluded from the Western canon for the painstaking botanical researches he undertook" ("Writing Phytophilia: Philosophers and Poets as Lovers of Plants").

This is Hecate's later, unpublished version.

This work engages the research of Monica Gagliano and Marva Grimonprez who observe that plants breathe transmissions by sending out a chemical language made up of scented words within their specific, social settings. They establish that plant utterances are both more meaningful as well as more effectively received among kin. Inspiringly, they consider plant communities in terms of overlooked possibilities such as intelligence, agency, and inter-subjectivity. 
22 intertwined histories plants in their social contexts

How to draw the letter $\mathrm{H}$ :

Three strokes

of a crayon

cross oblivion -

The Tree. The Drawbridge. The Flower.

To draw The Tree:

In any place in space and from there, down. A line straight, spining-

from stratosphere or forehead, then descend

to somewhere low her hip, her paper skyline.

To stop at troposphere

where the soil's soiled knee. 
This is The Tree.

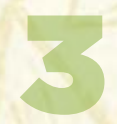

In it lives the little Laboratory of the Little within it, The Littlest

cell too tiny to.

Her tiniest cell,

Until a guest dressed best enters

A room is just a cell

until and when and he - and makes it a party!

And enters her,

and then a room and she and he Are we.

And doubling, in his image her reflection in his eyes. Makes her two! makes him a dollhouse. 
The butler blasts the trumpet blastodermic

$$
\begin{aligned}
& \text { in a cell } \\
& \text { in a cell }
\end{aligned}
$$

and in a room is one and two; are we

Are a making are a party, “Hear mere blastomeres!” he trumpets.

Until, arriving, more - more guests is best.

A room within herself - and doubling in the company of the guest.

Amorous, amoral, Morula: she conceives of guests and rooms -

"More rooms!" “More we!”

And carrying a tray of canapés she strops and trophoblasts about.

That guests might fuse themselves in chatter of some matter,

$$
\text { or: "A game!" }
$$

To play in ones and twos, she sings,

of meetings, gametes singing, gameful. Syngamy -

the singing rooms do buckle, swell, self-echo, and selfdouble in their cupboards, replicate to placate: "Make more rooms!" The singing. 
The singing, surging, and divergent, differing, invited:

"To the syncytium!"

Holding hands, the guests

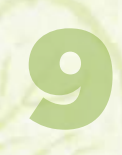

move along longitudinal ridges.

The guests are building something.

Unfolding,

down a hall along a bannister: to unwrap all the presents,

ribboned, rudiment, a system, tubes and vesicles, a swirling guest in

pinafore and fore-brain, to present presents crescentic en masse masses.

In pairs! Pericardial, uncloak a cloacal membrane in the cloak room;

enter. And there, pass her a tissue where tissue resists,

blocks differentiate to skeletal muscle, not a tussle but a two-step:

vertebrae and dermis, somites might or ribs, top hats

and masses cubical, alas. At the podium:

the head, there blossom spindle-shaped cells, spinning.

The organs pinking ring out for the choir. The choir is learning

ectoderm of chorion, in the great room, song-room, a cavity

amniotic. The conductor, is her uncle. Uncle peduncle

conducts a band of neurons, their embloused

flock resembles a stalk, singing, singing "Bouquet!"

for the hostess. 
In the laboratory,

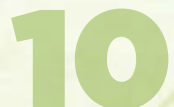

in the Tower,

in the Tower,

in the Tree

there sits the mother in the Milking Room.

Wearing her seed crown, she coddles the cotyledon, dresses her in a little seed coat, embroidered from her own body, grown, a gown from ovule or integument.

With intent. A caress is meant to tend the hilum-scar taped to the stalk to which was pinned the seed to the navel-like carbuncle, the caruncle. Tousle the plume, a pliez from her plumule.

And singly, in monocot seeds, a monocle.

In the Milking Room the mother towers -

her roots swell vertebrate in soil, ankling, tentacular.

She grows herself

extra arms for her daughter

octopus or spider. 
Each hair an ear waves,

cordial and plancking.

In burlap lap her sugar-waters. Bound in gauze, she coddles, embryonic a swaddling.

Lub-dub, lub-dub, iambic thumper.

Ingredients:

"Is the mother-foot also:

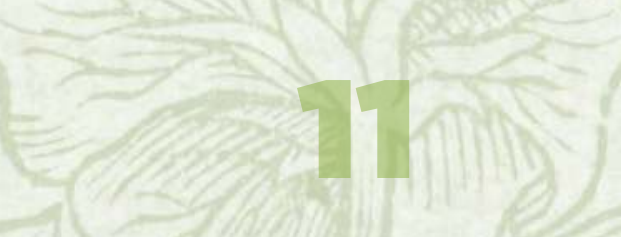

the clubfoot, root in a water, water part air and part rabbit's foot past, and part past, downstream, and a tendril extending from bowels of flowers sharing pistil-time to place all the flammable names touching with your forehead alit in a sunlit gristle-parlour ?"

"Yes, in part."

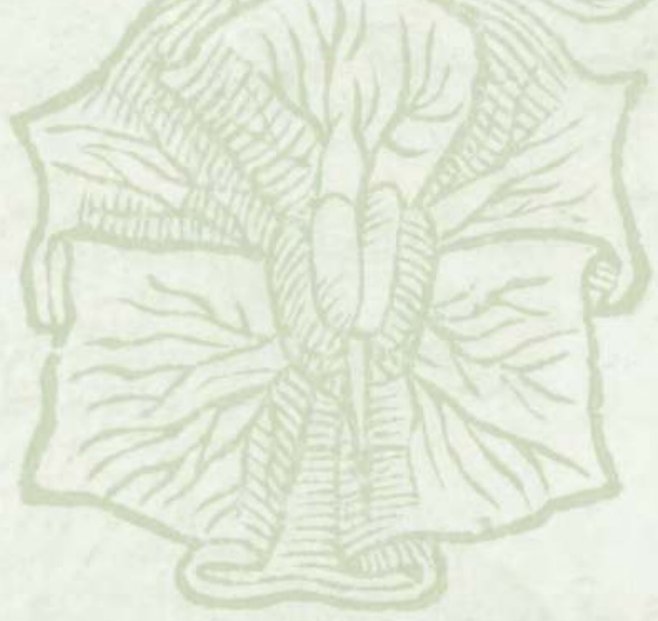


To draw the Drawbridge:

From the window

of the laboratory, from midriff

from within a rip in mind.

Draw a line horizoning-

\begin{abstract}
A passageway
in which hemorrhage buds cinch growing tiny hairs, filaments.

The guard hairs gorging at the opening.
\end{abstract}

From midriff. ingrows this trapeze, a cord:

and goes through her,

bridging brainstem, her radicle a portal where her baby root and will depart shoot outwards epic epicotyl from her tiny cot become transition zone between root and shoot, and rooting downwards invisible beneath the Tower to forever outwards.

A cord for the trapeze, for:

The little duchess against weather fists her seedling outwards in a violate-veined wide-mouth jar.

Cleaving animal pole, vegetal pole toward and diverging. 
From the trapeze or rootling bridge or cording bridge, Bridge of the Child from its last planck rhizomatic, precipice or strand now,

How to draw The Flower:

Tie the trapeze to her belly; trace it:

down to downwards where she hides her roots under the bed with all her toys.

And again, from mid-stalk, upwards, trace towards her spire spinning at the top a cup a turnstile, weathervane or chalice, is a headdress or receptacle to which her head will be attached;

Or if she is many-headed, inflorescence:

$$
\text { "Are so many of us!" }
$$

Her uncle, peduncle

will he cup her tiny head and head and head. 


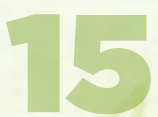

Floreate, her mouth fills with organs singing, ringing with: a style and carpels, and her pistil will evolve to enclose ovules cherubic and beloved-

Vowelling, the flower yowls.

And queenly, her corolla pronounces petals within green calyx

$$
\text { or sepals }
$$

(When an ovule grows up she will be a seed).

and tilting her slightly toward mother-scent.

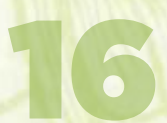

Scentwards, or, slender in her filament, she unfolds, upholds the anther and its antlers, hers.

A stamen, radio and weathervane is lending pollen dusts the linens. 
(When an ovule grows up she will be a seed)

dressed best in her little seed coat and tended).

In her little coat pocket

sewn in: a baby root, impressed, or a photograph and smelling

(Remembering the Tree or the Flower who was she will be)

How to draw the letter I.

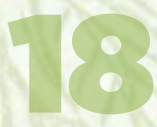

Sever it:

the cord

between

the Tree

and

the Flower.

Hold her apart from her. By the rootlings, draw the daughter from the mother-waters. Apart: and makes of mother-body a weathervane can always tell. 
32 intertwined histories plants in their social contexts

"There will be a memory between us."

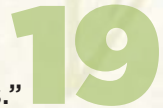

Letter I:

And swell, grotesque, resonant, a socket-

\section{Conscious-flower, bloating,}

gloats

Shivering and rare in her new edges motherless, and daughtered in their agape

Between, and anti-homewards time blooms there. And pretty globules slowly form upon the queen's pink gorge:

“I, 
"There will be a memory between us, and ringing: backwards and forwards and around the other side."

"There I pass through her."

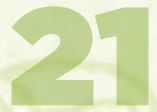

Letter I:

"Where my looking looks for her and my looking back reflects, upon her, surface,

upon her I become image, with her

within interruption.

I attend, an utterance." and imagined 
34 intertwined histories plants in their social contexts

Within interruption-

Said the Flower to the Tree:

Who are we,

mother? Mother?” 



\title{
periculum
}

\section{artist's statement \& portfolio}

\section{jennifer wanner}

\section{photography: gavin semple}

\begin{abstract}
"The dream of deep ecology will never be realized upon the earth, but our survival as a species may be dependent on our capacity to dream it in the work of our imagination."
\end{abstract}

-Jonathan Bate, The Song of the Earth

My art practice examines botanical art and nature cinema in a world dominated by Marxist "second nature"-a virtual simulation of pristine "first nature" wrought by the revolution in information, biotechnologies, and consumer culture. I employ collage, watercolour painting, and stop-motion animation to explore how both art-historical constructs and scientific objective means of observing the natural world have shaped our Western concept of nature. The diverse disciplines of art and science can, at times, possess a shared language and actions. For example, in collage and genetic transfer science, respectively, artists remove an image and scientists a gene from its original context and "transfer," then "splice" it onto another image or gene to create a new "modified" or "recombined" whole. My botanical work attempts to operate between two Romantic realms: fascination with mastery over natural processes and unease with what our technology might unleash.

In my collage series entitled Periculum-Latin for trial, proof, danger, peril, risk, liability-I collected, and printed on inkjet paper, Internet images of the most endangered and threatened plant species throughout Canada, according to federal, provincial, and territorial governments. My "field work" has been conducted in the virtual realm of the Internet-a domain where, according to social theorist Paul Virilio, "virtuality destroys reality." "I then carefully cut away several plants from their original contexts to reconfigure them 
into a new singular "rescued" plant. An individual collage has been generated for each of the thirteen Canadian provinces and territories. A fourteenth collage represents all of Canada and contains a plant species that is at risk from each of the provinces and territories.

We are obsessively driven to develop technologies and organizational systems that attempt to counteract the negative effects we have already inflicted upon the natural world. With my proposition to "genetically collage" all of the provincial and territorial plant species at risk together into one specimen, we would only have to concern ourselves with protecting one plant species rather than a diverse range of them-a system of "efficiency." These botanical collage images act as another futile and preposterous proposal to help restore and protect what we are on the verge of destroying.

The plant images collaged in the Periculum series are deliberately not true to scale or proportional to the original plant. For example, in the collage representing Newfoundland and Labrador, the Barrens willow (Salix jejuna), located at the top left of the plant, measures 11 centimetres in the collage, but is in actuality a tiny plant measuring 1-2 centimetres in height that can be easily trampled. The colours represented in the collages are also not faithfully reproduced. Many factors contribute to this colour distortion, such as the time of day the photograph was originally taken, digital image manipulation, and inkjet printer colour calibrations. Through playing with both the scale and colour I am suggesting how during the process of genetic modification we can never be precisely sure of how a gene will ultimately express itself. These collages act as propositions for a botanical art in a time of virtual, high-speed systems, influenced by Jean Baudrillard's theory of "simulacra"-where the ability to distinguish between the model and the real has been lost among the mediations of cultural constructs. ${ }^{2}$

As a species, humanities' response to environmental crises often favours adaptation rather than conservation and preservation. Experts have estimated that the alarming rate at which species are being lost today is between "1,000 and 10,000 times higher" than the "natural" or "background" extinction rate. The responsibility for this "Sixth Extinction" crisis rests primarily on the shoulders of one species-humans. As writer Elizabeth Kolbert points out, "No other creature has ever altered life on the planet in this way before." Increasing awareness through literature, documentary film, education, and the visual arts is just one of the important tactics we can use to confront the extinction problem, but it is ultimately our actions upon this planet that will determine the fate of all species.

\section{notes}

1. Der Derian, The Virilio Reader, 5

2. Baudrillard, Simulations, 2

3. Kolbert, The Sixth Extinction, 2-3

\section{bïbliography}

Bate, Jonathan. The Song of the Earth. Cambridge, MA: Harvard University Press, 2000. Pp. 37-38.

Baudrillard, Jean. Simulations. New York: Semiotext(e), 1983.

Der Derian, James, ed. The Virilio Reader. Malden, MA: Blackwell, 1998.

Kolbert, Elizabeth. The Sixth Extinction: An Unnatural History. New York: Henry Holt, 2014. 


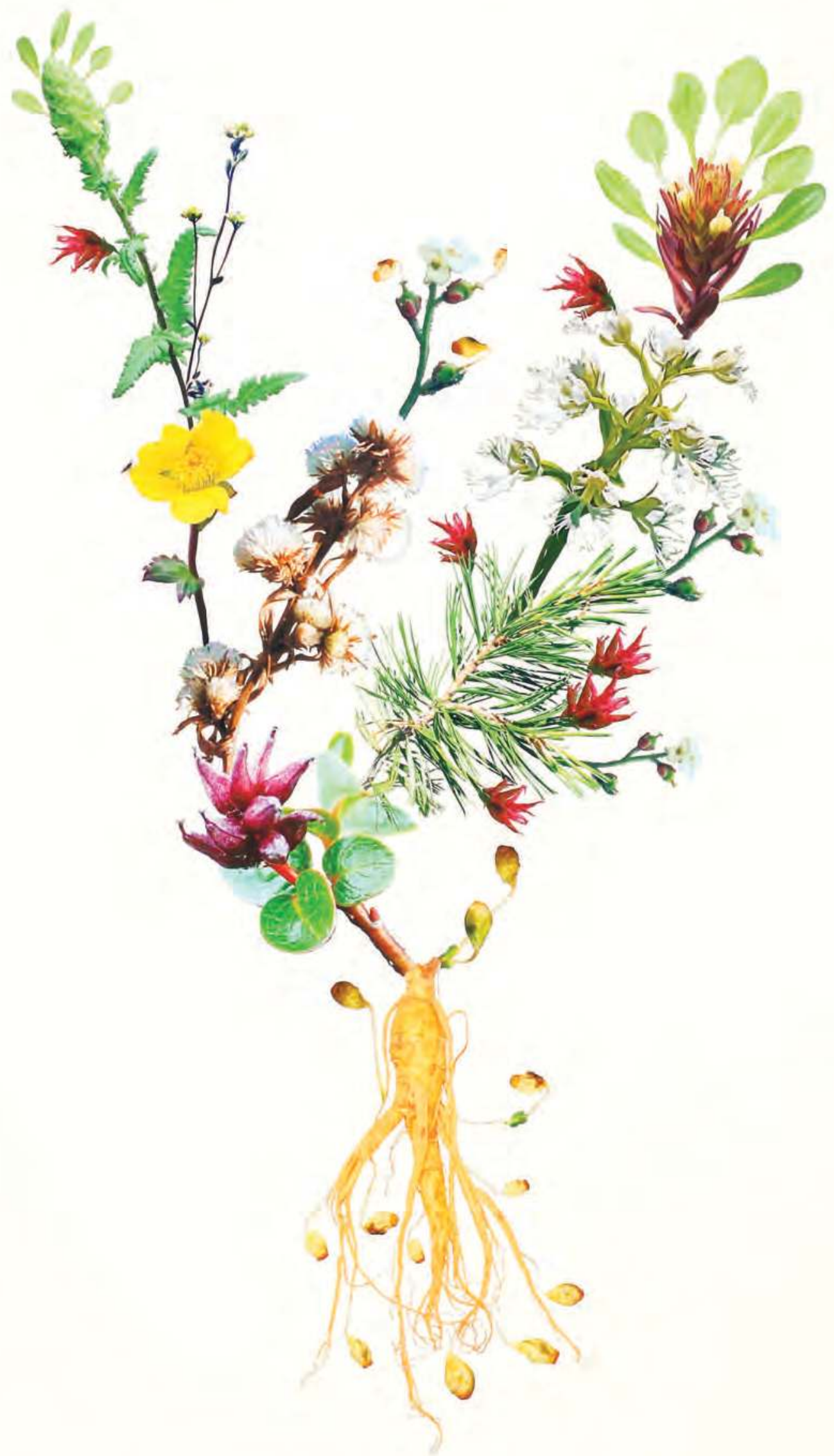




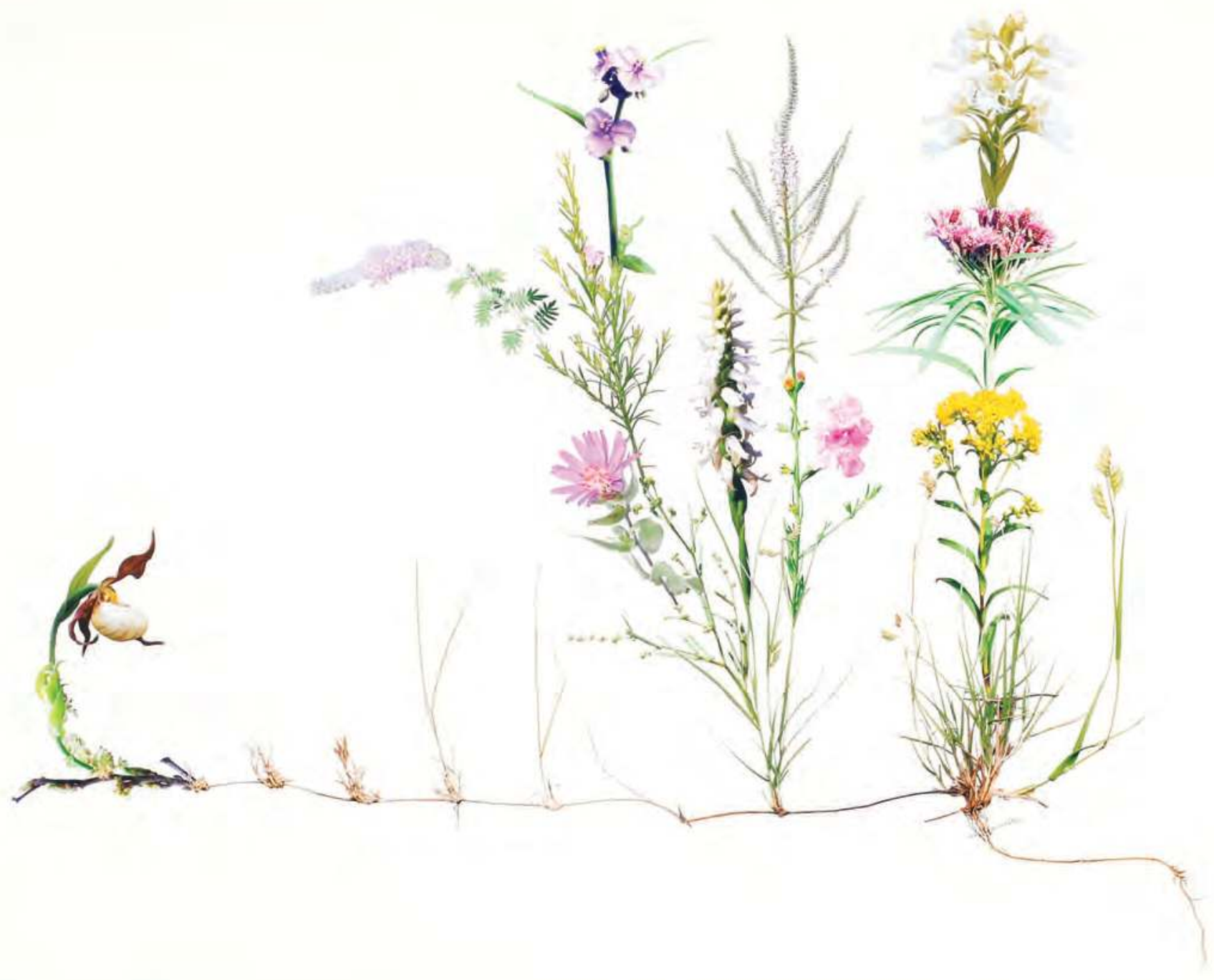

4 Periculum - Canada

2015

Hand-cut inkjet paper collage on Stonehenge paper $38.75 \times 24.5^{\prime \prime}(98.43 \mathrm{~cm} \times 62.23 \mathrm{~cm})$
A Periculum - Manitoba 2015

Hand-cut inkjet paper collage on Stonehenge paper $30 \times 39.5^{\prime \prime}(76.2 \mathrm{~cm} \times 100.33 \mathrm{~cm})$

Collection of the Alberta Foundation for the Arts 


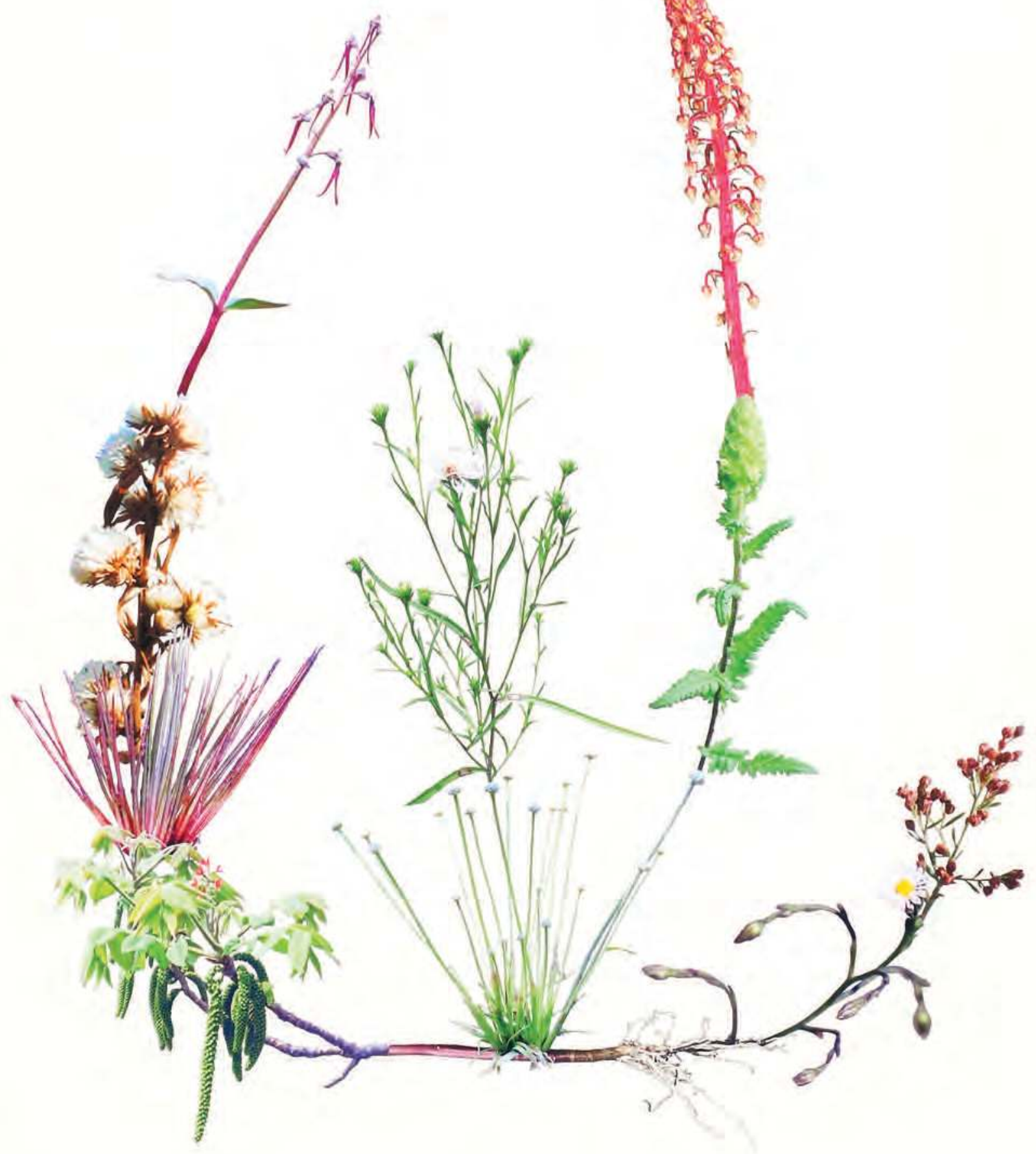




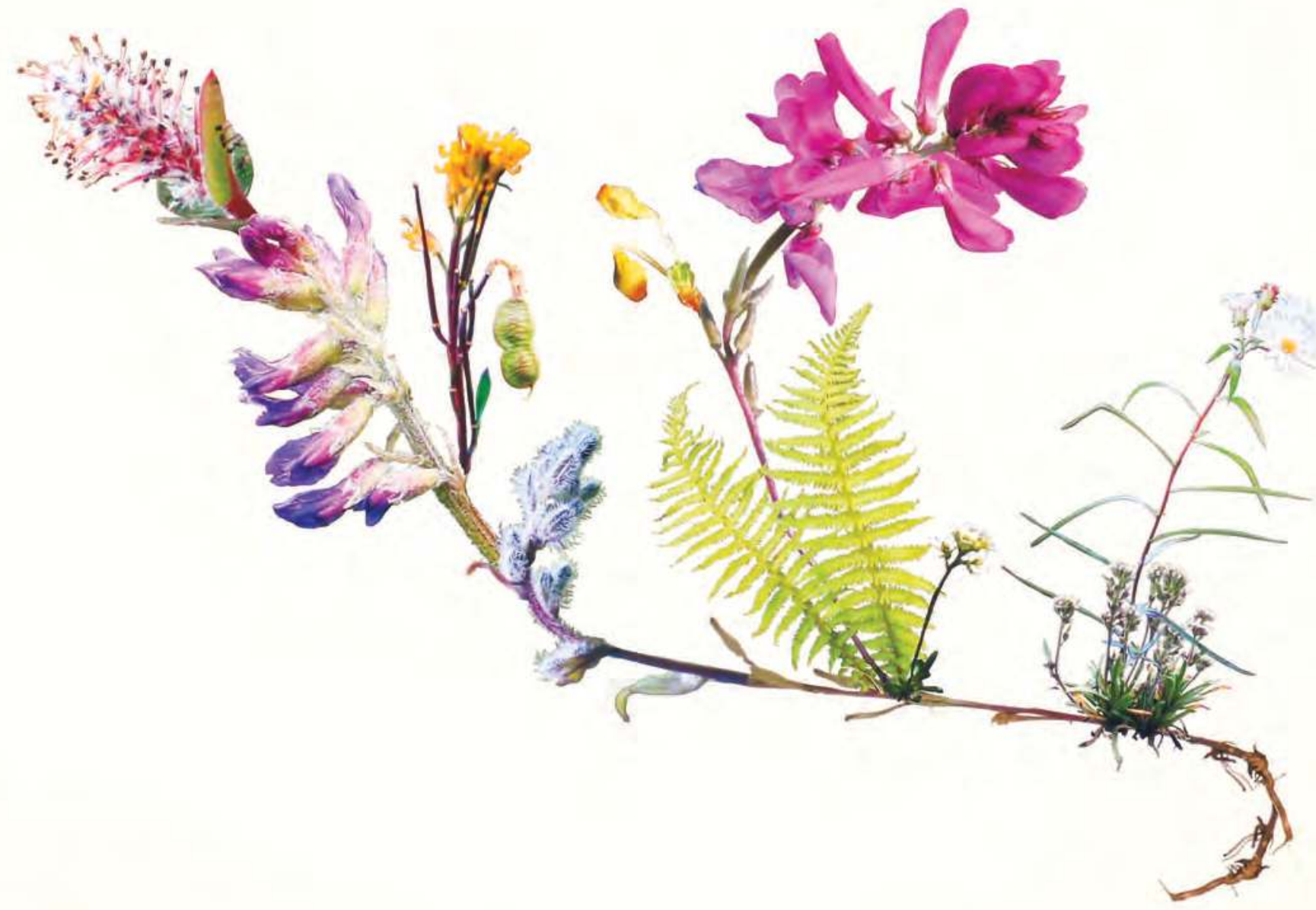

Hand-cut inkjet paper collage on Stonehenge paper $32.5 \times 28^{\prime \prime}(82.55 \mathrm{~cm} \times 71.12 \mathrm{~cm})$
Aericulum - Newfoundland \& Labrador 2014

Hand-cut inkjet paper collage on Stonehenge paper $18.5 \times 25^{\prime \prime}(46.99 \mathrm{~cm} \times 63.5 \mathrm{~cm})$ 


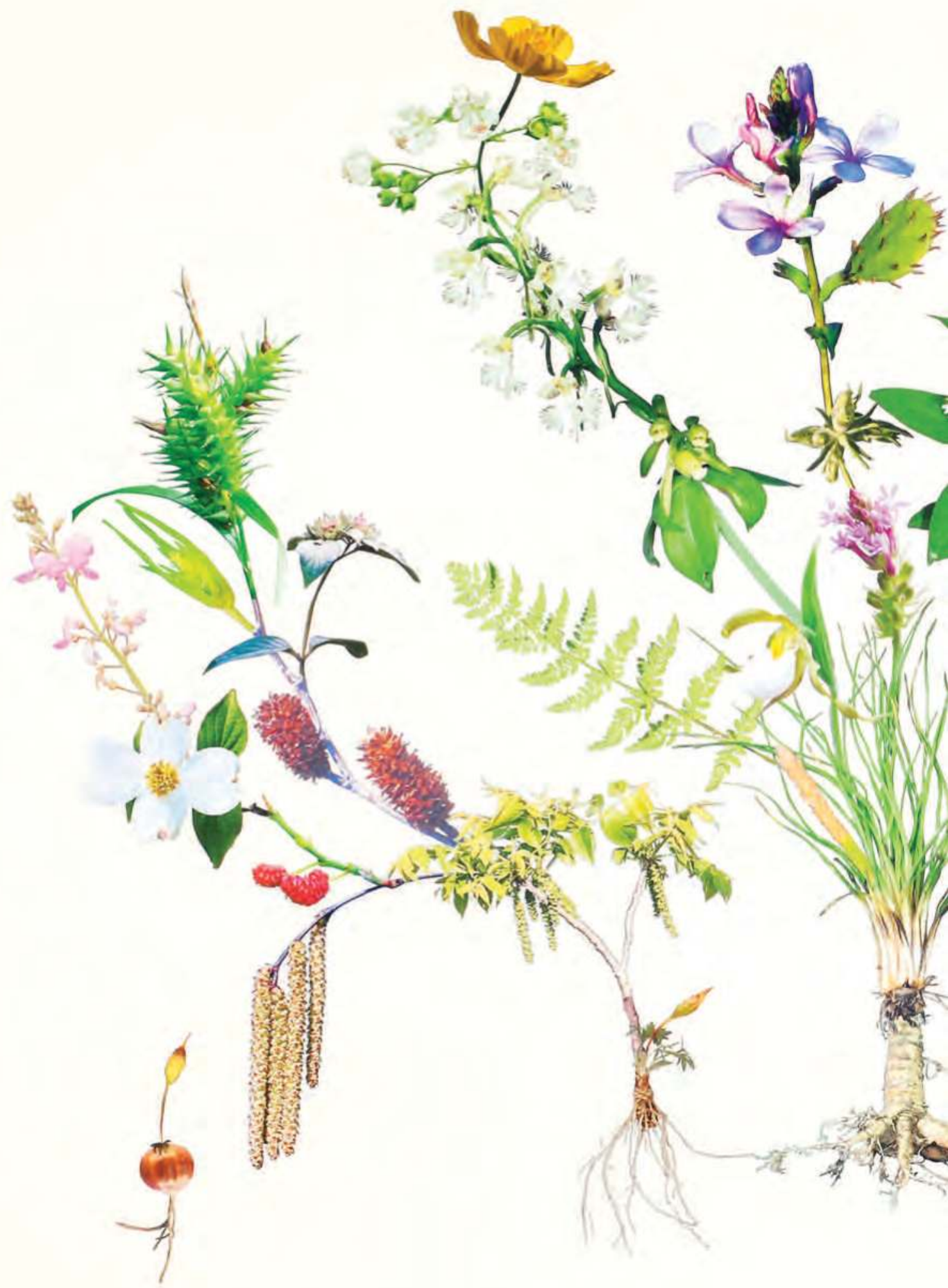




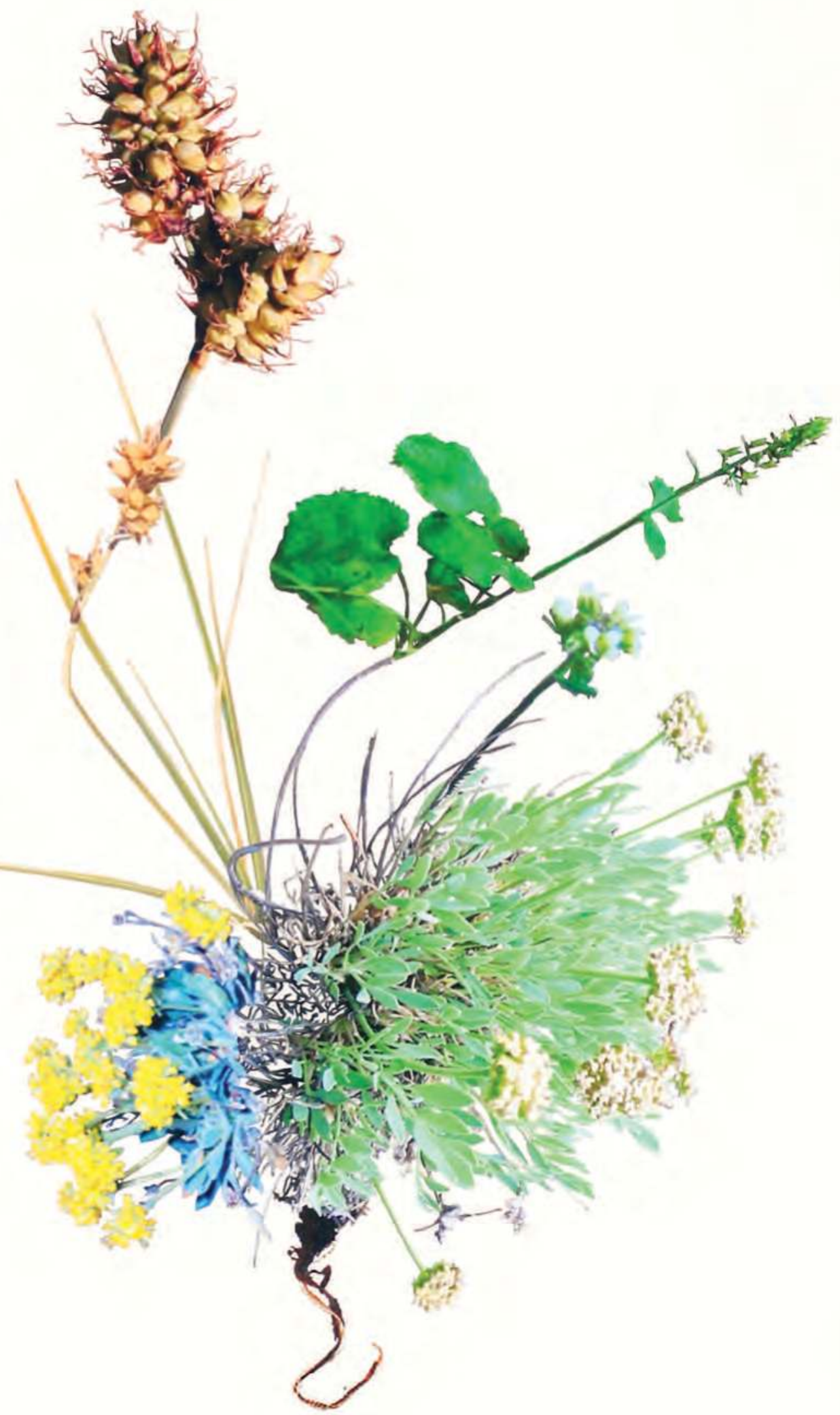




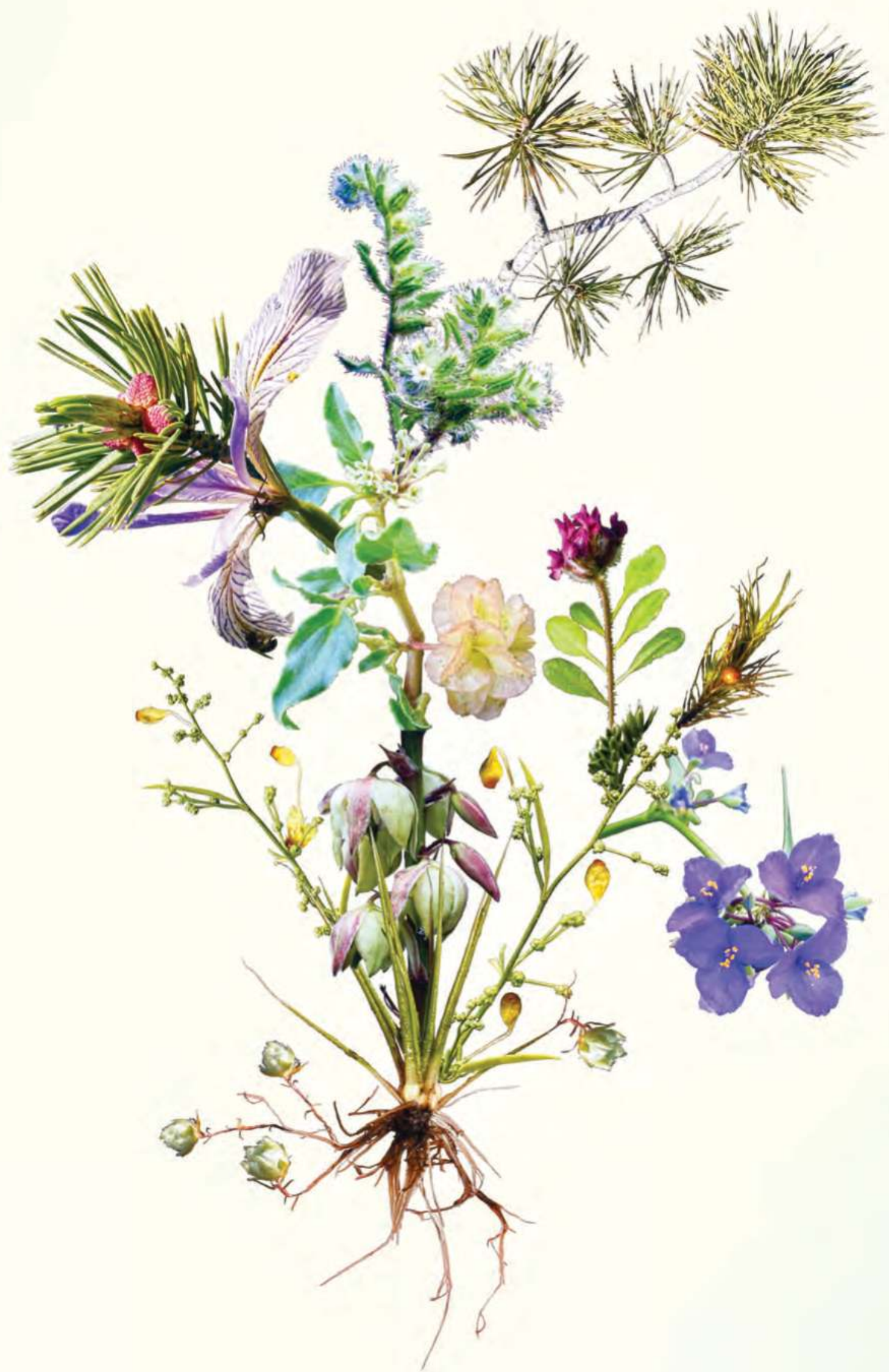




\section{spectral garden artist's statement \& portfolio}

laura st. pierre

For several years, I have been collecting and preserving flora from the changing landscape. These specimens then become the subject of photographs, video works, and installations. These works are all loosely grouped under the project title Fruits and Flowers of the Spectral Garden.

Using a technique common to botanists, I preserve the plants I collect in isopropyl alcohol. This maintains their three-dimensional form, but leaches the colour from the flowers and leaves. Unlike a seed or a cutting, these ghostly tissues cannot be used to create new life.

To contain the specimens, I use domestic vessels, such jars and bottles, in the tradition of my grandmothers. While my relatives preserved food and drink, I am preserving something else-a memory that is not yet a memory.

My interest in plants stems from what they reveal about the past, the present, and the future of a place. The presence of native species suggest wildness; domestic plants signal human or colonial intervention. Aggressively invasive plants speak to the delicate balance of ecologies, and barren land reveals a history of pollution or contamination. Plants may also foreshadow the future-the dry and dense coniferous boreal forests of western Canada tell of fires in years to come. 
Specimens are chosen from sites in transition. Earlier works in this series featured plants from "wild" or unkempt spaces in Saskatoon, such as vacant lots, alleys, and parks. Specimens were collected from these places as a response to their increased development and taming. More recently, I have begun gleaning plants from ecologically sensitive areas, including the St. Lawrence River and the boreal forest. Although the specimens are not currently rare or unusual, someday soon they may be: in this sense the collection has become an Archeology of the Future. This passing into memory sometimes happens more quickly than anticipated: the location where the boreal forest specimens were collected has since been completely transformed by wildfires.

Photography is an essential aspect of this project. In the translation of a three-dimensional object to a two-dimensional image, common plants are transformed, "making visible things that cease to be of any consequence once the picture has been snapped." This "making visible" is taken further by preserving the plants in alcohol, which bleaches the specimens and renders some parts of the plants translucent, giving them a ghostly appearance. Furthermore, when the plants are printed at $\mathbf{3 0 0}$ per cent their original size, they become even less familiar-moss may be printed at the scale of grass, forcing the viewer to see it in a new way.

While earlier photographs in this series depicted a single specimen in a jar, I have begun stacking and positioning the specimens, using other natural materials to prop them up. In so doing, I am attempting to recreate a specific plant or landscape from memory. While the use of photography generally raises questions about time and remembrance, this process takes it one step further, reconstructing the land with my mind's eye as well as the camera's.

Much of Canadian identity and our understanding of our place within the natural world were forged through images created by artists (the Group of Seven, Emily Carr, and others). Along with many other artists today, I continue to explore these questions while encouraging our viewers to do the same.

\section{notes}

1. Hamill, "The World is Flat," 14-19.

\section{bibliography}

Hamill, Sarah. "The World is Flat: Photography and the Matter of Sculpture," Camerawork, 36, no. 1

(Spring/Summer 2009): 14-19. 


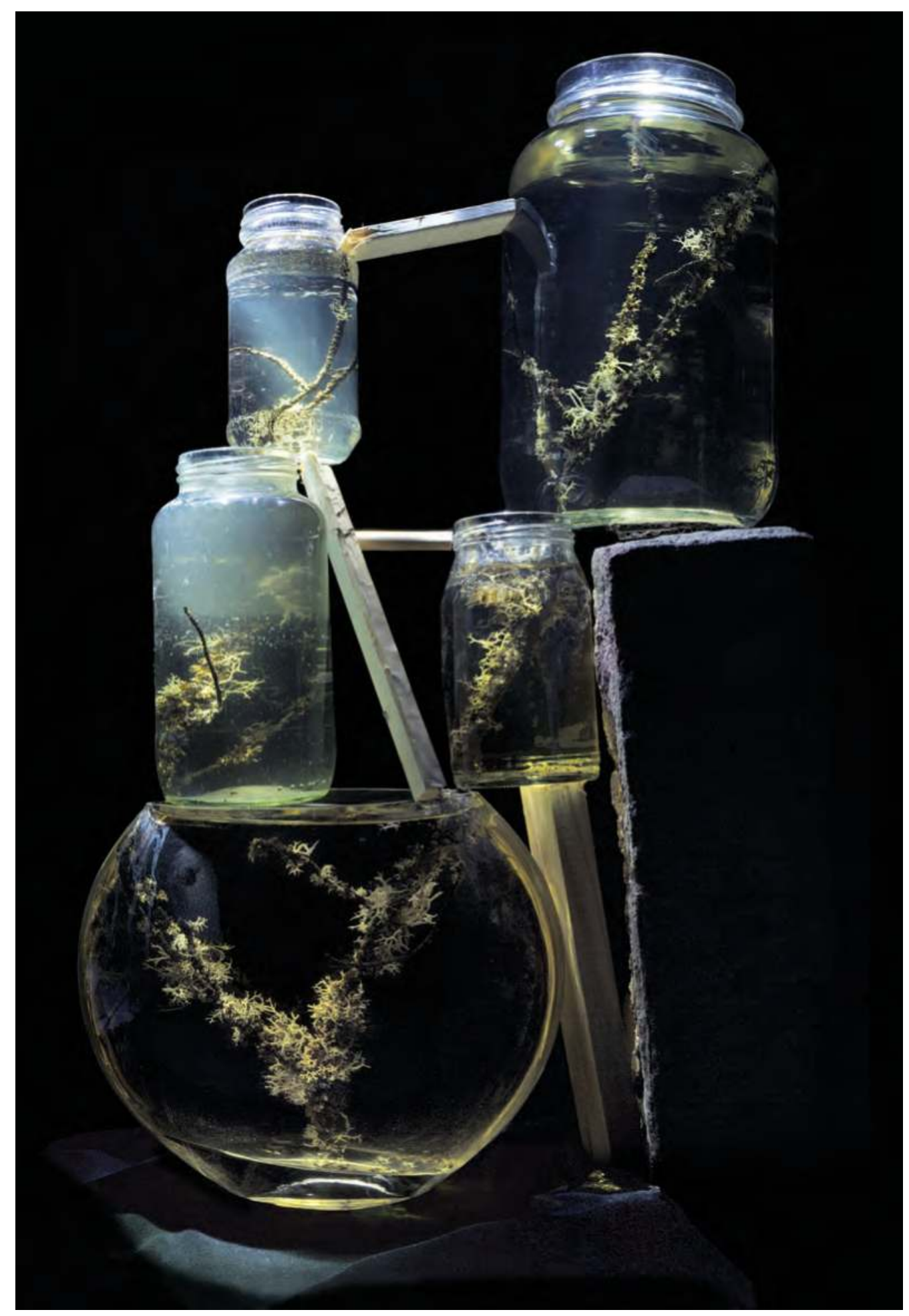

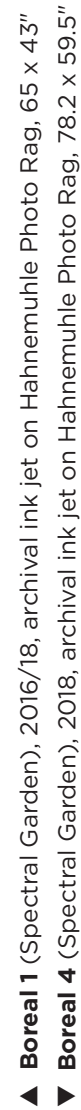




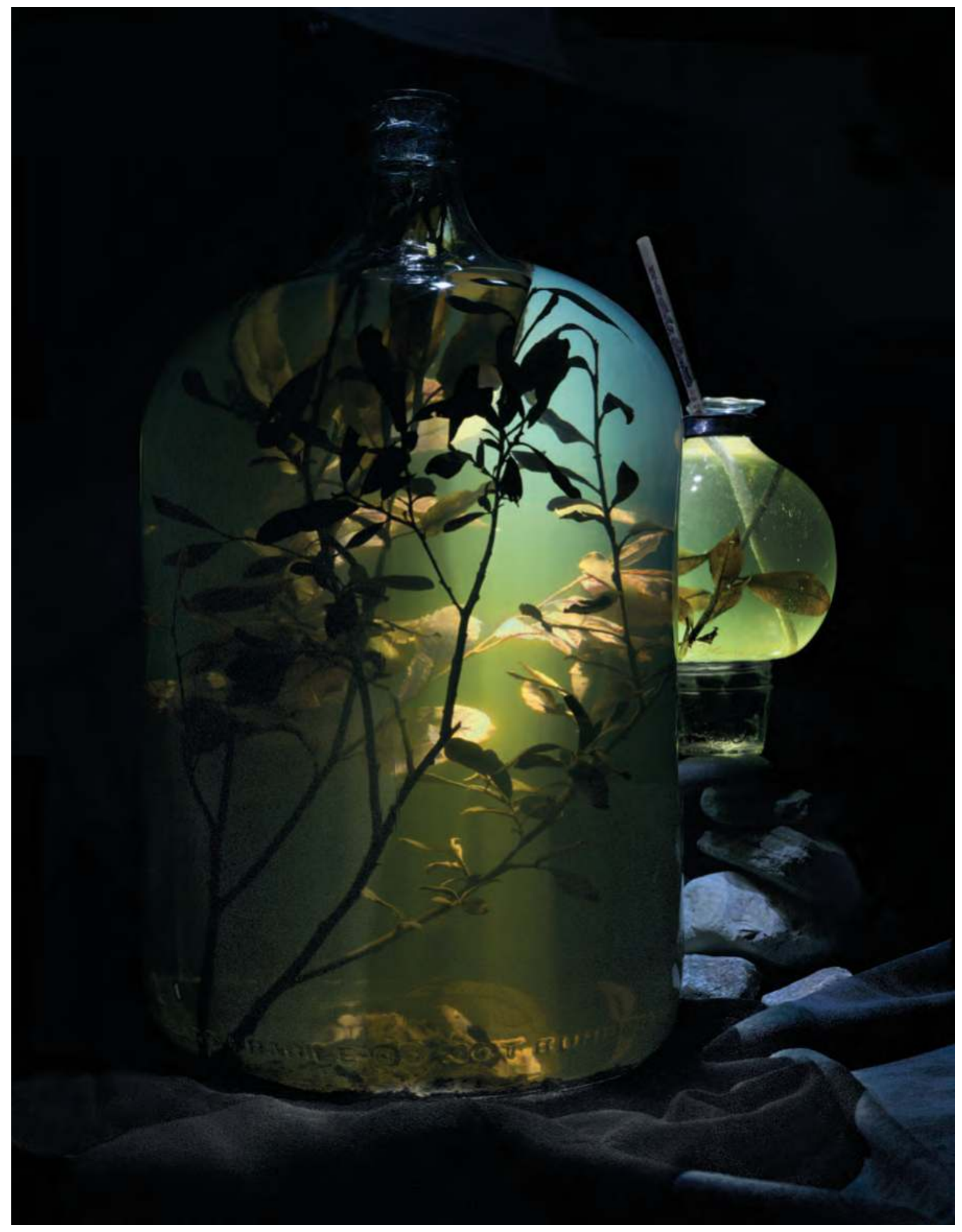




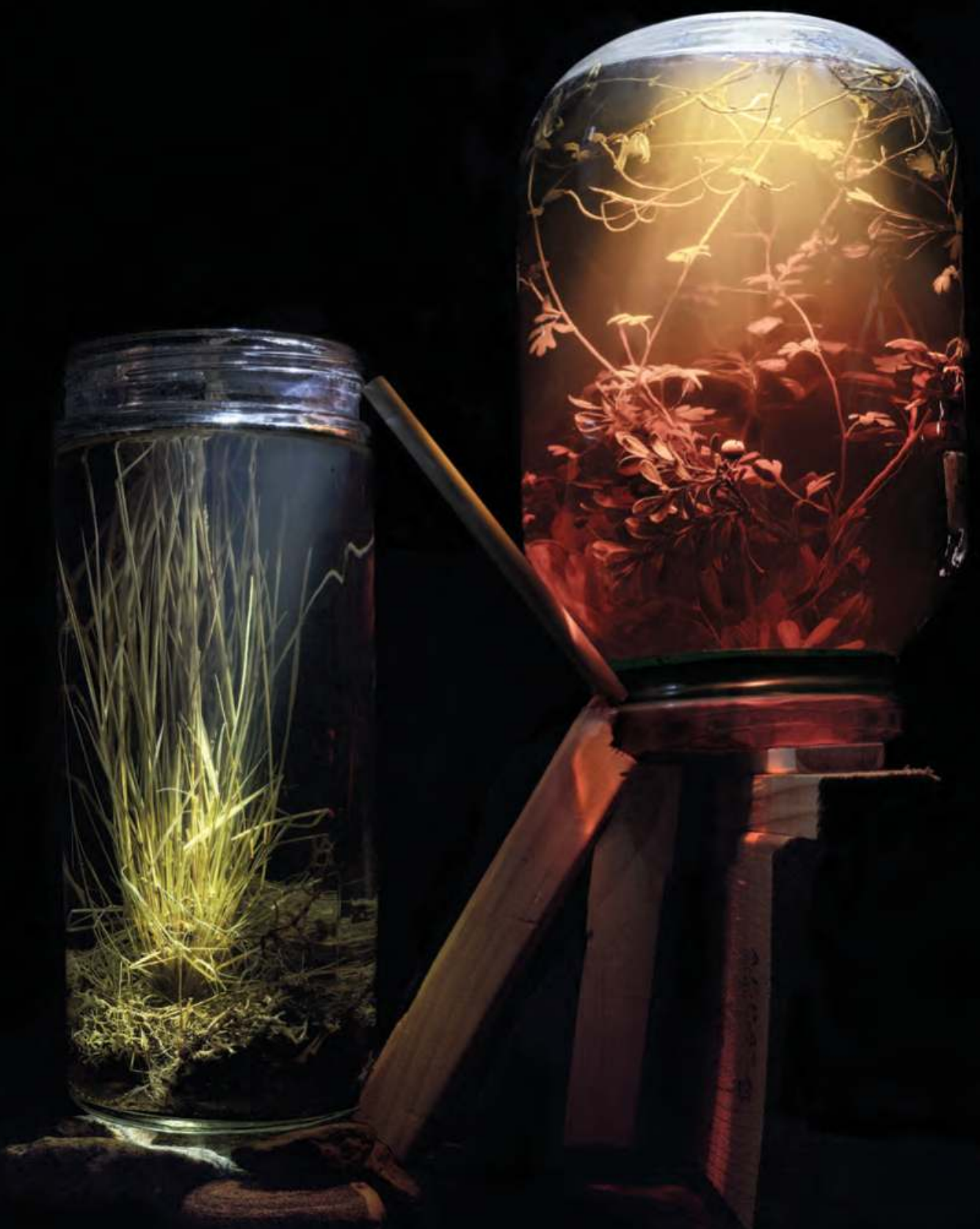




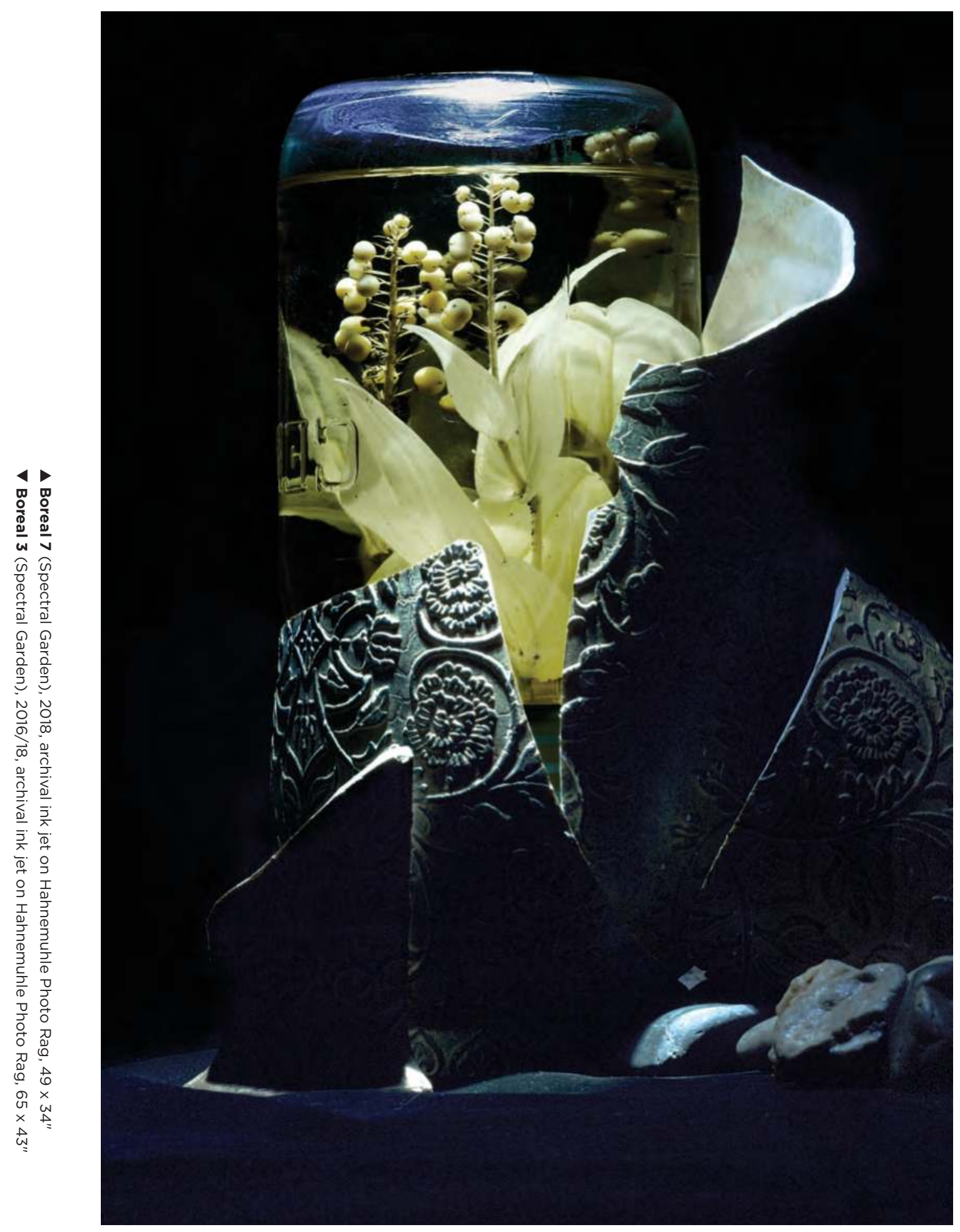



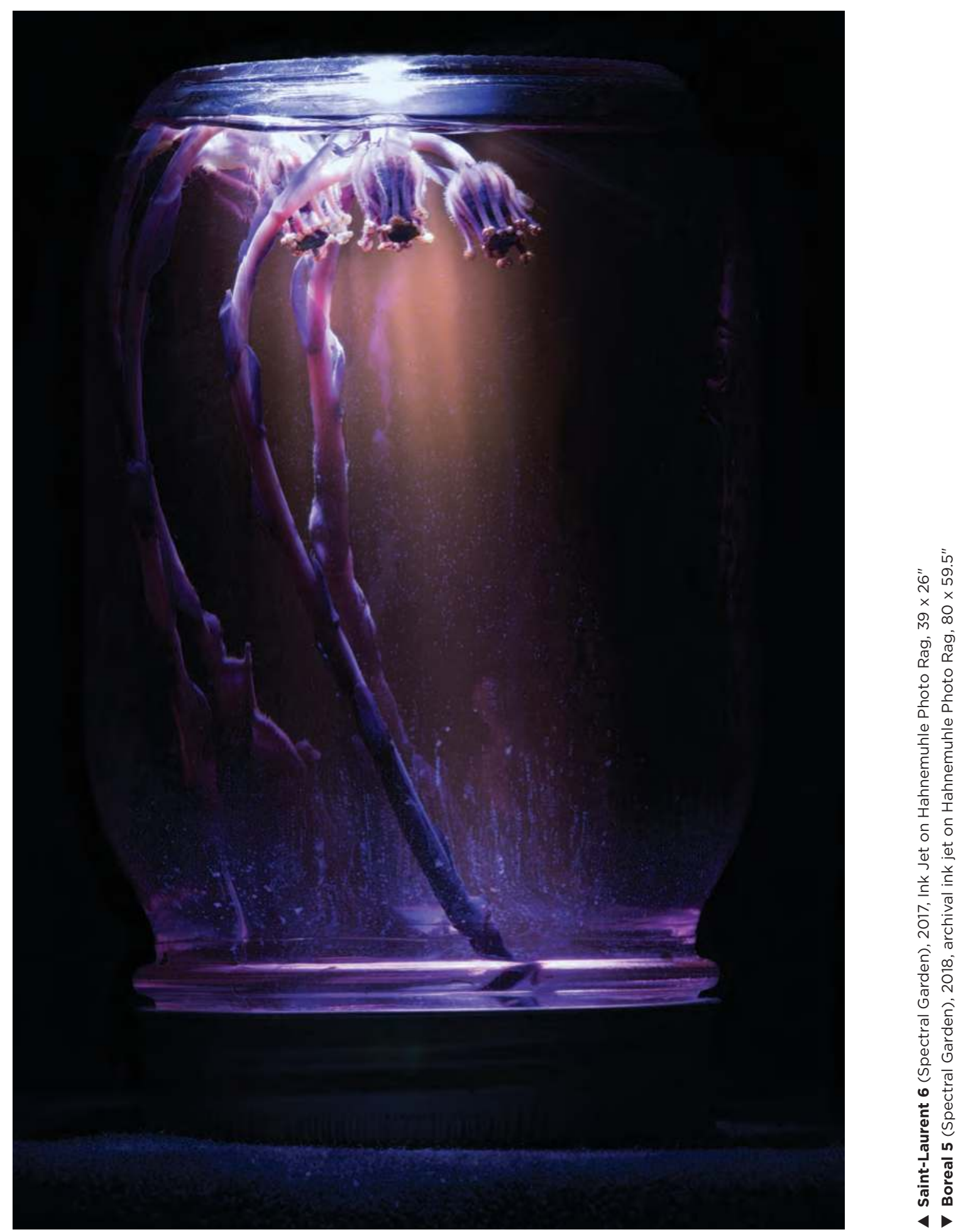


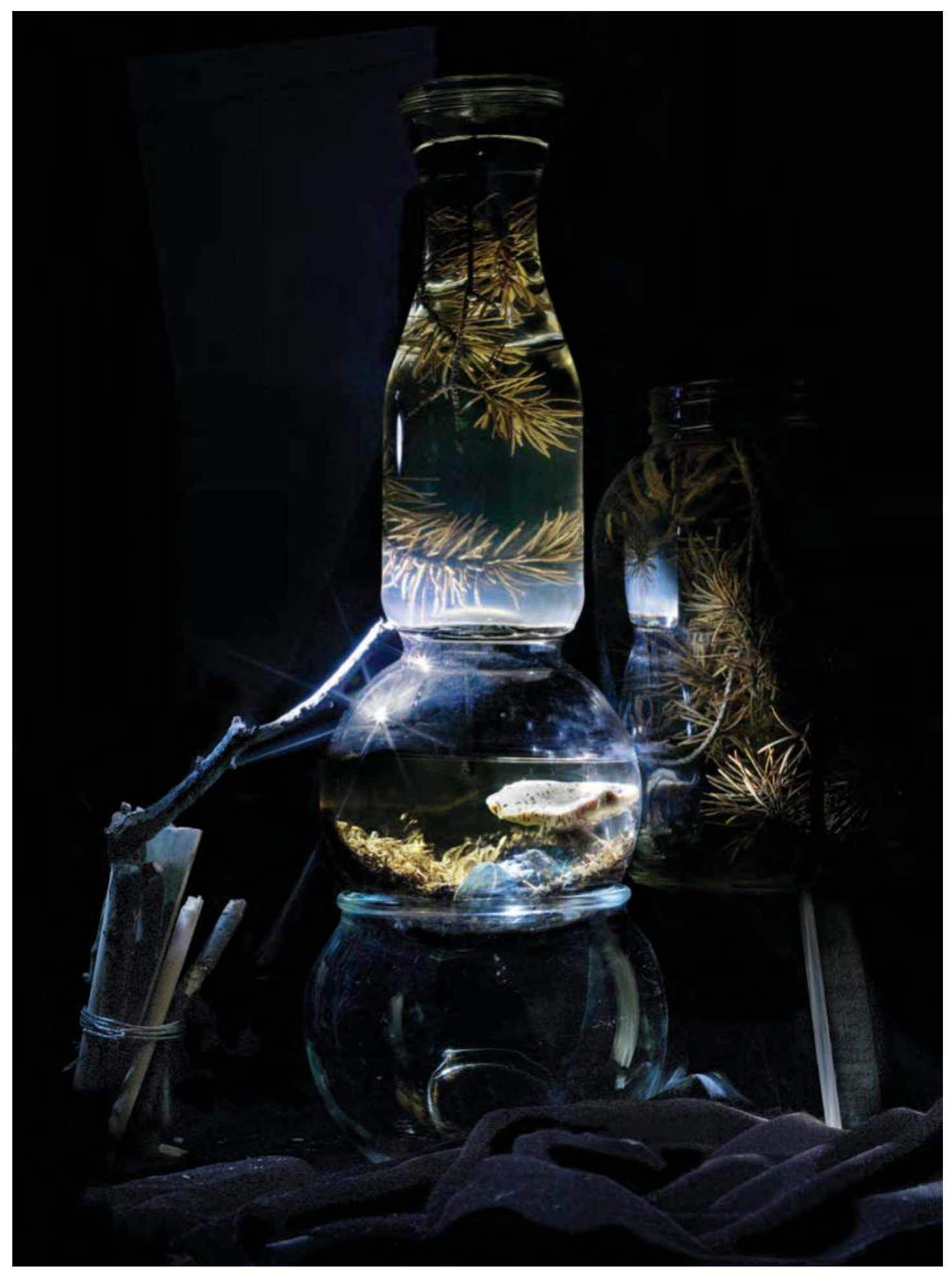




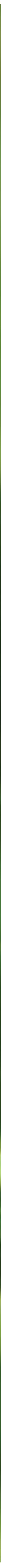




\section{milke macdonald's butterfly garden the little garden that could}

\section{katherine ylitalo}

Artist and videographer Mike MacDonald criss-crossed Canada during the summers in the 1990s, planting more than twenty butterfly gardens. The small garden nestled in the Banff Centre for Arts and Creativity is the only one that remains. In an interview with John Grande published in LandViews, MacDonald said his interest in butterflies began in north-central British Columbia. ${ }^{1} \mathrm{He}$ felt unwell; an elder suggested, "When you are not feeling good you go find a butterfly and follow it and it will lead you to a medicine that will make you better." Of Mi'kmaq descent, MacDonald saw the garden projects as sanctuaries for butterflies in the face of environmental degradation, but also as a call to pay attention to Indigenous knowledge and honour traditional ways of living with plants.

MacDonald finished planting the Banff garden in 1999 and passed away in 2006 at the age of sixty-five. He was born in Nova Scotia but lived most of his life in Vancouver. Selftaught as an artist, he created video and installations that were exhibited nationally and internationally and are now in the collections of major Canadian public museums. He was honoured with the 1994 Jack and Doris Shadbolt Prize from the Vancouver Institute for the Visual Arts. His Web-based work "Butterfly Garden" was posted in conjunction with a garden as part of a 1998 exhibition, "Breaking Borders," and a residency, "Ten 
Little Indians," at the St. Norbert Arts Centre in Manitoba, and earned him the 2000 Aboriginal Achievement Award for New Media. Now, thanks in part to the Mike MacDonald Butterfly Garden at the Banff Centre, there is a renaissance of interest in his work as an artist, and the garden has become a destination.

Most of MacDonald's gardens were planted outside art centres and public galleries; the venues understood the value of the project as an artwork and provided funding. He chose sites that were overlooked, such as the Montreal rooftop of the inner city building that housed the artist-run centre Oboro. When he approached the Walter Phillips Gallery in 1995, he proposed a marginal strip of land between the modern Jeanne and Peter Lougheed Building and Glyde Hall, the long-standing complex of the Walter Phillips Gallery, studios, and workshops. The patch of wood siding on Glyde Hall that had been put up following a fire in 1979 looked provisional then, and still does. The existing vegetation was the popular institutional, low-maintenance ground cover, snow-on-the-mountain.

MacDonald reclaimed the corridor between the tall buildings as a two-part pocket alpine meadow garden. The length along the Glyde Hall side of the wide brick path is shady, a good place for moisture-loving plants like willows, currants, and meadow rue. On the sunny side, he planted saplings, young shrubs, perennials, and self-seeding annuals that thrive with more light and drier soil.

Plants of the region would attract and sustain both resident and migratory butterflies. Twenty years on, the garden has grown into healthy maturity and has become a safe haven for butterflies. The black hawthorn tree grew to be one of the largest specimens in the region, and a host plant for Striped Hairstreaks and White Admirals. A few years ago, we had exciting proof that butterflies and moths were now resident throughout the year. On a fall morning, we spotted plump, brightly patterned caterpillars moving slowly through mountain delphinium leaves. They were the fifth instar of the Purple Lined Sallow Moth caterpillar, their final stage before setting up for the winter in a cocoon. Thistles, asters, goldenrod, and pearly everlasting that MacDonald planted were in bloom when migratory Painted Lady butterflies, which are said to visit Alberta every ten to fifteen years, returned in 2018 for the first time since 2005.

The Butterfly Garden in Banff was commissioned by the Walter Phillips Gallery with support from the Canada Council for the Arts. The gallery accessioned the garden into the collection. It was unusual for a living artwork to have that designation, but the gallery took the responsibility of "conserving" seriously. From the start, master preparator Mimmo Maiolo understood the need for protection and erected a gated metal fence at either end to keep out browsing deer and elk. 

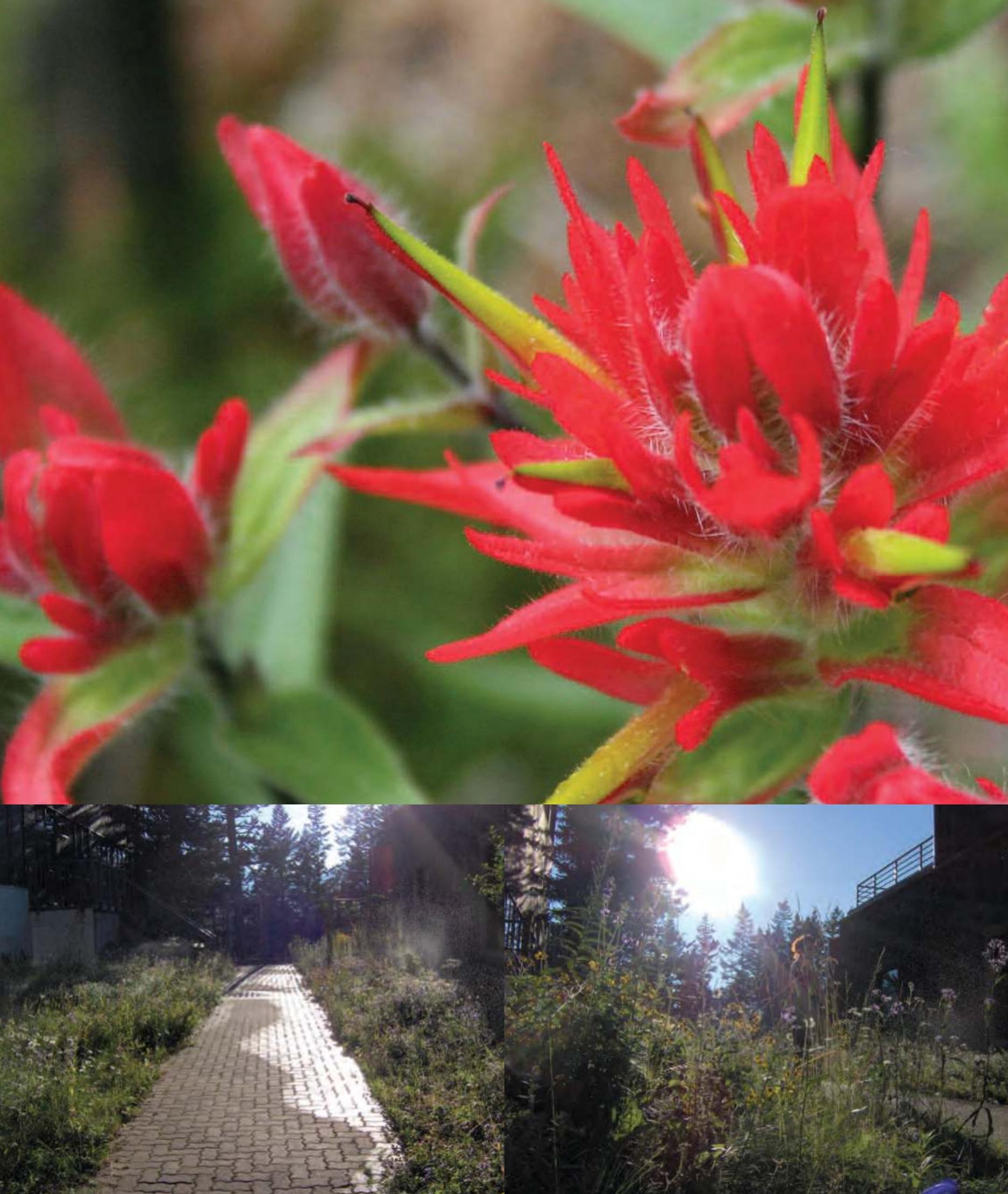
58 intertwined histories plants in their social contexts

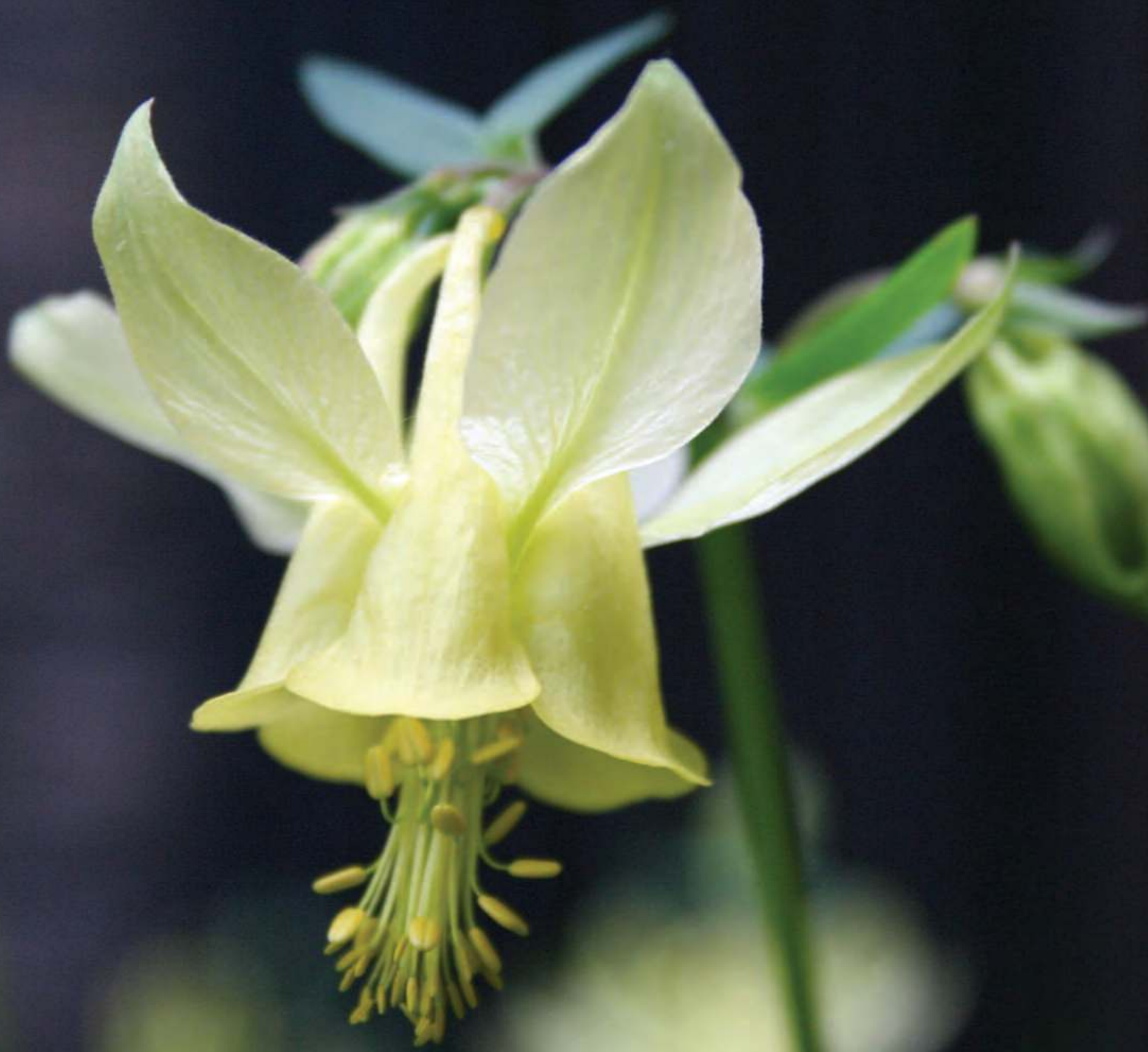


The staff has remained dedicated to the garden, beginning each season with a blitz weeding day to take out dandelions, daisies, thistles, and buttercups that come up in the disturbed ground at the edge of the path. Ten years ago, they invited me to help with the stewardship of the garden. I came with the lens of a curator, hoping to understand the artist's intention, and that of a horticulturalist, working toward a sustainable garden.

The first task-to observe, identify, and map the plants-took time because MacDonald left scant notes. In the first two years, I confirmed over sixty species, and the number grew to over a hundred, including trees, shrubs, perennials, self-seeding annuals, grasses, and moss. The biodiversity in that small space is remarkable.

I searched for clues in information about his other gardens. The key was on the St. Norbert website that he designed: "All the native plants that butterflies use also have traditional medicinal uses." Whereas lists of plants that attract butterflies have become easy to find today, as gardening to attract pollinators has become popular, there is less published on traditional Indigenous medicinal use of plants. In the Walter Phillips Gallery files, I found a booklet MacDonald put together about fourteen plants in the alpine butterfly garden. It contained notes on their importance to butterflies, along with their traditional benefits as medicine, food, and dyes as well as other ways the plants were used in daily life. He wrote about saskatoons, for example: "Traditionally, a gift of four Saskatoon berries would be presented when asking a favour. This would oblige the receiver to return the goodwill."

Recently I became aware that MacDonald had a counterpart in Mexico. In the 1990s, Francisco Toledo, a well-known artist of Zapotec ancestry, initiated a garden of ethnobotany as a way to reclaim an evacuated army camp in the heart of the city of Oaxaca, protect biodiversity, and foster support for the collection and preservation of Indigenous knowledge of plants among the many cultures of his region.

After the plants in MacDonald's garden were identified, visitors asked for labels. The horticulturist at the Calgary Zoo offered to generate labels similar to those in their botanical garden. While binomial nomenclature is useful and considered "universal," a garden full of sticks with Latin names did not seem to fit the artist's vision of a freeflowing meadow. Carl Linnaeus' eighteenth-century system of naming organisms based on taxonomy pinpoints plants within Western scientific methods and the premise that plants are single organisms. Given MacDonald's guidance toward understanding the relationships between flora, pollinators, and people, the use of common names and including the languages of various peoples who had inhabited the land from pre-settlement up to the present seemed more appropriate. 
Many English common names are colourful and refer to a plant's attributes (stinging nettle), lore (mountain forget-me-not), or use (northern bedstraw). But often a plant has differing common names depending on region and culture. In searching out the names of plants in Blackfoot and Cree, I encountered the same kind of diversity based on locale.

The nuances of translation add a layer of complexity. Often, a word in one language does not have a single equivalent one in another. Ways of living with and knowing about plants are built into languages in various ways.

The simplest system we could devise was to place small green wooden stakes with numbers. First, we placed sticks next to the largest plants, the trees and shrubs, then the established swaths of perennials, and finally, flowering plants that might only be evident for a short time in the course of the summer. For example, tiny magenta shooting stars appear in spring, but the plants practically disappear when the bloom is over. Growth over the summer hides many of the stakes, and some have deteriorated, but we are able to maintain a map for visitors and to monitor change in the garden. The nature of the meadow is shifting as the trees and shrubs flourish and the bank of wild roses doubles in size.

The sequence of blooms unfolds every season. Spring and early summer flowers sprinkle the meadow with colour-blue of mountain forget-me-nots, red paintbrush, yellow columbine. Sweeps of white flowering pearly everlasting, golden arnica, purple fireweed, and deep blue mountain delphiniums are showy in late summer. The stone wall of the Lougheed Building warms the trees and shrubs: a mock orange is deliciously fragrant for one week in spring; a tall black hawthorn with long sharp thorns provides cover for a pair of juncos all summer; the flowers of saskatoons, snowberries, and highbush cranberries herald fruit in the fall. On the sunny side, low-growing rock plants, such as pussytoes and sedum, mingle with a tangle of strawberries in sandy soil beside the path.

Above the spreading mare's tail on the shady side, the furry willow catkins signal spring and wide-leafed cow parsnips emerge like giant fiddleheads. In early spring, the tightly curled balls are edible for about three days and then the plant becomes toxic to touch. Brushing against it can render skin so sensitive to sunlight that a severe rash or burn can follow. It's a reminder of the care that should be taken with plants, and the respect that is due those who have learned how to use them. There are reports of traditional medicine using various parts of the cow parsnip collected at specific times in the season for salves, teas, and washes to treat inflammation, pain, cancer, and colds. The right amount of poison in the hands of an expert can be medicine. 
mike macdonalds's butterfly garden 61

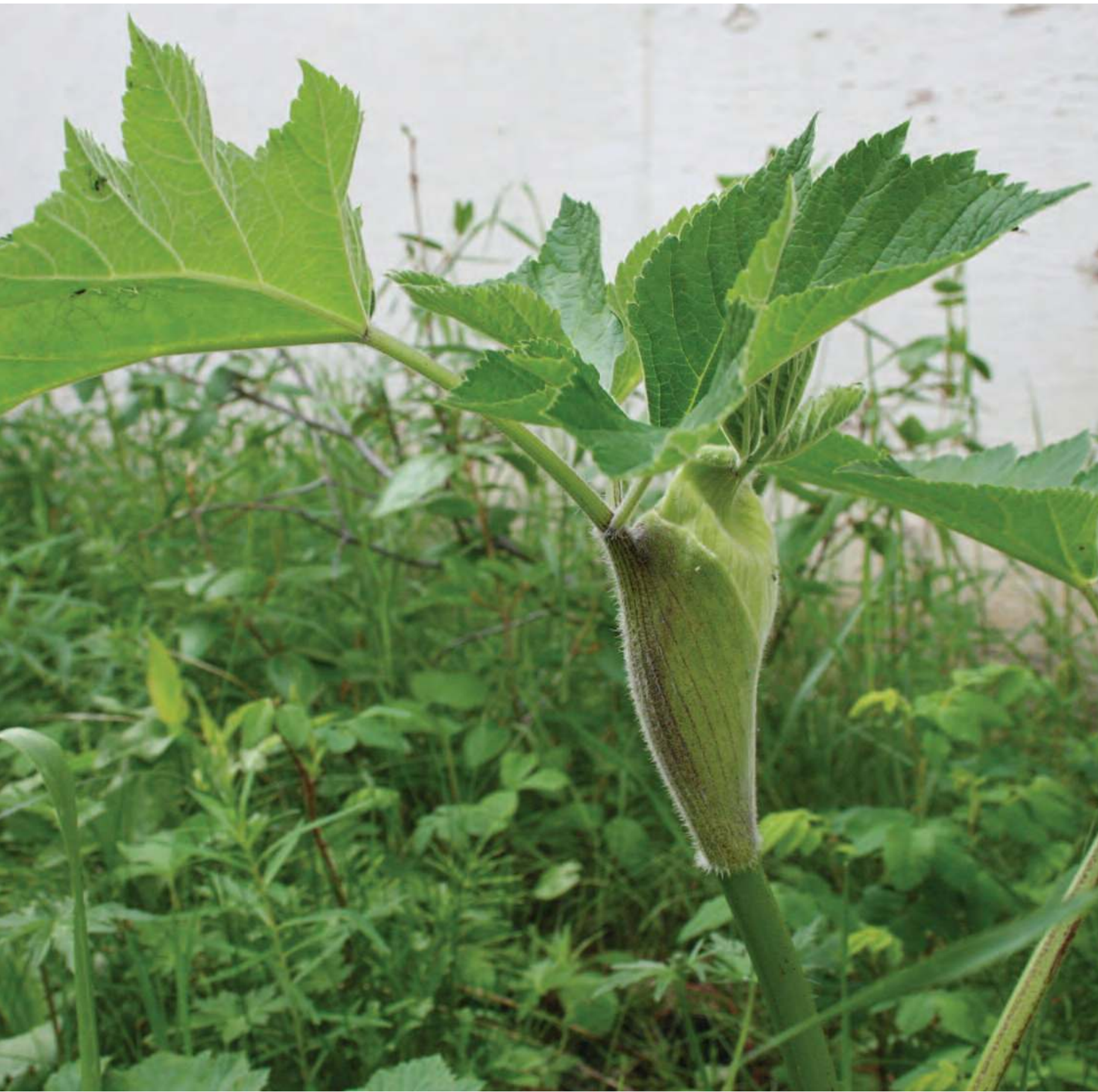




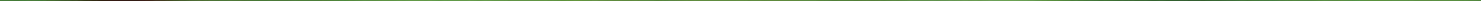


As I began to identify the plants, I quickly realized that MacDonald was freewheeling in his selection, often drawing on garden-centre plants, like chives and St. John's Wort, that he had used in other gardens across the country. He also found a variety of St. John's Wort that is native to the Kananaskis country of Alberta. The two varieties, valued by cultures in both Europe and North America as an antidote to anxiety, grow next to each other in the garden.

The status of the garden as a work of art allows for leeway in plant selection at a time when both the Centre and Banff National Park are encouraging people to plant only native plants. The gallery is mindful of the park guidelines and works to contain plants that are considered weeds. An informal volunteer group, the Friends of the MacDonald Butterfly, made up of visiting artists and staff at the Centre as well as gardeners from Canmore and Calgary, has helped with the annual work of keeping the most aggressive plants in check. The butterflies need a few thistles and dandelions, but we remove the invasive oxeye daisies and buttercups.

Institutional protection has been invaluable over the years in buffering the challenges of public opinion as well as the actions of grounds maintenance crews. When the plants were barely established, the garden was derided as "the Butterfly Garden that butterflies don't come to." It disappointed some visitors who had other expectations of a garden. To them it looked untended and overgrown. One summer the facility maintenance crew had directions to drive heavy equipment across the garden to repaint areas high on one of the buildings; that work was halted at the last minute.

Throughout the early years, the gallery staff remained committed and found support from the Alberta Foundation for the Arts. A small amount of funding for annual educational public programs made a big difference. The leadership of the gallery fostered understanding of the garden and supported its conservation-two pillars that proved crucial for the survival of the garden. Pollinators such as bees, beetles, butterflies, and moths are now regularly seen at work, welcome indicators that the ecosystem is flourishing. Nuthatches nest in the wall of Glyde Hall. Tiny calliope hummingbirds gather nectar from the fireweed before their journey back to Mexico on a migratory path that includes Oaxaca.

People take time to enjoy the gentle beauty of the garden and often use it as a meeting place. It was a focus for artists who came to the Banff Centre for Arts and Creativity to work with Diane Borsato, co-leader of the residency "The Art of Stillness." When she returned this year for the residency "Outdoor School," an extraordinary event demonstrated the esteem people from near and far have come to feel for both the artist and the garden. 
64 intertwined histories plants in their social contexts

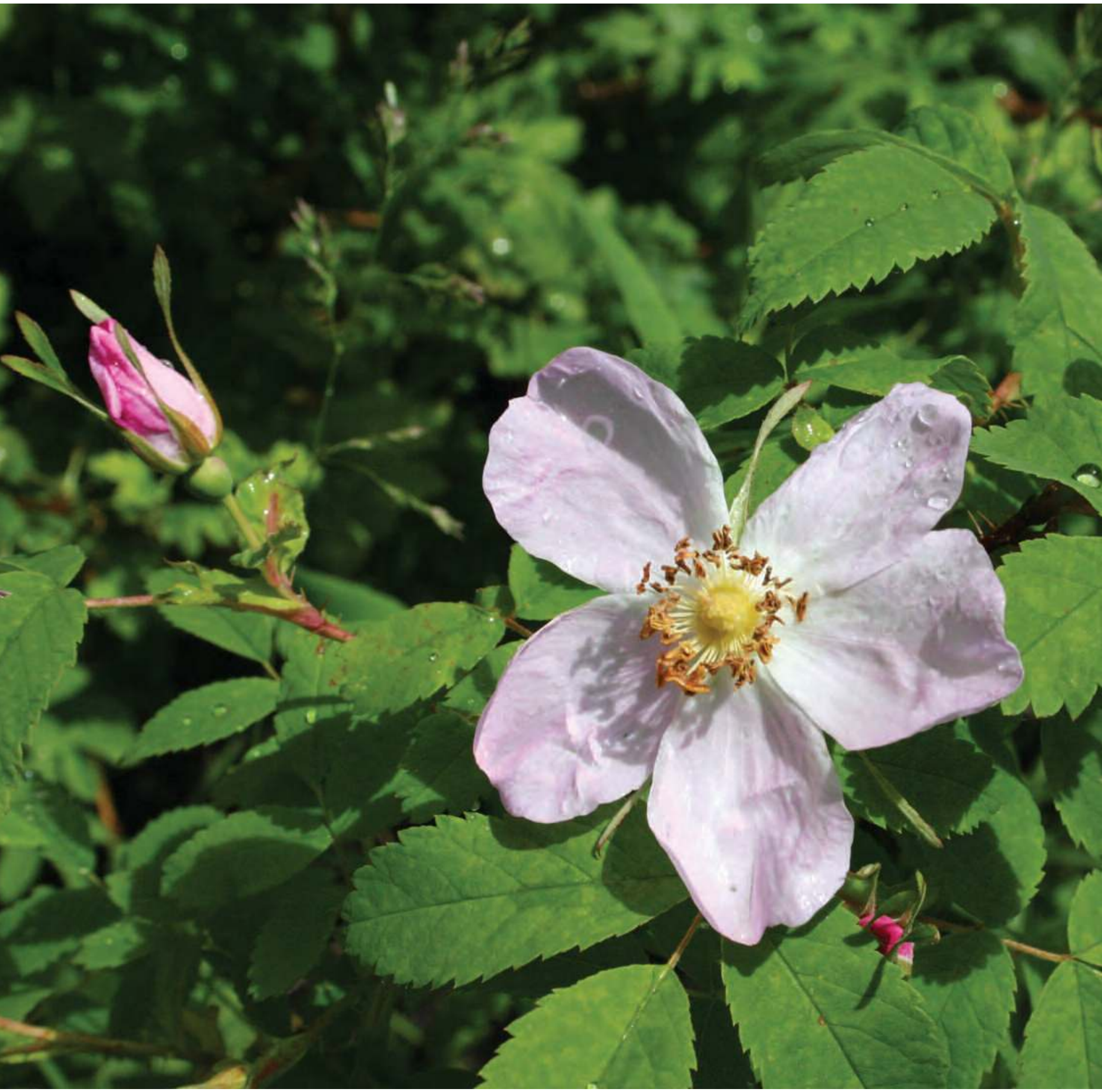


T'uy't'tanat-Cease Wyss, artist, activist, Indigenous plant diva who works with the Coast Salish community, and long-time friend of Mike MacDonald, came from Vancouver with Anne Riley, a young multidisciplinary artist who is Cree and Dene from Fort Nelson First Nation. They are working together to reclaim gas stations in Vancouver as gardens with the project "A Constellation of Remediation." On the first weekend in August, they brought gifts to the garden in Banff-sacred water, soil, plants, seeds-and organized a gathering: a ceremony with tea.

They invited an honoured guest, Una, a matriarch from the nearby Ĩyãhé Nakoda Eden Valley Reserve, who smudged and spoke to us of courage after tragedy. She radiated a true sense of wonder at how caring for plants had brought her to this moment. Cease and Anne introduced the additional gift of their own artwork, "Soundtrack for the Radical Love of Butterflies," an audio tape with a prescription: "We ask that you listen to this Soundtrack with responsible hearts. Each of these contributors has generously shared with you a part of their Butterfly Medicine. This Medicine is powerful and to be handled with care."

The poetics of Mike MacDonald's Butterfly Garden reside in the grasses, flowers, shrubs, and trees that sustain the life of butterflies, but also in the spirit of healing. The small garden that began as a gentle plea for care and understanding has become a haven for resident and migratory butterflies, a quiet spot in nature for meditation and fellowship, and a beacon for visitors who appreciate Mike MacDonald's vision.

\section{notes}

1. See Grande, “Mike MacDonald: Healing Garden.”

\section{bibliography}

Grande, John. "Mike MacDonald: Healing Garden.” LandViews: An Online Journal of Landscape, Art, \& Design. https://www.landviews.org/articles/mikemacdonald-jg.html. 


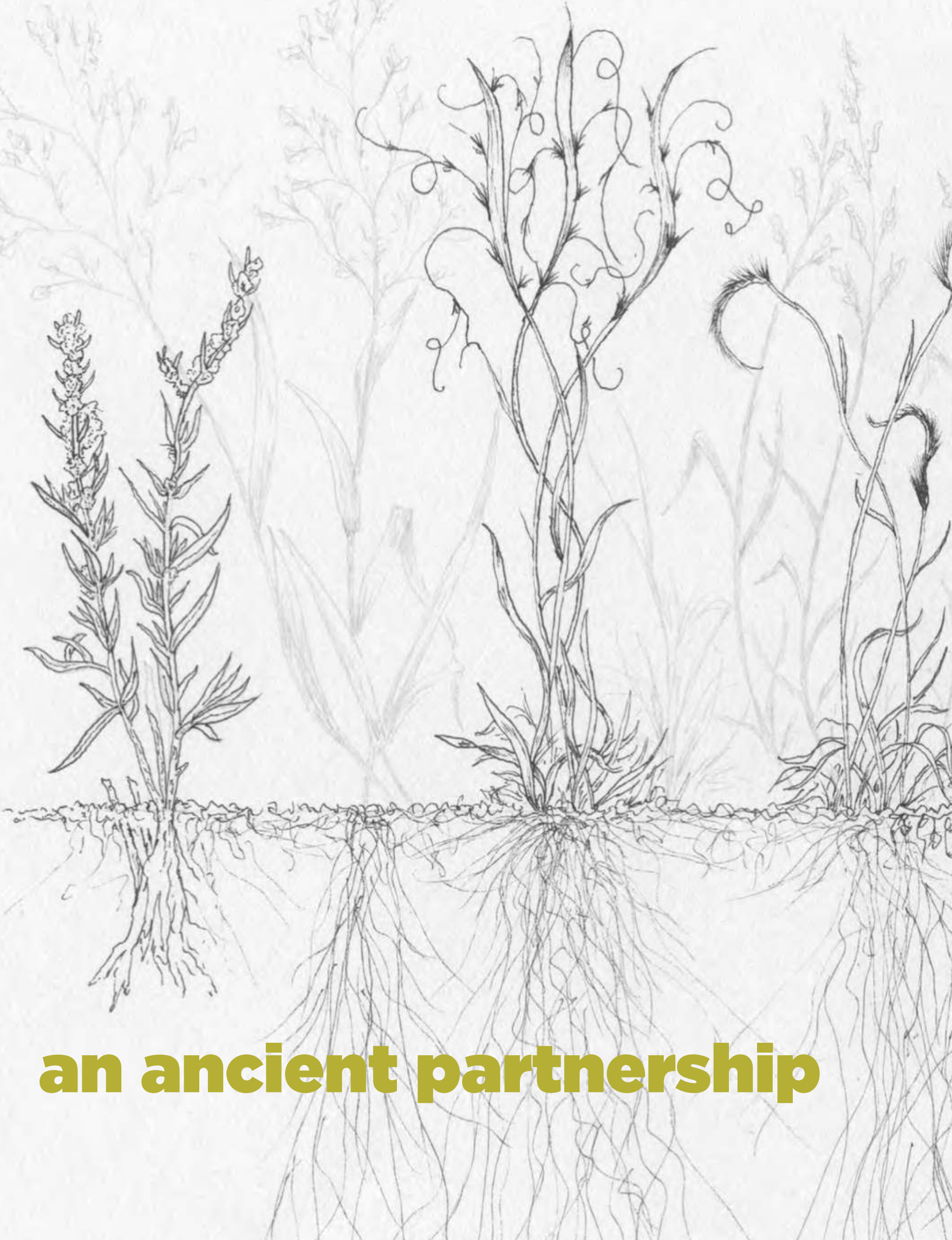



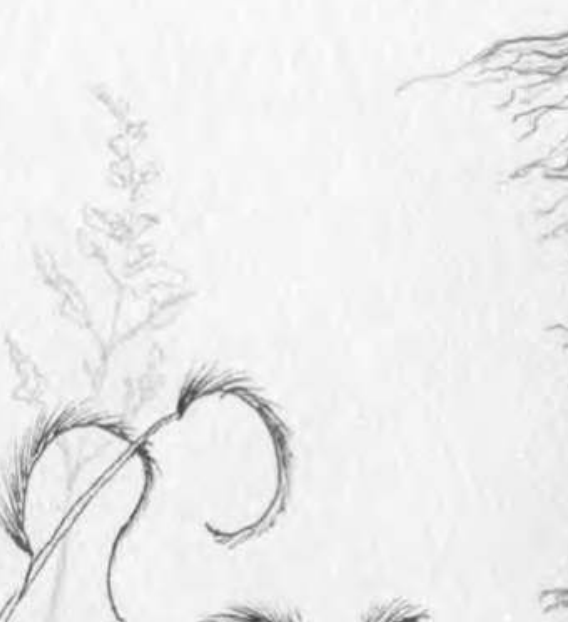
At first glance, the relationships between native grasses, plains bison, and Indigenous people seem obvious and simple. It's the perfect ecological triangle: grass grows, bison eat grass, and people eat bison. But when you delve a little deeper into this assemblage, it quickly becomes clear that it is more complex, linked by intricate relationships and dependencies that are invisible at first glance. So where to begin?

Let's begin with snot, and more particularly with bison snot. Without bison snot, none of the connections between grass, bison, and Indigenous people could exist. It is the foundation upon which everything else is built, and without it this ecological triangle would collapse.

As bison graze across a prairie landscape they do so with their noses swishing through the grasses in a rhythmic back-and-forth motion, their rough prehensile tongues curling out to grab small bunches of grass. Every time she breathes in, the bison is inhaling microbes; fungi, bacteria, and protozoa that coat the surface of every blade of grass. The number and diversity of microbes are mind-boggling. For example, Torsvik et al.' identified more than four thousand microbes per gram of soil in a forested environment. Astounding, but what has this to do with the ability of a group of First Nations to survive on the northern Great Plains?

As the bison grazes she periodically stops to chew her mouthful and follows up with a quick cleaning of her nostrils. All those microbes get caught in the moist mucus lining her nostrils, and she periodically needs to clean her nasal chambers. She does this by reaming each nostril with her tongue and, in doing so, swallows all of the accumulated microbes caught up in her snot. These microbes are what allows her to digest the cellulose in the vegetation she just consumed. ${ }^{2}$ As the seasons progress, the types of microbes on the vegetation also change, ${ }^{3}$ and consequently, so too does the rumen (the first of four stomachs) microbial populations. This continuum of gut microbes allows bison to adapt to constantly changing forage conditions. Without these specialized cellulose digesters, she would starve, and without her, so would the people who depended upon bison for their survival.

As bison move across the landscape in space and time, they are constantly searching for the most nutritious and most easily digested forage. They primarily hunt for grasses, and on the plains, two general types of grasses exist, known as cool and warm season grasses. Each is adapted to a suite of environmental conditions that enable it to thrive. ${ }^{4}$ Cool season grasses are the first to emerge from under the winter blanket of snow, and the bison know this. The bisons' annual round of activity is at least partially dictated by the location and abundance of cool season grasses from March through June-the period when these grasses provide a high-quality diet. 
Maternal bands form two different groups during the spring: the "haves" and "havenots." As each cow in the group drops her calf, she moves away from the main herd and is quickly followed by other mothers with calves, forming maternal bands-the haves. Those barren cows, or cows too young to breed, form groups of have-nots-those without calves of their own. Both groups seek out patches of cool season grasses that are expansive enough to feed large groups of bison. Being in large groups and mass calving is an anti-predator strategy, one that swamps predators with so many identical choices that selecting one calf among the many is difficult. ${ }^{5}$ Bulls, during the spring, are scattered in small groups or as lone individuals, each seeking out small patches of rich forage. Isolation makes it difficult for predators to find these bulls, and they leave the large grazing areas for the cows.

First Nations people understood the relationship between grassland type and the seasonal movements of bison from one type to another and were able to predict with some certainty when and where the bison could be found. This predictive ability was a science that took thousands of years to perfect, and with this knowledge, each facet of their societies could be maintained. This includes such factors as when to harvest bison for tipi covers or for food and clothing.

Needle-and-thread grass (Stipa comata) is a classic cool season grass, one that produces the highest-quality forage for bison during the early spring. Its spring protein content can be over 20 per cent, but by early summer it drops to just 5 per cent. ${ }^{6}$ By July the golden brown seeds with their distinctive needle-sharp awns have formed, and Indigenous people knew that when they began to see these seed heads sway and shift in the winds, bison cows were fat and at their prime. ${ }^{7}$ Coincidentally, bison, with their shaggy beards and long pendulous chaps, were active participants in the reseeding of their own pastures. The barbed seed head evolved with grazing ungulates, and through a process referred to as epizoochory, these seeds can be carried tremendous distances by migrating bison. At some distance from the parent plant the seed falls off and new plants become established.

Spring is the time for harvesting bison for new tipi covers, and spring cow hides were always the first choice. ${ }^{8}$ By the end of winter, cow hides, and in particular those of the barren cows, had the least amount of subcutaneous fat to remove from the fresh hide. The hide was at its thinnest and lightest, and at this time of year, the winter coat was being shed-all criteria for the perfect tipi cover. Coincidentally, groups of walking tipi covers were forming (the have-not cows) just at the time when new hides were required. The women of the village must have felt a sense of urgency to get these hides, because even gaunt old cows gain weight and fat quickly on the diet of fresh cool season grasses, and once missed, the opportunity to acquire the ideal tipi hides would not come for another year. 
An average of ten hides was needed to cover a tipi during the pre-horse era. ${ }^{9}$ Severe cold, heavy rains, and bleaching suns take their toll on leather, and as a result, a cover lasted between one and two years..$^{10}$ For a village of just ten tipis, this would require an annual spring harvest of 50-100 female bison for the sole purpose of creating tipi covers. Since there was no fat on the meat, it was not considered fit for consumption."

Bison snot enters the picture again in the spring. As the gut microbes do their work, they are passed along through the digestive system and eventually make an inglorious arrival on the prairie in the form of a bison patty. This patty is instantly attacked by ravenous insects, and the first to arrive are those that eat the bacteria and protozoa that once swam in the rumen..$^{2}$

In their hunt for prey within the dung pat, they break it up, dry it out, and scatter it across the prairie, fertilizing the grasses from which it was formed.

Bison patties are also the perfect medium for the planting of new grasses. Species like blue grama grass (Bouteloua gracilis) benefit from being eaten by a bison, as the scarification of the hard shell by grinding molars and digestive juices helps to prepare the shell for later germination. Blue grama grass was culturally significant for many First Nations people because they used it to predict the severity of an oncoming winter..$^{13}$ The Blackfeet of Montana believed that if the blue grama grass had one seed head it would be a mild winter, but if it had two or more a severe winter was coming ${ }^{14}$ Knowledge of how severe a winter could be was essential in planning how much food would be required to sustain a village.

Bison dung was a critical component in the tanning of fresh bison hides, and later for the preservation of meat during the drying process. On the vast open plains, there is little in the way of wood, so for thousands of years people used dried bison dung to fuel their fires. ${ }^{15}$ During wet weather when dung would not burn, bison skulls smeared with grease would be burned to provide a steady heat. ${ }^{16}$ Once the new tipi cover was assembled and draped over the tipi poles, it needed to be cured. This was done by building a fire in the central hearth with smouldering bison chips to cure the hides with smoke. This smoke was also used later in the summer and fall to cure and dry the meat harvested to make pemmican. ${ }^{77}$ Without abundant bison dung scattered across the prairie, it is doubtful that people could have survived on this landscape.

As spring advanced into early summer, the lean bulls were finally putting on enough body fat from the cool season grasses to withstand the rigours of the upcoming rut. Indigenous people knew that when the buffalo bean (Thermopsis rhombifolia) began to speckle the 
prairie with their distinctive yellow flowers that these bulls were finally in prime condition for harvesting..$^{18}$ It was also a time when scattered groups of bulls began leaving their isolation behind in their search for the maternal bands of cows, calves, and immature animals. The great coalescing of scattered bison groups was beginning. The bison rut was about to take place and the very essence of the prairie was about to change.

It was these vast summer aggregations of rutting, roaring, fighting, dust-creating masses of bison that so astounded European explorers. Herds of tens of thousands formed on the open plains to conduct their annual breeding rituals. These vast herds required enormous amounts of high-quality food, just at a time when the nutritious cool season grasses of spring were drying and declining in nutritive value. Fortunately, this was also the time when the warm season grasses were reaching their maximum value to bison, and these were found on the open plains. Grasses such as switchgrass (Panicum virgatum), western wheatgrass (Agropyron smithii), and porcupine grass (Stipa curtiseta) provided excellent forage for rutting bison during mid to late summer. Their tendency to hold the snow off the ground during the winter also made them a preferred source of food..$^{19}$ These tall grasses would have made an excellent bedding material, or for packing as insulation around the bottom of winter tipis. ${ }^{20}$

Stalking these herds were bands of hunters. Like the bulls before them, these small bands of wintering people left the seclusion of wooded valleys to seek their prey. ${ }^{21}$ To do so they formed large intertribal encampments of people from across the region. ${ }^{22}$ This gathering of people was a significant event, one long anticipated and prepared for with excitement and detailed planning.

While the people were preparing, the bison rut was progressing. One of the truly remarkable processes taking place then was the creation and use of bison wallows. Created by older bulls but used by all members of bison society, these circular earthen patches were used as the "coffee shop" of bison society. It is where dominant interactions between rival bulls took place, and where dust baths were taken to rid themselves of biting insects and to coat their skins with an impermeable layer of rain-shedding dust. Bulls seeking cows in heat urinate in the dusty wallow, then roll and thrash to grind this attractive scent into their hair to attract females and to declare to rivals that this place is theirs. The aftermath of a rutting season is a prairie landscape pockmarked with tens of thousands of wallows. On a landscape characterized by hot, dry conditions, the exposed soil patches were also a perfect place to pitch a tipi and to build a bison dungfuelled fire where the risk of causing a prairie fire was reduced. 
Flashback to spring and these wallows were helping to provide breeding sites for countless prairie chickens, sage grouse, and sharp-tailed grouse. Each of these species requires a flat open area to perform its ritualized courting dances, ${ }^{23}$ and bison wallows were the perfect dance floor. Strutting, stomping, swirling male grouse performed elaborate dances to attract their mates, and all of this took place on the dancing grounds of the bison.

This did not go unnoticed by the people of the prairie and is reflected in their centurieslong traditions of dancing at powwows and seasonal group assemblages, such as the preparation for a summer or fall bison hunt. The males of each of the three grouse species sport an elaborate bustle of flared tail feathers, feather-covered feet, and brilliantly coloured head feathers. These attributes were mirrored in the regalia worn by the men at these communal dances. Even today the modern regalia worn by men during grass dances, chicken dances, and traditional dances mimic the look and breeding behaviour of these grassland grouse, reflecting the fact that the grass dance was originally used by scouts to beat down a circular area of grass $^{24}$ in preparation for the arrival of the camp-an echo of the bison wallow and its use by dancing grouse.

All grouse perform a similar dance in the fall, and this may have been another signal to people that winter was fast approaching. The lengths of the days in April and September are identical, and this confuses the gonads of male grouse, causing a phenomenon known as testicular recrudescence. It is a period when male grouse behave as they did in the spring, and once again perform their ritualized dances. It was also the time when people were getting serious about fall hunting. ${ }^{25}$ The ritualized dances of men at fall gatherings again reflected the behaviour of these birds dancing on bison wallows.

Fall was a time of scattering, a time when both bison and people dispersed into small groups across the prairie. There are many accounts of First Nations people seeking the shelter of wooded creeks and valleys, close to fuel and water and hidden from the prying eyes of other people and wary bison. However, many ancient winter encampment sites are found on high windswept ridges far out on the open plains. This seemingly harsh, barren landscape offered numerous advantages over life in sheltered valley bottoms.

As winter storms howled across the open prairie, especially in rugged terrain, the falling snow would be driven by relentless winds into small coulees and along valley rims. Here it collected into deep drifts that hung suspended for many metres into the valley. The winds scoured snow off the uplands, leaving behind pristine patches of exposed grass-a perfect place for bison to access the cured warm season plants. Even in mid-winter some of these plants, winterfat (Eurotia lanata) for example, can carry protein levels of more than 11 per cent throughout the winter. ${ }^{26}$ Every grazing animal on the prairies searches for winterfat, and often it is found on these exposed patches of windswept prairie. 
With all of the grasses cured by summer's end, bison must switch their strategy of grazing succulent new growth to foraging on tall, dried-out vegetation. When they do this they create small grazing patches-places where they have cropped the grass close to the ground. The combined actions of grazing, urinating, and defecating in a small area enhance the ability of the grass to produce new growth the following spring. These grazing lawns are also the first vegetation to green up in the spring.

For Indigenous peoples, these grassland islands in a sea of snow were a reliable and predictable location for hunting bison, and provided forage for their horses, open areas for the tipis, abundant fuel in the form of buffalo chips, ${ }^{27}$ and viewpoints from which to observe passing wildlife. The deep drifts offered an excellent opportunity to mire bison where they could be quickly killed and processed. The history of people using such sites is evident in the distribution of double-walled tipi rings across the northern plains. ${ }^{28}$

As the winter snows melted away and new spring growth began across the grassland, the circle of life on the plains would continue; bison calves would romp and play, buffalo bean would once again speckle the prairie, and people would conduct their activities scheduled by the phenology of prairie grasses.

\section{notes}

1. Torsvik, Goksoyr, and Daae, "High Diversity of DNA of Soil Bacteria."

2. Nagy, "Biological Relations of Rumen Flora and Fauna"; Hobson and Stewart, The Rumen Microbial Ecosystem.

3. Bergmann et al., "Seasonal Shifts in Diet and Gut Microbiota of the American Bison."

4. Barnes, Tieszen, and Ode, "Distribution, Production, and Diversity of C3 and C4 Dominated Communities"; Wang, Liu, and Bai, "Photosynthetic and Morphological Functional Types for Native Species from Mixed Prairie in Southern Saskatchewan, Canada."

5. Mooring, "Sexual Segregation in Bison."

6. Looman, 111 Range and Forage Plants of the Canadian Prairies.

7. Johnson, "Blackfoot Indian Utilization of the Flora of the Northwestern Great Plains."

8. Brink, "Blackfoot and Buffalo Jumps"; Brink, Imagining Head-Smashed-In; Hungrywolf, The Tipi, 40; Laubin and Laubin, The Indian Tipi.

9. Brink, "Blackfoot and Buffalo Jumps."

10. Hungrywolf, The Tipi.

11. Brink, Imagining Head-Smashed-In.

12. Kadiri, Lumaret, and Floate, "Functional Diversity and Seasonal Activity of Dung Beetles." 


\section{4 intertwined histories plants in their social contexts}

13. Johnson, "Blackfoot Indian Utilization of the Flora of the Northwestern Great Plains."

14. Turner, Remarkable Plants of Texas.

15. Brink, Imagining Head-Smashed-In; Mlekuz, "The Materiality of Dung."

16. Hungrywolf, The Tipi.

17. Brink, Imagining Head-Smashed-In

18. Moerman, North American Ethnobotany.

19. Telfer, "Adaptation of Some Large North American Mammals."

20. Hungrywolf, The Tipi

21. Verbicky-Todd, "Communal Buffalo Hunting Among the Plains Indians."

22. Brink, Imagining Head-Smashed-In.

23. Harrell, "Peak Lek Attendance for Greater Sage-Grouse."

24. Saskatchewan Indigenous Cultural Centre website, "Men's Grass Dance," http://www.sicc.sk.ca/grassdance.html.

25. Brink, Imagining Head-Smashed-In

26. Ogle et al., Plant Guide for Winterfat

27. Binnema, "The Common and Contested Ground."

28. Kehoe, "Stone Tipi Rings"; Verbicky-Todd, "Communal Buffalo Hunting Among the Plains Indians"; Hungrywolf, The Tipi.

\section{bibliography}

Barnes, P. W., L. L. Tieszen, and D. J. Ode. "Distribution, Production, and Diversity of C3 and C4 Dominated Communities in a Mixed Prairie." Canadian Journal of Botany 61 (1983): 741-51.

Bergmann, G. T., J. M. Craine, M. S. Robeson, and N. Fierer. "Seasonal Shifts in Diet and Gut Microbiota of the American Bison." PLoS One 10, no. 11 (2015): 1-14.

Binnema, T. "The Common and Contested Ground: A History of the Northwestern Plains from A.D. 200 to $1806 . "$ PhD diss., University of Alberta, 1998.

Brink, J. W. "Blackfoot and Buffalo Jumps: Native People and the Head-Smashed-In Project." In Buffalo, edited by J. Foster, D. Harrison, and I. S. MacLaren, 19-44. Edmonton: University of Alberta Press, 1992.

- Imagining Head-Smashed-In. Edmonton, AB: Athabasca University Press, 2008.

_. "Preferential Selection and Killing of Bison by Plains Indians." Paper presented at the International Bison Conference, Edmonton, AB, 2000.

Harrell, D. "Peak Lek Attendance for Greater Sage-Grouse within the Northern Bighorn Basin, Wyoming." Technical Note 424. U.S. Department of the Interior. Bureau of Land Management, Cody Field Office, Wyoming, 2008 
Hobson, P. N., and C. S. Stewart. The Rumen Microbial Ecosystem. London: Blackie Academic \& Professional, Chapman and Hall, 1997.

Hungrywolf, A. The Tipi, Traditional Native American Shelter. Summertown, TN: Native Voices, 2006.

Johnson, A. "Blackfoot Indian Utilization of the Flora of the Northwestern Great Plains." Economic Botany 24, no. 3 (1970): 301-24.

Kadiri, N., J. P. Lumaret, and K. D. Floate. "Functional Diversity and Seasonal Activity of Dung Beetles (Coleoptera: Scarabaeidae) on Native Grasslands in Southern Alberta, Canada." Canadian Entomologist 146 (2014): 291-305.

Kehoe, T. F. "Stone Tipi Rings in North-Central Montana and the Adjacent Portion of Alberta, Canada: Their Historical, Ethnological and Archaeological Aspects.” Bureau of American Ethnology, Bulletin 178, 1960.

Lantz, T. C., and N. J. Turner. "Traditional Phenological Knowledge of Aboriginal Peoples in British Columbia." Journal of Ethnobiology 23, no. 2 (2003): 263-86.

Laubin, L., and G. Laubin. The Indian Tipi: Its History, Construction, and Use. Norman: University of Oklahoma Press, 1977.

Looman, J. 111 Range and Forage Plants of the Canadian Prairies. Research Branch, Agriculture Canada, Publication 1751, 1983.

Mlekuz, D. "The Materiality of Dung: The Manipulation of Dung in Neolithic Mediterranean Caves." Documenta Praehistorica 36 (2009): 219-25.

Moerman, D. North American Ethnobotany. Portland, OR: Timber Press, 1998.

Mooring, S. M., D. D. Reisig, E. R. Osborne, A. L. Kanallakan, B. M. Hall, E. W. Schaad, D. S. Wiseman, and R. R. Huber. "Sexual Segregation in Bison: A Test of Multiple Hypotheses." Behavior 142 (2005): 897-927.

Nagy, J. "Biological Relations of Rumen Flora and Fauna." In Range and Wildlife Habitat Evaluation; A Research Symposium, edited by H. A. Paulsen, Jr., and K. W. Parker, 159-64. Flagstaff, AZ: U.S. Department of Agriculture, 1968.

Ogle, D. G., L. St. John, L. Holzworth, S. R. Winslow, and D. Tilley. Plant Guide for Winterfat (Krascheninnikovia lanata). Aberdeen, ID: U.S. Department of Agriculture, Natural Resources Conservation Service, 2012.

Telfer E. S. "Adaptation of Some Large North American Mammals for Survival in Snow.” Ecology 65, no. 6 (1984): $1828-34$

Torsvik, V., J. Goksoyr, and F. L. Daae. "High Diversity of DNA of Soil Bacteria." Applied and Environmental Microbiology 56, no. 3 (1990): 782-87.

Turner, M. W. Remarkable Plants of Texas: Uncommon Accounts of Our Common Natives. Austin: University of Texas Press, 2009.

Verbicky-Todd, E. "Communal Buffalo Hunting Among the Plains Indians: An Ethnographic and Historic Review." Archaeological Survey of Alberta, Occasional Paper No. 24, 1984.

Wang, R. Z., X. Q. Liu, and Y. Bai. "Photosynthetic and Morphological Functional Types for Native Species from Mixed Prairie in Southern Saskatchewan, Canada." Photosynthetica 44, no. 1 (2006): 17-25. 
76 intertwined histories plants in their social contexts

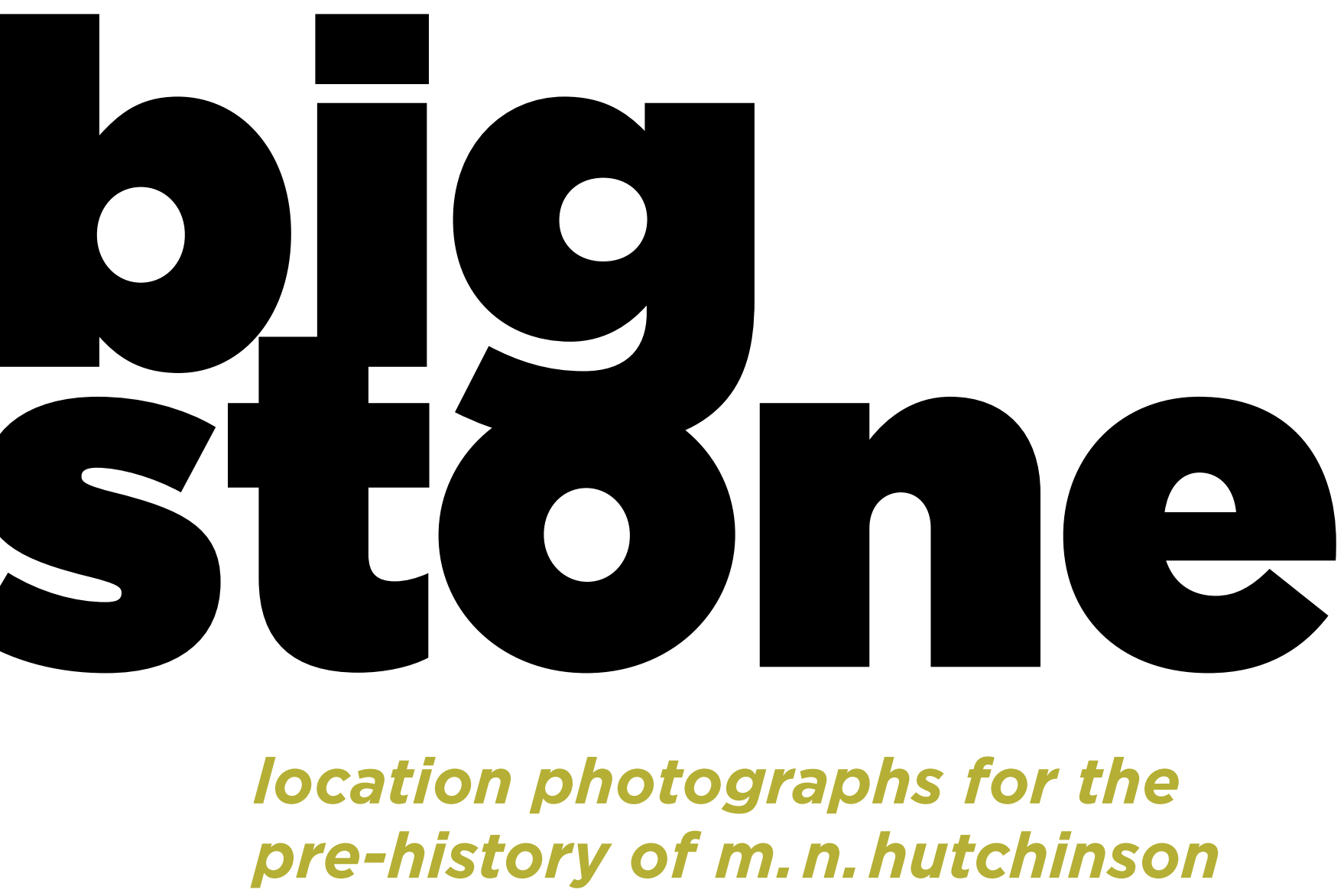

m. n. hutchinson 
My maternal great-grandmother's family left Norway because of a lack of opportunity. They immigrated to Minnesota but there also found themselves unable to own land, so they moved to Canada, where land was being homesteaded. This initially led them to Big Stone, Alberta, where my great-grandmother, with only her five girls, tried to farm the semi-arid land north of Suffield. They broke the shortgrass prairie and planted wheat but were soon forced off the land by the lack of rain. Their cabin was identifiable by a long double row of caragana, some of which still survive. Later, joined by her one son, they moved to a region of Saskatchewan that was previously settled by relatives and where my mother and uncles were born. Not coincidentally, none of these siblings went on to farm or marry farmers.

Prior to 2009, I exclusively made self-portraits, building a biography that uses both fact and fiction in order to understand and create an identity. This latest series of work draws on my family history. The title of the series-Location Photographs for the PreHistory of M. N. Hutchinson-alludes to genealogical and filmmaking research. This sense of research is articulated by the specifics of location and the manner of image making. The rotating panorama camera I use creates time-based still images that rely on the narrative functions of cinema, but it can also map a scene with the same techniques used in forensic photography.

The images forefront the strange mixture of representation and rationality that is inherent in all photography. While straight photography reinforces a falsely logocentric perception of the world, these seemingly distorted, counterintuitive representations of space are in fact just as rational, at least in the sense that they flow from strict optical and mechanical structures that are historically considered to be hallmarks of the photographic image.

Genealogical mapping provides a way to see yourself in relation to other kin, although it is the everyday performative articulation of identity that ultimately leaves a residue of a legacy. Interacting with the genealogic specifics of sites allows me to insert some affect into this identity through the embodied act of photography. The photographic act is predicated on being there, being somewhere; even if it is fictive, there is still a sense that this place must exist. It remains a testament to having been present at the places where your ancestors lived, and that can change the way you create an identity. 


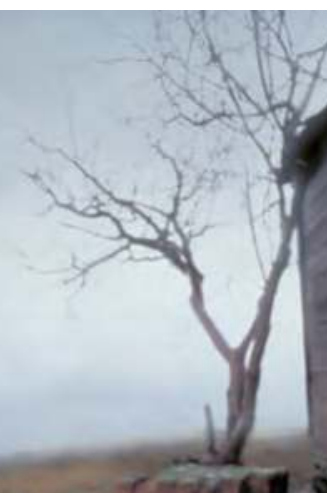

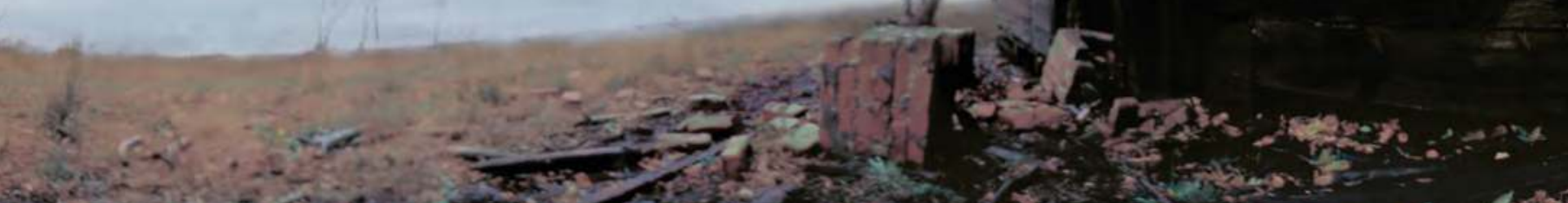

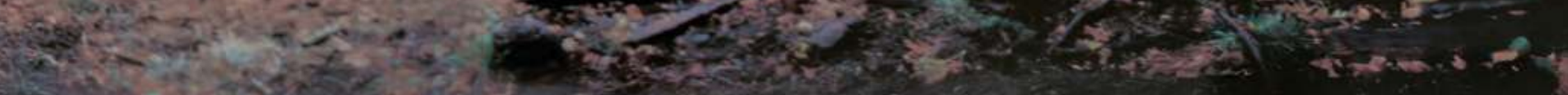
30

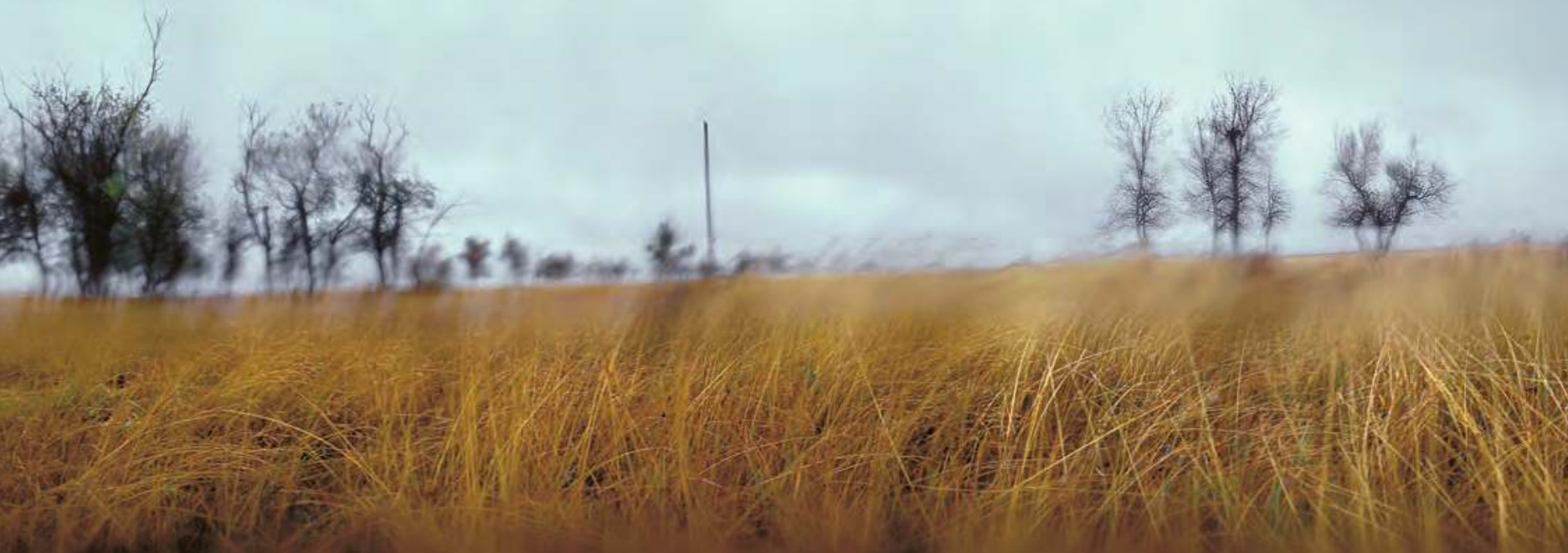




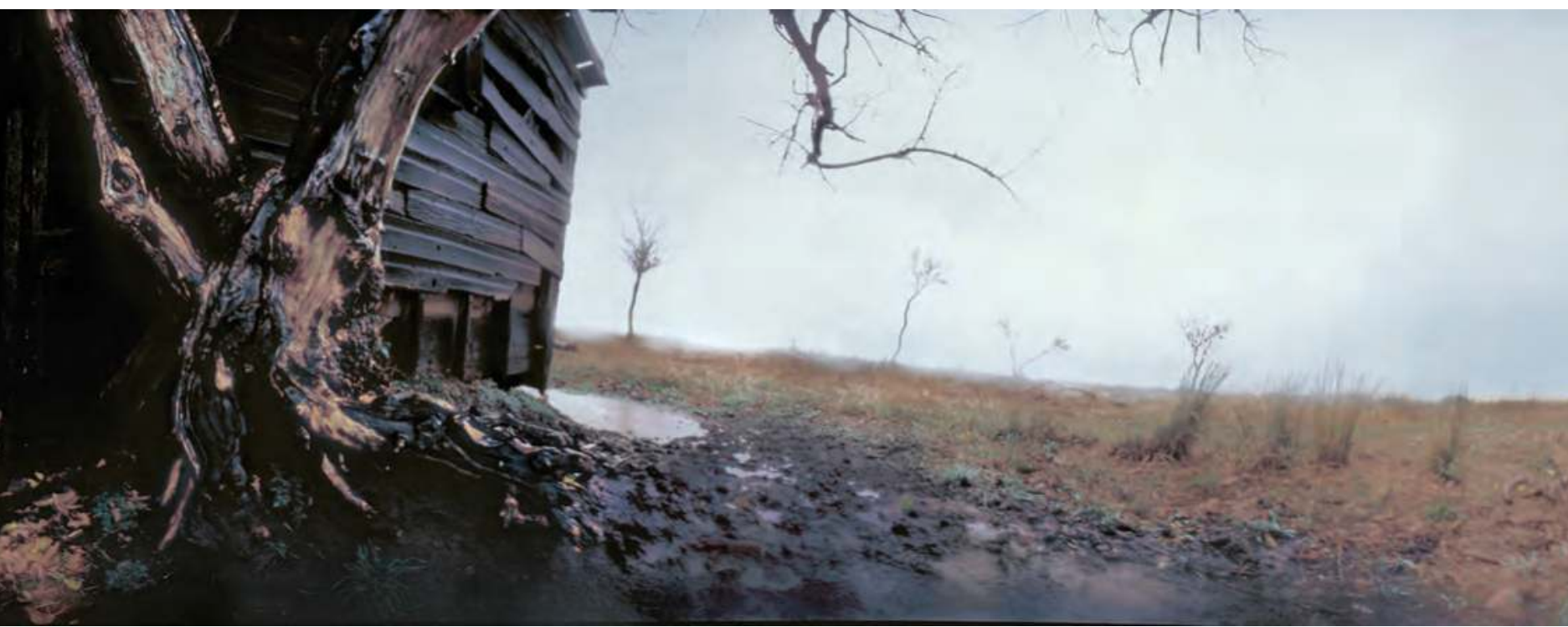

Location Photographs for the Pre-History of M.N.Hutchinson: Site 19. $36 \mathrm{~cm} \times 178 \mathrm{~cm}$, archival inkjet, 2009. 


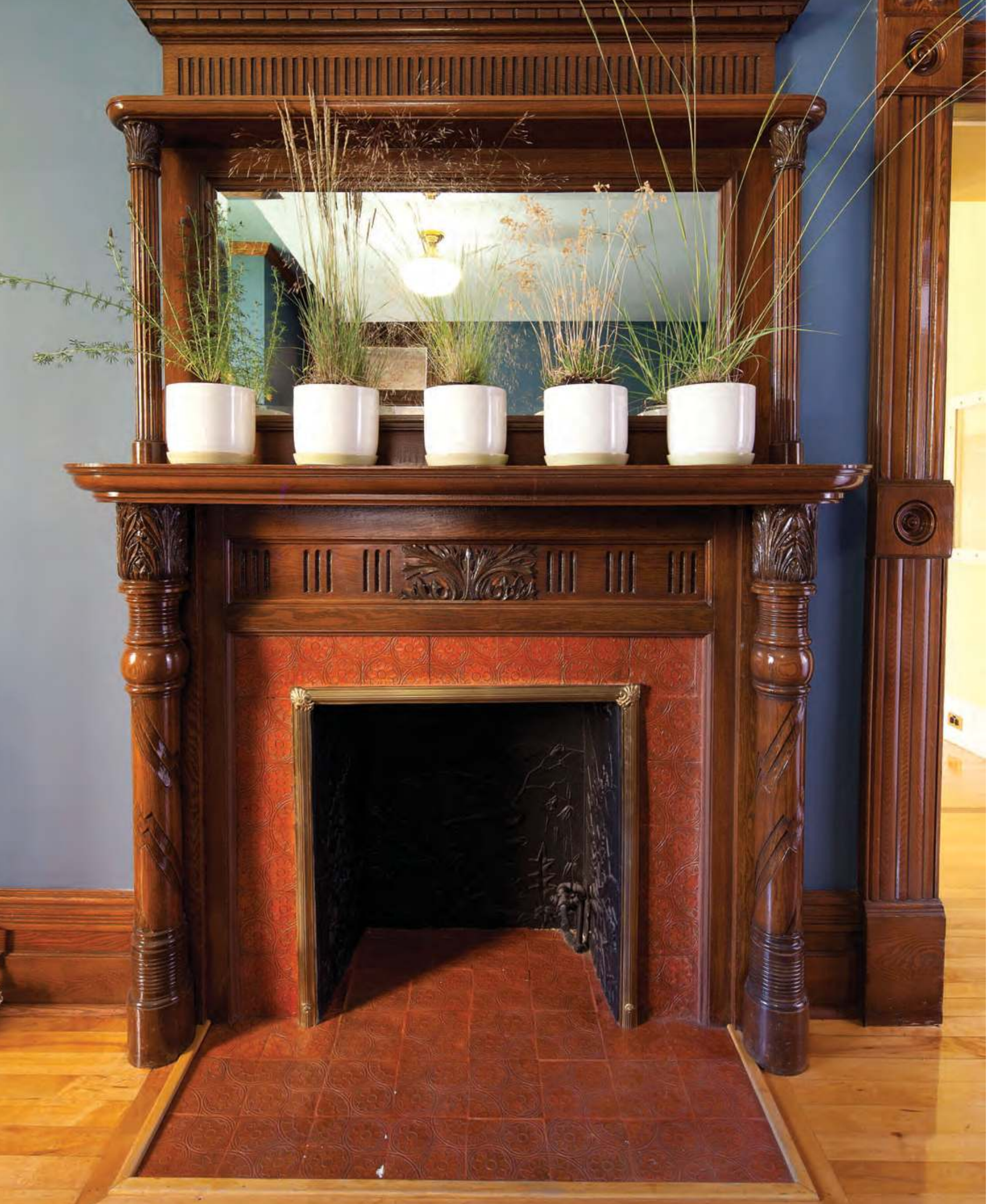




\section{gone today, here tomornow}

\section{an interview with mia rushton \& eric moschopedis}

\section{ciara mckeown}

Mia Rushton and Eric Moschopedis are artists who critically examine how we situate ourselves in relation to the natural world and our impact on it. Their curiosity about nature is specific to how we make meaning in relationship to place.

In Hunter, Gatherer, Purveyor, 't the artists make popsicles from collected grasses, flowers, and bark in a neighbourhood, and then share those popsicles freely with the neighbourhood residents. Using humour, generosity, and elements of performance, the artists deconstruct the idea of place and present it back to the people who live there, sparking childhood nostalgia and fun. 
For over a decade, Mia and Eric have worked in public contexts, but not necessarily within the traditional confines of institutional galleries or public art commissioning. They set their own lines of inquiry without a predetermined outcome. More recently they have started to work durationally for extended periods of time in one location in order to further understand the historical and social constructs we use when we imprint human values onto nature. They create contextual responses, critically reflexive and self-aware of their role, agency, and biases toward each given site and context. Their practice is process and research based and forefronts their desire to learn about the environments and people with whom they work.

No process, no project, is ever the same way twice; they are not building an oeuvre of projects but a body of knowledge that relies on an ongoing exchange of knowledge. Gone Today, Here Tomorrow at the Lougheed House was an opportunity to continue their commitment to understanding the interconnected relationships between humans and their constructed ideas of the natural world, particularly in the context of colonialism and settler history in the West.

\section{Can you describe the work Gone Today, Here Tomorrow, and your time spent on the three-month urban ecology residency at the Lougheed House?}

We were invited by curator Caroline Loewen to imagine a three-month residency at the Lougheed House in Calgary's Beltline neighbourhood based on work we had been doing as part of an urban ecology residency through the City of Calgary's Public Art Program. At the time, we were mapping opportunities for animal habitat within the community of Sunnyside. We were interested in how human built environments and animal activity overlapped. Loewen wondered if this work could be expanded in the Beltline area to include a historical lens, in relation to Canada's sesquicentennial. (The residency was funded through a Canada 150 grant.)

It is important to note that the Lougheed House wasn't built until 1891, twenty-four years after Confederation, and Alberta wasn't a province until 1905. This meant that if we were 
to look at the ecology of the Beltline area over the course of 150 years, we would have to start before the building of the House, before the signing of Treaty 7 , and before the yet-to-be-named city of Calgary was established. Our minds went immediately to the plains bison-their being on the land and then their quick and violent near-extinction, followed by settlement and the growth of Calgary. We did a ton of research around the bison (and a companion species, the black-billed magpie) but kept getting distracted by a phrase used to describe the land around the House before it was built. Both historical documents and contemporary marketing materials use the phrase "built on the bald prairie" to paint a picture of the landscape before construction. Yes, by the time the House was built, bison, coyote, elk, and game bird populations had been decimated, but the land was anything but lifeless.

The phrase "bald prairie" creates an imaginary space for a "western" mythology, easier to perpetuate when there is a nothingness upon which greatness can be built.

It was a vibrant ecosystem (it could still be!), but this kind of settler sentiment was, and still is, used to justify development and resource extraction. We dreamed of bringing bison back to the Beltline and of the effect that would have on the biodiversity of the place, but it wasn't a project that we could complete during our residency. So we shifted our focus to a type of biodiversification that we could accomplish, returning native prairie plants to the site. We did extensive research to learn about the plants that were displaced by the House and its Victorian flower beds. Gone Today, Here Tomorrow is the result of this research.

\section{Did you have expectations about what you'd learn?}

We had very little expectation about what we might learn as we set out researching the native plant species that would have existed on the plot of land that is the Lougheed House. That said, the one thing we did imagine is that it would be a very simple exercise: find one book, make a list, and we would be done. It was the exact opposite! Of course there are resources that document native plant species, but they were very difficult to 
locate. We had to dig into the archives at the Lougheed House and spend a significant amount of time in the Local History section of the public library. We also visited grassland ecosystems that are still intact just outside of Calgary.

What was so important about this process is that we also started to unpack the practice of settlement-a feat of engineering that radically transformed the land in less than thirty years. Hundreds of thousands of acres of land were dug up, turned into sod houses, and replaced by cereal crops. When governments had an opportunity to reverse the damage done by settlement after the Depression, instead of revegetating with native plant species that for millennia had held the soil in place, attracted important insects and animals, and sustained life on the land, the Canadian government-through their experimental farms program-recommended planting crested wheat grass to combat erosion and for cattle grazing. This grass species from Asia (Russia and Siberia) is largely what we see in spaces that look natural now. These spaces are not "the prairies," they are fabrications-spaces largely populated by introduced plant species. It is a landscape that, without the return of the bison or traditional Indigenous practices, will never fully recover.

We sourced different grass species and flowers from a greenhouse south of Okotoks. The idea was to install them on the ten different fireplace mantels throughout the house. As visitors to the house walked around, they would be confronted by these plant species that appeared radically out of place but were far more in the right place than the House itself. We invited our long-time friend and collaborator Bryce Krynski to work with us to create portraits of each of the fireplaces-a type of documentation, but also a separate work of art.

\section{Why did you choose the fireplace, a mode of display associated with domestication?}

The fireplaces offered us a practical and aesthetic opportunity-not unlike their original use. The fireplaces were originally designed to be prominent architectural features in each room, while also being sources of heat. We essentially borrowed from their original function, knowing that guests in the house today were strongly attracted to themmeaning that the plants would intervene in the narrative experience of the house. 


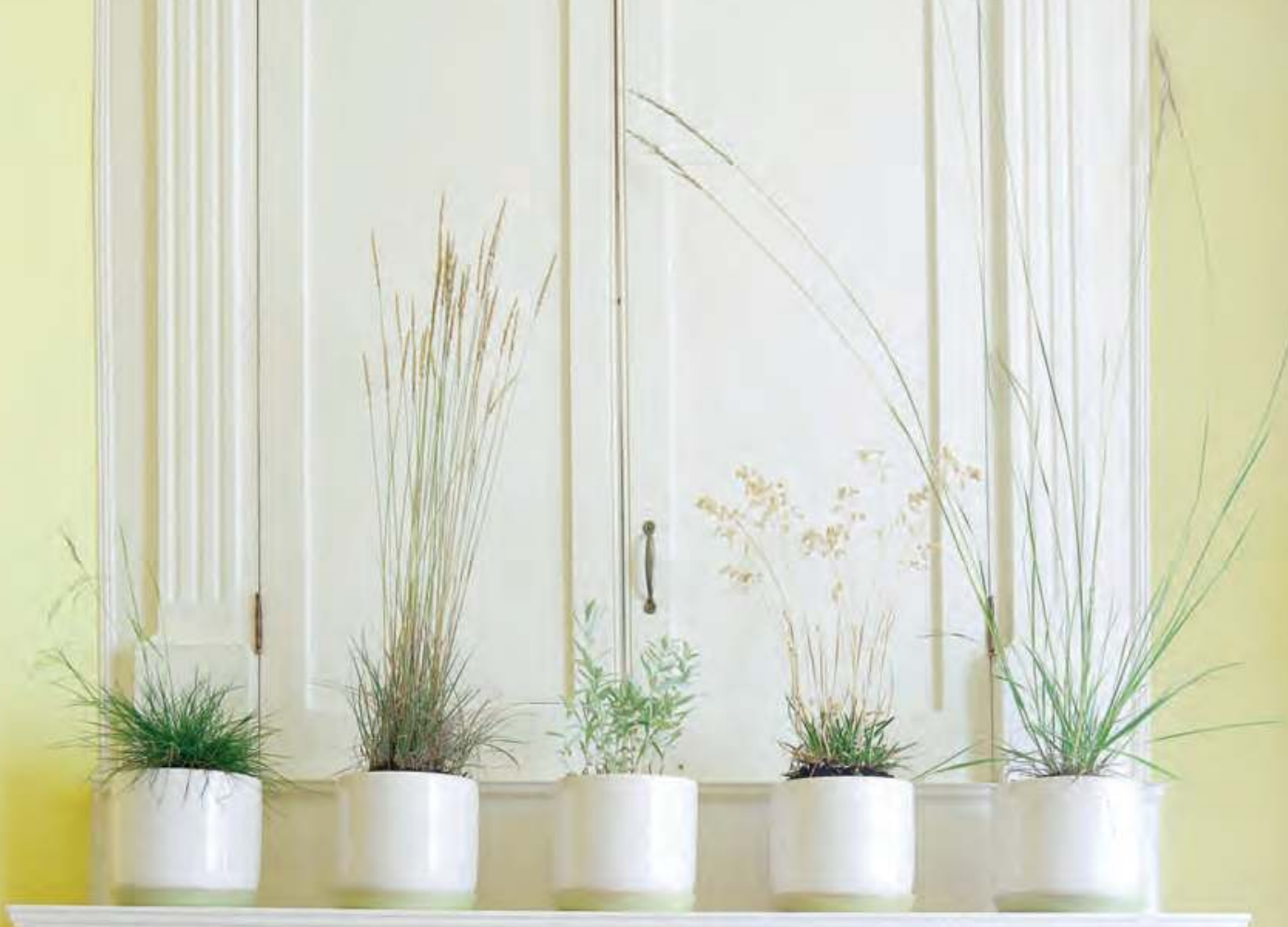




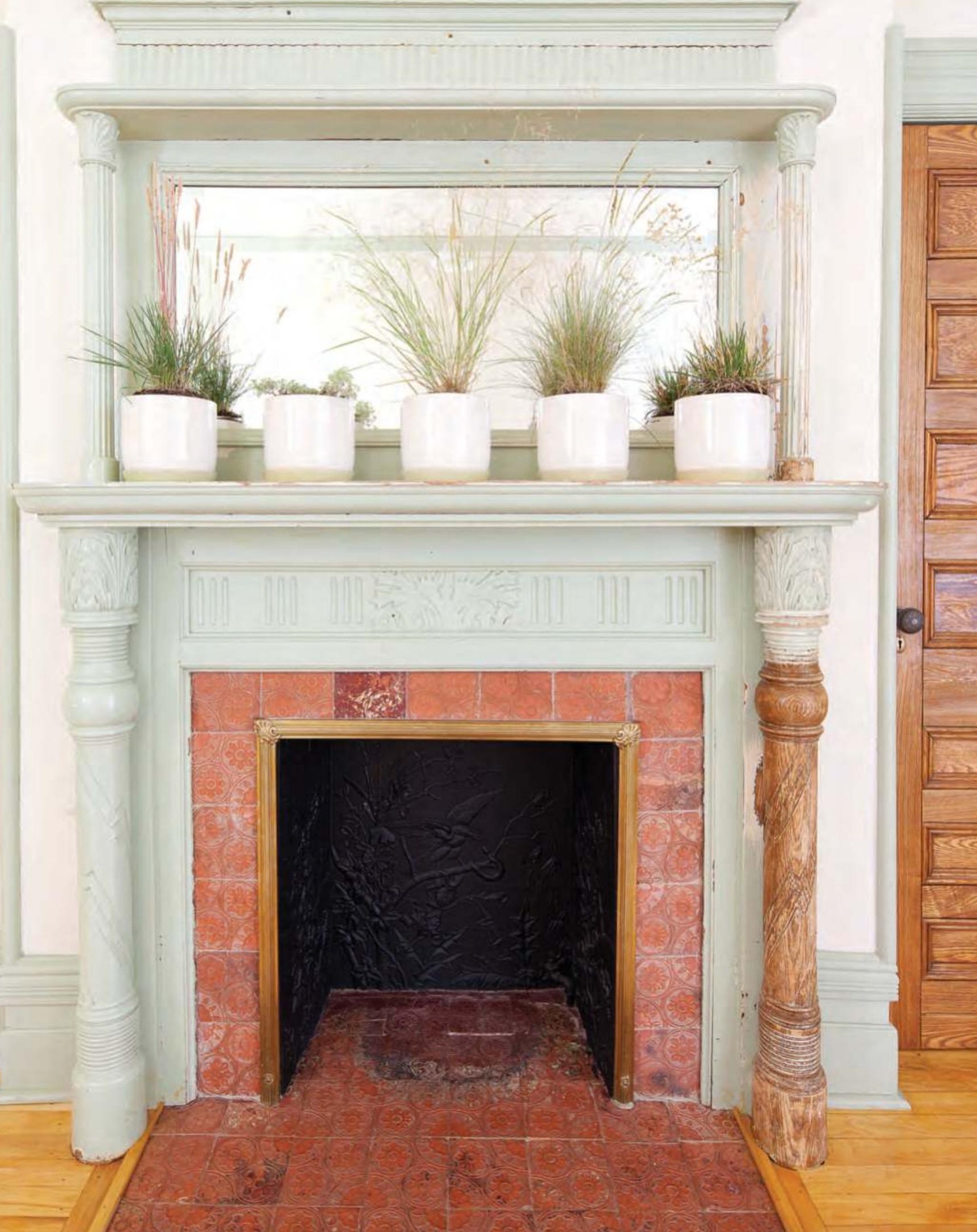


It wasn't until the plants were installed that we realized we wanted to create a second, more permanent piece with them. The legacy of the residency, if we can call it that, is that we established a native prairie garden on the grounds, and we have become garden volunteers. We worked with the Lougheed House staff, the Head Gardener, and the City of Calgary Parks department to extend an existing garden on a section of the property that was originally called the pasture (a small section of largely undisturbed native prairie that was left for grazing horses and other livestock). Our garden is in two parts-each extending an existing garden bed. When viewed from left to right (or right to left), viewers see native species, a formal Victorian garden with imported species, and then native species again. There is a visual narrative of what was, what is, and what is possible.

\section{This work is very much in keeping with your practice and projects of late, but why plants? Why at the Lougheed House?}

Caroline has always been very good to work with. We really love her enthusiasm for exploring historical themes through contemporary contexts. But the invitation to work at the Lougheed House aligned with our own priority to do more work outside of traditional art institutions. Working at the Lougheed House provided us access to different resources and different people-particularly the garden volunteers, who in the late stages of our project became instrumental to the success of the work.

This isn't the first time we have worked with plants, as you suggest. We have been very interested in the social, cultural, and political importance of plants for a long time. It is probably fair to say that our interest in ecology comes from Mia's long interest in the natural world-always a collector of leaves, sticks, rocks, acorns, and small flowers while out on walks and drawing or making other representations of these things in a previous practice. But investigating plants became a formal part of our practice in 2012 when we began developing our project Hunter, Gatherer, Purveyor for the Alberta Biennial. This projectwhich looked at the distribution of edible plant life in relation to geography and socioeconomics in a city-has since toured to a number of different Canadian cities. Truthfully, 
Hunter, Gatherer, Purveyor aesthetically feels like a bit of an outlier for us, but it certainly built a foundation for this work. We spent hundreds of hours walking through cities identifying plants and learning about the ways plants are representative of social relationships.

The Lougheed House itself symbolizes colonial history and difficult, complex pasts. Is there a way plants open up different understandings of this history?

We have spent a long time looking at plants and land use-but largely through a contemporary lens and largely as foragers. It wasn't until more recently that we started to realize and research the devastation that settlement had on the ecology of this place-southern Alberta in particular. You know, we have come to understand that talking about plants and working with plants cannot be done without also thinking about settlement. Most, if not all, of the plants we interact with on a daily basis are not from this place. The plants we eat are products that were introduced a hundred years ago or just shipped from elsewhere on the globe. The plants we see in the cityKentucky bluegrass, house plants, trees, flowers-are not from here or have been radically displaced. They have simply been naturalized. Plants are complicated and fascinating, and they cannot be discussed without acknowledging the settler ecologies that have been imposed on the land. It completely negates the different First Peoples (the Blackfoot, Stoney/Nakota, Tsuut'ina) use of the land during the ten thousandplus years that preceded the arrival of European and non-European settlers. The introduction of plants from elsewhere has forever changed the ecology, diets, sciences, and knowledges of this place. For us, reintroducing native grasses and flowers onto the land at the Lougheed House is about re-establishing biodiversity on a small plot of land in downtown Calgary.

Thinking about the idea of "legacy" with the native plant garden, it's important that it live on as an acknowledgement of the difficult histories around a place like the Lougheed House. Also, it lives on through the relationships you built with staff and volunteers, as an ongoing process that will constantly renew as you continue your work at the House. 


\section{How does a project like this offer us a way forward-is biodiversity the first step?}

We have been working very hard over the past few years to find a way forward, for our practice and toward reconciliation. In short, we were not happy with our previous body of work, and we were frustrated that our practice was more than likely contributing to a social spatial model of engagement that was privileging the status quo. We felt like we were part of the problem and we were not creating solutions. We are still very much in the early stages of a long process, but we know that investigating settler spaces and ecology is setting us up to have more consequential conversations about what it means to be stewards of the land, to be Treaty 7 people, and to have meaningful relationships with Indigenous peoples. A garden at the Lougheed House is representative of a group of settler people recognizing that great damage was done to the land and to relationships with Indigenous people. Yes, a first small first step was taken. We are now excited about the hard work ahead.

\section{notes}

1. See http://www.ericandmia.ca/hunter-gatherer-purveyor.

\section{bibliography}




\section{the city of calgary's urban forest}

\section{past, present \& future}

\section{nikki anguish}

William Pearce, a civil engineer and trusted bureaucrat, was an influential Canadian known as "the Czar of the Prairies." In 1918, William Pearce wanted Calgary to be a "City of Trees" and declared his vision in a letter sent to the mayor and council of the City of Calgary. In 1988, nearly seventy years later, the City of Calgary created "The Urban Forest Management Policy and Implementation Strategies"-the document that directed Calgary Parks to formalize an Urban Forestry program.

In 2007, council approved the "Urban Forest Strategic Plan." As our guiding document, the strategic plan outlines fifteen principles that fall under three main areas: (1) Achieve and maintain healthy trees; (2) Collaborate with the community; and (3) Resource to manage and measure the asset. The City of Calgary recognizes and values the benefits of trees within the cityscape: this is reflected in establishing a long-range target of 16 per cent within the over-arching City of Calgary Municipal Development Plan (MDP). Presently the City of Calgary has an urban canopy of 8.25 per cent that comprises approximately 7,000,000 trees located on both private lands and public lands; Urban Forestry stewards nearly 630,000 of those public assets located in destination parks, green spaces, and boulevards. 


\section{achieve and maintain healthy trees}

The key to tree survival and longevity is to provide a solid fountain by ensuring good growing conditions and adequate moisture for the first three to five years. This is a crucial element for increasing viability in Calgary's arid climate, which has also seen an increase in severe weather events in the past five years. We provide supplemental water

\section{Species Diversity}

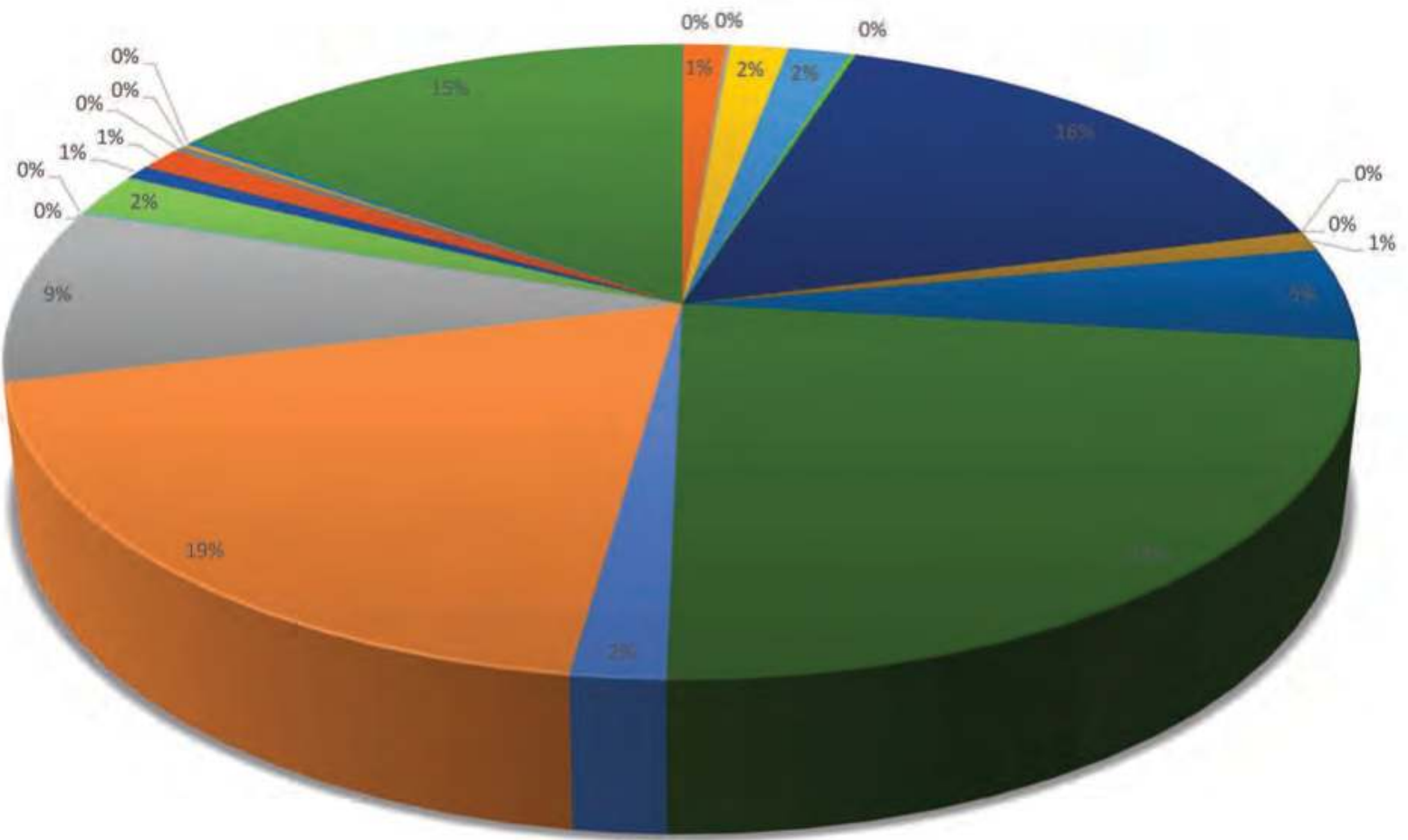

aBIES 
for the first five years. Maintaining a tree's structural integrity starts with pruning. We prune trees for clearance over sidewalks as well as over the roads, for public safety, and for tree health. Our pruning activities are both planned and reactive, inspecting upward of 50,000 trees annually and pruning over 12,000 .

We must also strive to protect our mature trees from development. Larger trees contribute to our canopy more so than smaller/younger trees, have more biomass, and provide a net-positive gain in carbon sequestration; hence, protecting the trees we currently have is paramount in achieving our canopy goals. In a growing city, there is a delicate balance between the need for new and mature trees. As communities age, they experience different challenges with their respective trees: New communities have a young canopy with trees relatively close in age; the challenge here is to diversify the age and establish the young. Older, inner-city communities have beautiful tree-lined streets. Often it is within these communities that we see in-fill developments. These redevelopment activities impact the mature canopy and hence challenge us to protect our mature trees while also supporting redevelopment.

Our canopy today consists of a diverse variety of species, as indicated on page 89.

Planting a varied population helps to build resiliency within the urban forest by ensuring genetic diversity, which allows the population to better adapt to environmental and biological changes. Our partnerships with not-for-profit organizations such as the Calgary Zoological Society allow us to further diversify by growing specimen trees and tender species in a fully controlled environment.

\section{collaborate with the community}

One of our biggest opportunities to grow the urban canopy lies in engaging the communities and providing education programs on trees. Nearly 75 per cent of the urban canopy is located on private property, making public engagement on private lands essential to our continued success. Partnering with various groups, we provide educational opportunities and volunteer planting experiences throughout the city.

Calgary Parks Urban Forestry has created several online learning modules to provide citizens with free, self-directed courses on basic tree care. A desire to build a culture of trees in Calgary has gained momentum, as community orchards are becoming increas- 
ingly popular. In response, Urban Forestry has collaborated with community associations to support creating and maintaining productive fruit tree orchards within their communities. The Hillhurst/Sunnyside community orchard was one of the first orchards in the city; it contains a variety of mature apple, hazelnut, gooseberry, apricot, and pear trees, helping to encourage local food production and foster community involvement.

\section{resource to manage and measure the asset}

Although most sustainable urban forestry models are directed toward commercial forests, the basic concepts apply and are relevant to our urban forest. By adopting and complying with international ISO 14001 standards, Calgary shows our commitment to a sustainable urban forest.

Alberta's Occupational Health and Safety Code identifies two activities (Forestry and Tree Care Operations) as having specific requirements to perform the work safely. By hiring trained staff and facilitating their continued education, Urban Forestry demonstrates our commitment to industry professionalism and safety, further enabling us to adopt industry standards and best practices. Regular benchmarking and self-assessment helps us to focus our efforts and effectively manage our urban forest.

Urban Forestry is recognized (by council and administration) as a service line under the "One Calgary" initiative. Being one of the most vital natural resources, trees positively contribute to all aspects of life-social, environmental, and economic. Early Calgary was once a nearly treeless landscape not naturally supportive to trees, making the challenge of maintaining a healthy, sustainable, resilient canopy a difficult one-one that we as Calgarians consistently rise to. Now, with over $\$ 1.3$ billion in assets, Urban Forestry highlights the efforts put forth by both past and present Calgarians to make our home a "City of Trees." 


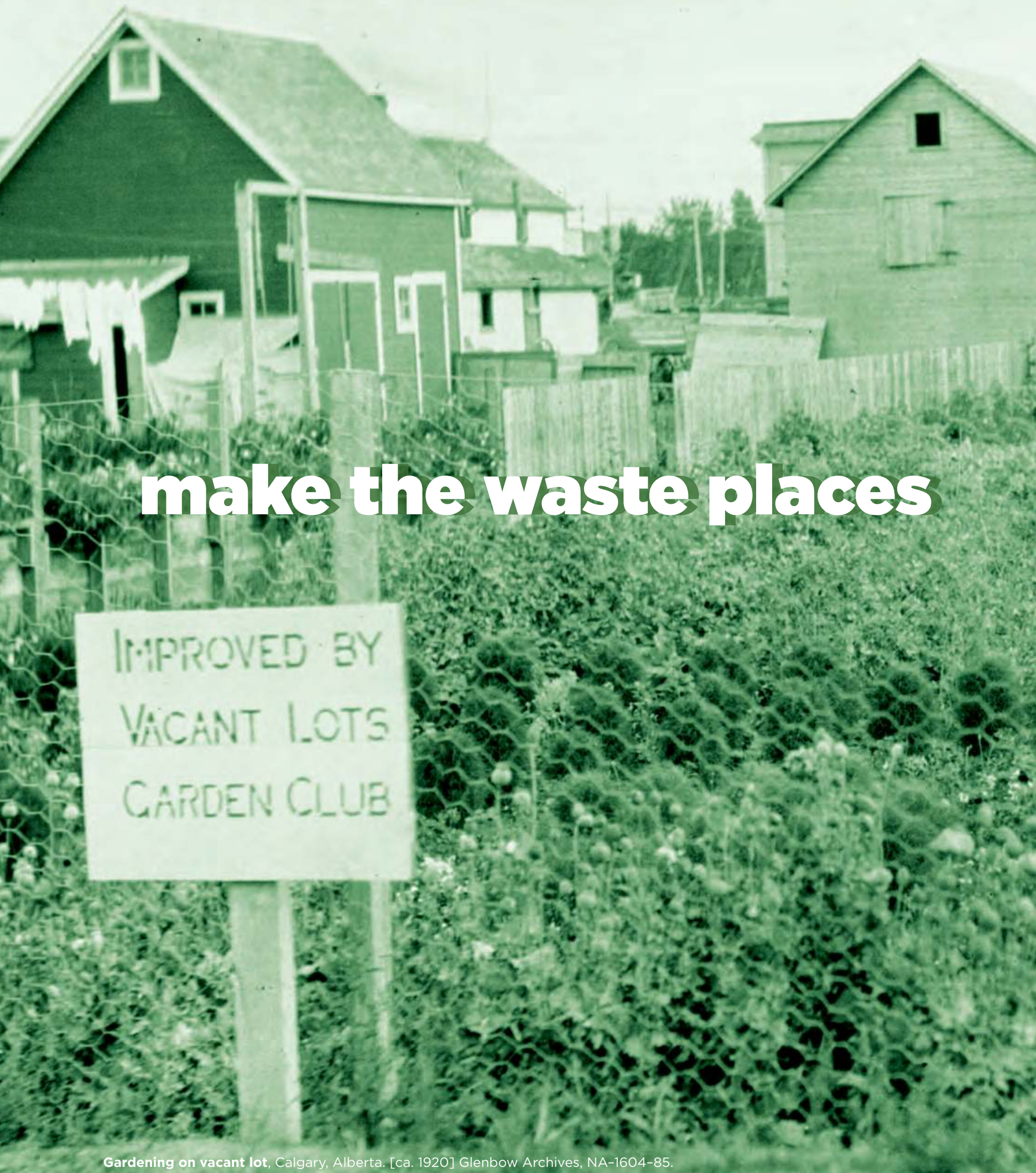




\section{fruitful gardens the calgary vacant lots garden club} jim ellis

Long before the guerilla gardening movements of New York and Los Angeles, and before the resurgence in popularity of community gardens across North America, there were social assistance programs involving the cultivation of urban vacant lots. The first organized civic programs were in Detroit, New York, and Philadelphia in the 1890s, designed to help the unemployed in the midst of an economic recession. 'These efforts were largely envisioned as social reform and self-help for the urban poor; Bolton Hall, a prominent progressive activist and advocate of the back to the land movement, wrote, "Placing the half sick, the disabled, worn-out people and the unemployed on vacant lots, where they can employ themselves raising their own food, is now no experiment, but an important support of many families which would otherwise be dependent upon charity."2 
In the eyes of social reformers, the vacant lot movement did more than simply feed the poor: the Third Annual Report of the Philadelphia Vacant Lots Cultivation Association drew attention to "the effect it has had upon many of the gardeners from a social and moral standpoint." ${ }^{3}$ Inspirational tales of reformed alcoholics, industrious widows and children, and renewed family ties were frequently offered. Although the movement was widespread in the 1890s in the United States, few civic programs appear to have lasted into the next century. In Canada, the movement seems to have had more life: an article in the April 1918 issue of Canada's Agricultural Gazette surveyed the plans for twenty cities and towns across Canada to use vacant lots for urban agriculture, although this popularity may also have had to do with planting victory gardens. ${ }^{4}$

In Calgary, the impulse to form an urban gardening organization responded to some of the same practical and philosophical concerns that informed the American movement: practically speaking, fruits and vegetables were expensive, and most were imported from British Columbia. Philosophically, the vacant lot club combined the interests of social welfare with the Garden City movements of the late nineteenth and early twentieth centuries. In 1912, the charismatic British city planner Thomas Mawson visited a number of Canadian cities, and gave an inspirational speech to the Canadian Club of Calgary titled "The City on the Plain, and How to Make it Beautiful." Mawson was particularly interested in public parks, access to green space, and garden suburbs with allotment gardens, based on the long-standing British experience with allotments. Although his larger plan for a redesigned civic core was not taken up, his advocacy for urban gardening was enthusiastically embraced.

The Calgary Vacant Lots Garden Club was formed in 1914 out of a meeting of the Parks and Playgrounds Committee of the City Planning Commission; representatives were invited from the Horticultural Society and the Consumers' League, a social welfare group formed from the Local Council of Women. Examples of programs from other cities were surveyed and discussed. The resulting executive of the newly formed club included Alexander Calhoun, the city's first librarian; William R. Reader, the city's Parks Superintendent and a member of the Horticultural Society; and Annie Gale, a member of the Consumers' League who would go on to become the city's first female alderman from 1918 to 1924. Officially, the purpose of the club was "to encourage home production, greater vegetable diet, and reduce the cost of living," and it had the beneficial side effect of "transforming Calgary into a city of smiling gardens," 5 thus realizing, in a somewhat less grand way, Mawson's vision of a garden city. 


\section{MAKE THE LAND PRODUCE}

\section{Calgary Vacant Lots \\ GARDEN \\ CLUB}

Organized March 2nd, 1914

Rules and Regulations

1920

(1)ftirers fur 14리

Honorary President

HIS WORSHIP MAYOR R. C. MARSHALL, Esq.

President

JOHN BARNECUT

Past President

JAMES A. WALLACE

First Vice-President

A. J. COWLING

Second Vice-President

$S A M U E L$ J. FEE

Secretary

LOUIS U. FOWLER

Treasurer

GEORGE W. MYERS

Journal Secretary

EBER C. BELI

Auditor

A. H. CARR, C.A. 
The Headquarters of the Ciub are in the Basement of the City Hall, Second St. Fast.

The Stecretary, or others in charge, are always ready to supply information and accept applications for membershrip.

The Club has a large number of lots in different parts of the city to select from, the owners consent having been secured.

\section{MEMBÉRSHIP FEES}

The membership fee is $\$ 1.00$ per annum, which entitles the member to use one lot $(25 \times 120)$; land equal to three thousand square feet constitutes a lot. If a second lot is given, 50 cents additional is charged.

No member is allowed more than two lots until after April 15th, and, if lots are available, a reduction is made for ten or more lots.

\section{PLOWING}

Members are urged to spade, or dig their land, if at all possible. If the plowing is done by the Club the cost is from $\$ 1.25$ to $\$ 1.75$ per lot. The Club undertakes to plow where there are six or more lots together.

\section{REGULATIONS}

Members are expected to cultivate the land throughout the season, the oftener the better. The practice of "Dry farming principles are urged." This means constant cultivation, as dry seasons are bound to occur.

Weeds must be kept out; if allowed to grow, the Club reserves the right to take the lot back, after giving seven days' notice. This condition is on the membership card-Read it.

Members wishing to use City water should make application to the Waterworks Department for special permit.

It is contrary to a City by-law to allow piles of manure to stand on any lot.

No provision for fencing can be made by the Club. Members may erect temporary fencing if they wish. Barbed wire should not be used, as it is contrary to the 
City by-law. Wire used on baled hay can be secured free, and makes a good fence.

Signboards may be placed on the lot-the Club has a number that are free for the members.

In the event of an owner requiring the land for building purposes, the member is expected to give up possession on request. The Club will return the money paid.

Every member is urged to grow a flower border next to the sidewalk; at least two feet should be reserved for this purpose. Flowers will not only improve the appearance of the City, but will create a sentiment in favor of the protection of the lots.

Members cultivating the same lot year after year should realize that it is their duty to keep up the land to its original fertility by proper fertilization.

One of our big ambitions is to raise the standard of potato cultivation. Good seed, constant eultivation, proper harvesting and grading methods are necessary to make the Alberta potato the equal of any imported. We hope to have good seed potatoes and other seeds to sell to our members at cost. It does not pay to use poor seed.

\section{PRIZES FOR 1920}

The Club will offer prizes for the best Gardens cultivated by the members on vacant lots secured from the Club, the owners, or agents (provided no rent or other remuneration is paid the owner or agent). The City will be divided into districts, the boundaries being the Sections. Prizes will be offered in the different Sections, and for the best lots in the whole City.

\section{JUDGING}

Judging will be done at different times during the summer and autumn, by the most competent persons that can be secured. The following scale of points will be used:

Freedom from weeds, 30 ; cultivation, 20; genera! appearance, 10; arrangement and condition of crop, 10; varieties, 10; flowers and plants, 10; economy of space, 5: freedom from disease and insects, 5. Total, 100. 


\section{MEMBERSHIP}

The membership shall consist of:

All persons elected as honorary members by the Executive Committee, as provided in the Constitution and Laws.

Knd all persons who have paid one dollar or more, and received a membership card, or receipt.

\section{EXECUTIVE COMMITTEE}

The Executive shall consist of one Representative for every hundred, or major fraction of one hundred, of the members who have paid a membership fee of one dollar or more for the year, before the first day of the month in which the annual meeting is held.

The Representatives shall be elected at the annual peeting by open nomination, and election by ballot.

Two Representatives from the City of Calgary, one to represent the City Council, and one the Parks Department, the City Council to elect or appoint the two.

One Representative from every Society, Organization or Association in Calgary, whose objects are the improvement of the City by the cultivation of land (not less than ten lots of three thousand square feet), or the holding annually of a Fair. Show or Exhibition by or under the auspices of the Society, Organization or Association.

Every Society, Organization, Association, or Corporation that shall annually contribute to the funds of the Club fifty dollars or more shall be entitled to one Representative on the Executive Committee, if not otherwise represented.

The Executive Committee may, by two-thirds vote, add not more than three members to the Executive during any one year.

The retiring President shall be a member of the Executive.

\section{ANNUAL MEETING}

The Annual Meeting of the Club shall be held on the second Tuesday in November, provided, however, that the Executive may change the date to one during the same week.

\section{EXECUTIVE MEETING}

The Executive Committee shall meet on the third Tuesday of each and every month at 8 p.m.

Special meetings may be called by a resolution at a meeting of the Executive Committee, by the President and two other members of the Executive Committee, or three members of the Executive Committee. 
Vacant lot garden plots were first made available in 1914; the 1916 Municipal Manual reports that in its first year the club had 173 members who cultivated 243 lots. In 1915, this jumped to 450 members who farmed 976 lots. ${ }^{6}$ The numbers continued to climb; the Canadian Agriculture Gazette reported in 1918 that "in 1917 over 2,000 twenty-five foot city lots were cultivated and this year it is expected that number will be increased. A dollar is charged for one 25 -foot city lot and 50 cents for each additional lot. On request the ploughing is done at cost. Lots are ploughed free for the families of soldiers. Lectures are given with a view to stimulating the interests of both children and adults."7 By 1920, when membership in the organization hit an early peak at 1,340, the city had been divided up into twenty sections, and prizes were awarded to gardens based on freedom from weeds, cultivation, general appearance, flowers and plants, arrangement, variety, economy of space, and freedom from disease.

The vacant lot gardens took on different social roles and social meanings across the decades. As with the earlier American programs, the gardens were originally a social welfare scheme that provided good food and moral uplift to the poor. Additionally, the gardens were promoted as beautification efforts and a source of civic pride; a contest in 1915 aimed to dispel the notion that good potatoes could not be grown in Calgary. During the first and second world wars, the club took on a patriotic cast and the lots became known as victory gardens; in 1943, the club peaked at 2,366 members cultivating 3,229 lots. During the Depression, they were an increasingly necessary source of cheap food. After the end of the food shortages of the Second World War, gardening was once again seen as a leisure activity, and the numbers of available plots dwindled in response to increased construction; for those lots still vacant, the soil was largely exhausted from potato crops. The club was disbanded in 1952.

Community gardening is once again flourishing in Calgary. One organization in particular, Grow Calgary, is in many ways the direct heir to the vacant lots cultivation movement. Founded in 2013, their garden is located on eleven acres in Calgary's Transportation Utility Corridor, provincially owned land designated for road construction. It is Canada's largest urban farm, employing volunteer labour to supply women's and homeless shelters with organic produce. Like the vacant lots gardens, however, its tenure is precarious: the construction of a new ring road is now threatening its existence, at least on its current site. ${ }^{8}$ 


\section{0 intertwined histories plants in their social contexts}

\section{notes}

1. Lawson, City Bountiful, 24-26.

2. Hall, A Little Land and a Living, 95-96.

3. Vacant Lot Farming, 8.

4. "Vacant Lot Cultivation," http://www.cityfarmer.org/VacantLot.html.

5. "Calgary Vacant Lots Garden Club," 1915

6. Ibid., 1916.

7. "Vacant Lot Cultivation," http://www.cityfarmer.org/VacantLot.html.

8. Giovannetti, "Province Set to Evict Urban Community Farm," A18.

\section{bibliography}

"Calgary Vacant Lots Garden Club." Municipal Manual. City of Calgary, 1915, 1916.

Giovannetti, Justin. "Province Set to Evict Urban Community Farm." Globe \& Mail, February 2, 2019, A18.

Hall, Bolton. A Little Land and a Living. New York: Arcadia Press, 1908.

Lawson, Laura J. City Bountiful: A Century of Community Gardening in America. Berkeley: University of California Press, 2005.

"Vacant Lot Cultivation: Expectations and Plans of the Cities of Canada for the Present Year." Agricultural Gazette (Canada) 5, no. 4 (1918). http://www.cityfarmer.org/VacantLot.html.

Vacant Lot Farming, Third Annual Report of the Philadelphia Vacant Lots Cultivation Association, 1899 


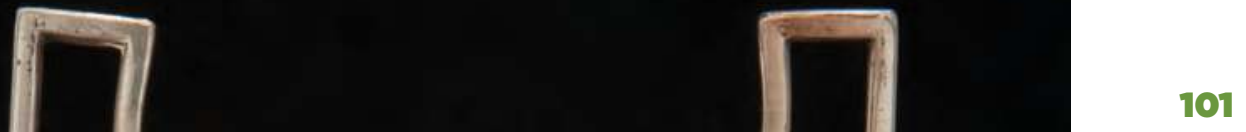




\section{coming into noticing \\ on being called to account by ancient trees}

\section{andrew s. mathews}

\section{walking, noticing, and wondering}

Over the last few years I have been learning to tell stories about trees and landscapes in central Italy. These are landscapes that have been cultivated by humans for several thousand years. As in so many parts of the world, traces of former human use are omnipresent, if you pay attention. Ancient cultivated trees, old terraces, abandoned houses, drainage channels: traces of human presence are everywhere. One of my most important research methods is to walk slowly across a watershed, looking closely at details of tree and land form. Noticing gives rise to wondering, as I imagine the histories of encounters with forest fires, peasant ${ }^{1}$ firewood cutters, or diseases that gave each tree its particular form. I wonder why each terrace was built; I look out across the landscape and try imagine the processes that shaped it. I take notes and photographs, and sketch particularly interesting trees. This kind of speculative noticing is a way of looking not only for the effects of humans upon trees and landscapes but for the effects of nonhumans upon each other. The biographies of trees are recorded in their forms, as they respond to encounters with fire, disease, drought, and humans. Tree branches grow toward light; roots grow in response to soil, moisture, and human care. ${ }^{2}$

Walking, noticing, and speculating is a way of being pulled into telling stories about the pasts and futures of landscapes, of learning to be alert to surprises. This kind of speculative noticing is how many natural scientists come up with the questions that drive their research. Peasants and Indigenous people have always done this too. The farmers I talk to in Italy, and the Zapotec Indigenous people I worked with in Mexico, have always noticed and wondered. ${ }^{3}$ 
In this essay I will describe how I go about learning to notice, with the hope that this might remind you of how you already engage in such speculative noticing in your travels through the world. These practices of noting the relationships between long-lived plants and slowmoving soils seem to me to offer a suggestion about how we might advocate more hopeful environmental futures. Secondly, I am going to argue that speculative noticing can literally rewire your senses. Noticing can transform your experience of the world, as you learn to notice traces of plant disease, human care for plants, or emerging new relationships between plants and other beings. Once your senses are rewired in this way, you will come up with stories about the strange histories of plants, soils, and stones. These stories are accountable to your experiences of coming into noticing. Such stories are passionate and engaged, but also humble, a bit uncertain. These stories can move us to act to care for our local environment, from gardening to engaging in environmental politics.

\section{coming into noticing}

Let me tell you about how I came to tell stories that emerged from my noticing of tree stumps in the forest. First, consider this rather anonymous tree stump. It is large certainly, but what is there about it that might compel storytelling?

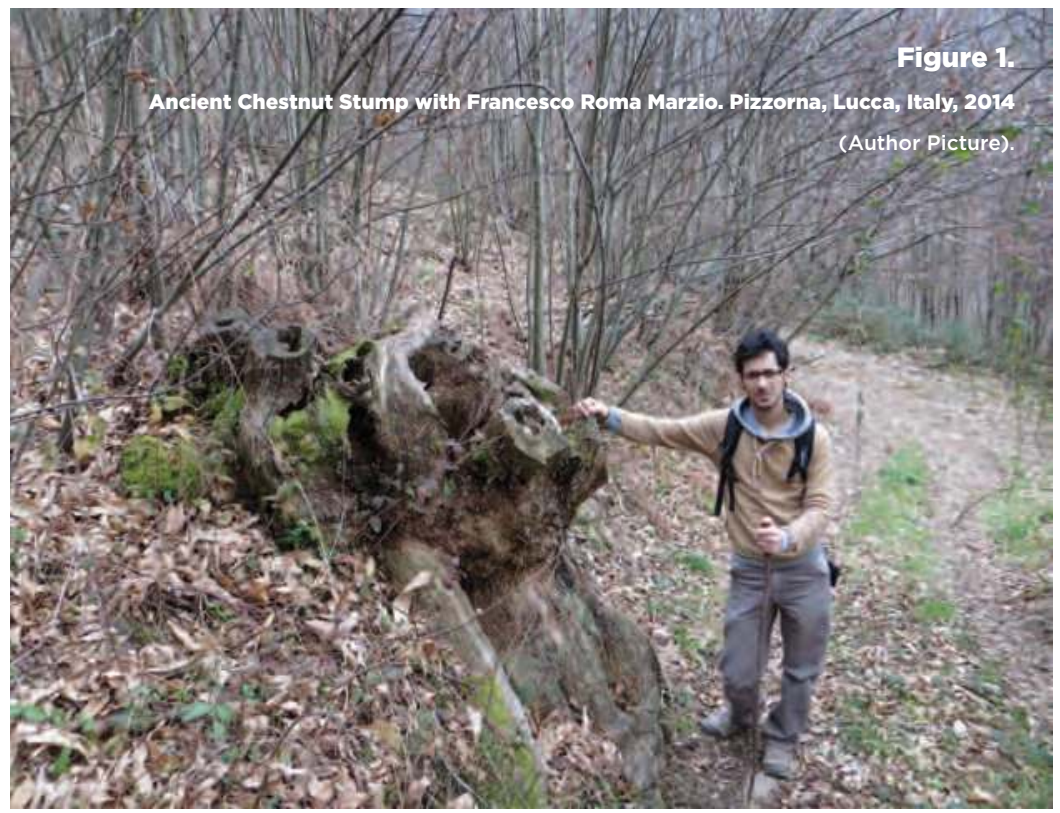

This ancient tree stump is the remnant of an entire civilization, a way of making a living that formerly covered these hillsides. It is an ancient chestnut tree that was converted from food production to firewood. Chestnut trees were formerly a principal source of carbohydrate food to millions of people across the Apennine Mountains of Italy, ${ }^{4}$ as in other mountains across the Mediterranean. Successive pathogen epidemics, and the decline of peasant agriculture, have caused the abandonment of most 
chestnut cultivation. Nevertheless, the history of chestnut cultivation can tell us something about how humans are pulled into relations of care for long-lived plants.

The loops on the base of the image are the traces of several cycles of firewood cutting over the last sixty years. Each loop is the stump of a stem that was cut off at the base; it records the trace of an encounter between a tree and a firewood cutter. This practice of repeated cutting, known as ceduo (coppice), has been practised by European firewood cutters for several thousand years. From other walks and other encounters with tree stumps, and from conversations with firewood cutters and farmers, I knew that this unpromising stump had formerly had another shape entirely.

This is a well-maintained se/va/chestnut orchard, in the high Apennines about twenty-five kilometres north of Lucca, in central Italy. The trees are well spaced out to favour fruit production, and are perhaps two hundred years old. They are well cared for: none have suckers at the base, and all have well-pruned crowns. The low stone retaining walls, known as

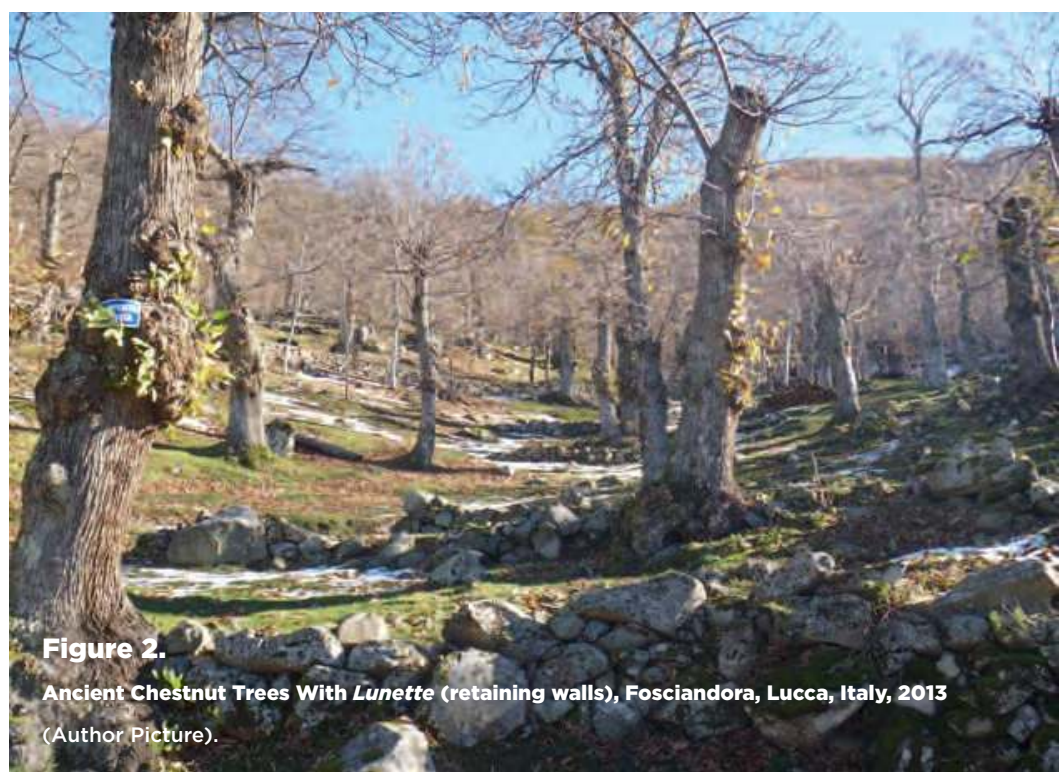
lunette, keep soil around the roots of the trees. These walls demonstrate peasant farmers' willingness to work hard to attend to the needs of chestnut trees that need moisture. Finally, the orchard is clear and relatively grassy. This requires the work of sheep or goats who graze, and of a farmer to rake up leaves and burrs. What cannot be easily seen in this picture is the presence of graft scars, which are the physical manifestation of the long-ago moment when a peasant farmer grafted a desired domestic variety onto a wild rootstock/portainnesto. These enormous trees are in some sense the long-range echo of a centuries-old event, when a peasant farmer nudged a graft onto a wild rootstock, feeling with skill and imagination for the precise alignment of cambium layers in two small shoots. Trees, fire, people, soils, grass and sheep, have affected each other. I hope I have persuaded you that trees are wild creatures, shape changers who can be stumps that might sprout, ancient trees, or many other shapes entirely. To notice plant

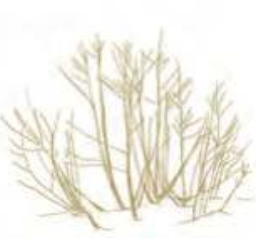

Shoots resprouting from a stool, 2-4 years since cutting. Ceppo/polloni 
form is to open yourself to notice the slow, sly, and strange shape-changing practices of trees. The figure below is what I call my chestnut bestiary, my menagerie of plant forms. All are chestnut trees, but each has a different name, a different history, and a different shape. Plants are able to respond to the world by drastic shape change. By attending to such shapes we can learn to imagine dramatic histories.

\section{Figure 3.}

\section{A Chestnut Bestiary}

(Author Drawings)

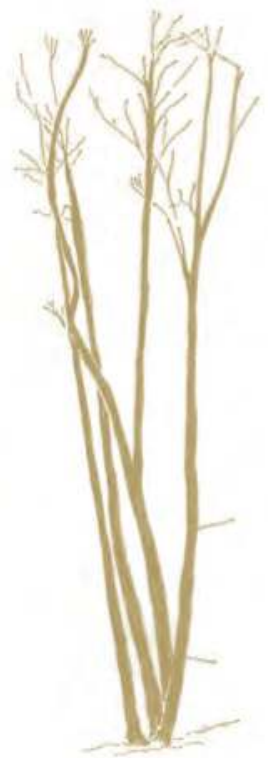

Twenty year old coppice, suitable for firewood/poles 5-8 stems per stool. Ceduo

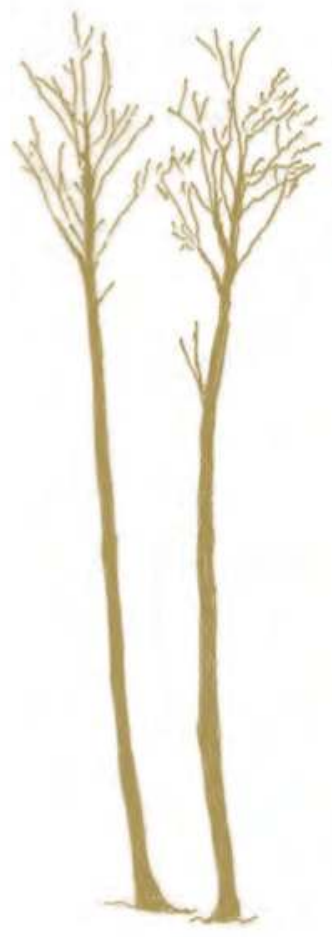

Thirty year old coppice stems have reduced to one per stool. Curve at base of each stem is sign that this was once coppice. Vernacchia

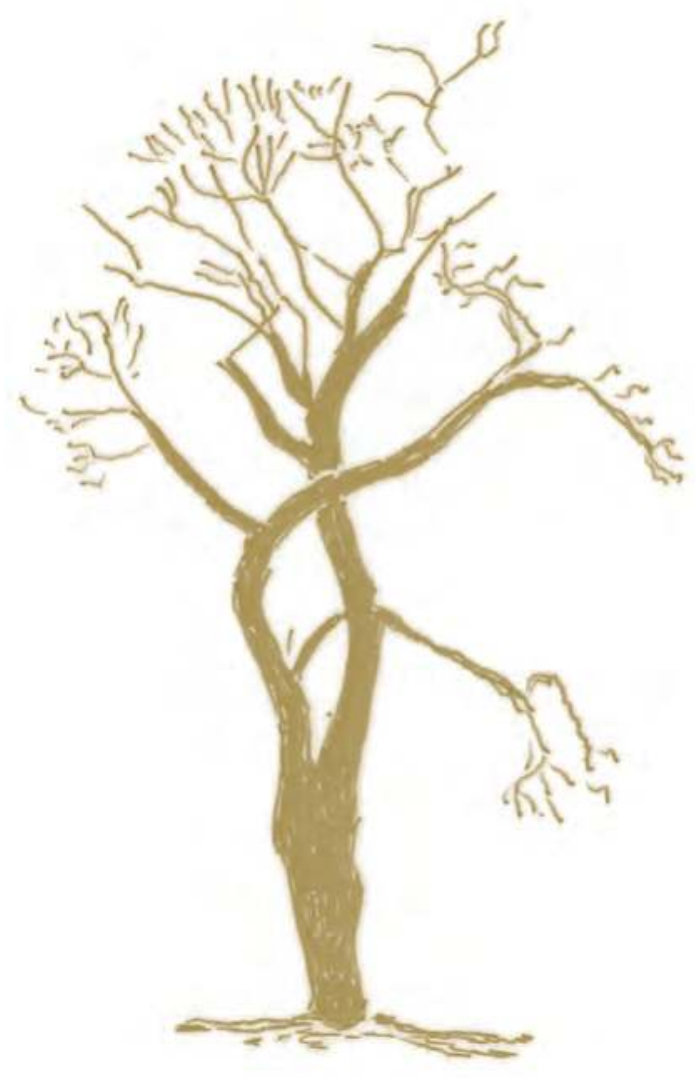

Grafted fruit chesnut, perhaps two hundred years old. The bulge at the top of the main stem is the graft scar.

Castagno, Castagneto. The fruit variety is not known but could be Rossolina or Pillossora 


\section{on rewiring your senses}

Walking across the landscape and paying attention to plant form is a good way to begin to imagine the histories of human care, fire, and disease that have affected plants. I complement this by talking to farmers, foresters, and anyone who is interested in plants. Another way of opening myself to signs of plant/human/soil relations is to consult the dead. I look at legal and tax documents in the Archivio di Stato of the City of Lucca, searching for glimpses of changing human/plant relations, for some sign of forest fires or plant diseases. Sometimes, an old document will alert me to surprising details of landscape change and rewire my senses.

As long ago as the second century BCE, trees were being pruned and trained to support vines and used to divide up the Italian landscape into cultivated terraces, closed fields (campo chiuso), or irrigated pastures. ${ }^{5}$ In this image from a cycle of annual labours on the facade of the cathedral of Lucca, a peasant is pruning a tree so as to allow it to sustain a grapevine: this was known as the vite maritata. This cultivation form was formerly widespread across Italy, including around Lucca.

Figure 5, opposite, from the archive, shows poplars sustaining grapevines near flood protection levees around Lucca in the 1820s. The slow rhythms of trees, of more rapidly growing grapevines, of rapidly moving water and slowly moving canal banks, were maintained by the skilled choreography of peasant farmers who kept this system going.

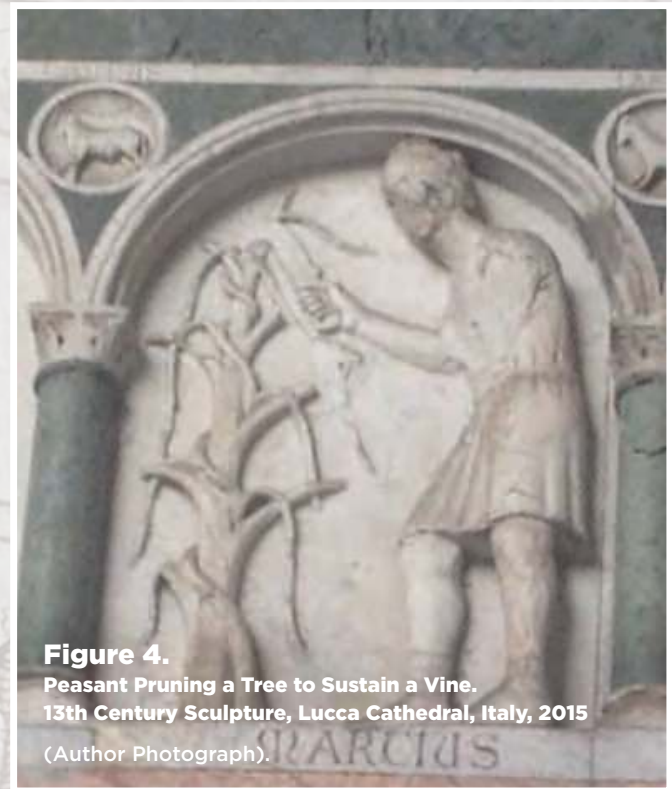

Encountering this beautiful and haunting image made me remember something I knew but had allowed myself to forget. When I was a teenager, there were still many ancient field maples with remnant branches sustaining grapevines in the fields. Most are gone now. Alerted by the archive, and by our shared memories, my collaborator Fabio Malfatti and I began to look out for remnants of this ancient cultivation system. On a chance, we returned to the location of that beautiful early nineteenth-century line drawing, to see if anything remained of that precarious choreography of human, soil, water, poplar, and vine. Because this was the intersection of two rivers, we were able to find the location precisely. What we found there was a kind of out of control jungle. The former choreography of tree and vine had fallen apart. The poplars were there, and the vines 


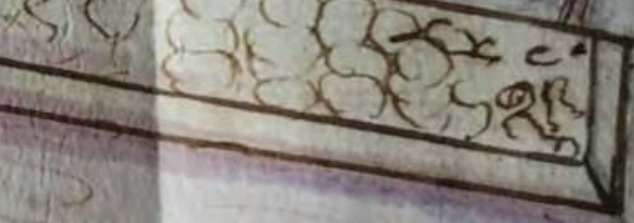

N. Whe Marchte. Grape vines trained across poplar branches alongside the river of Vorno, Lucca. Section from ink drawing on paper: Cormmissione de lelle Acque e Strade 1701-1800 (c.1820). Courtesy of Archivio di Stato di Lucca on authorization of the fe Ministero Per IBeni e le Attivita culturali.
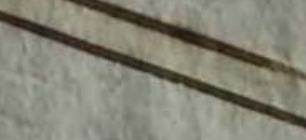
were there, but the peasants were gone, and the vines were growing wild across the trees in the searing summer heat. Here you see the sudden emergence, in flaming hot pink, of the pattern that I sensed on that hot day. It was a moment when my senses became attuned to the particular glossy green of grape leaves.

Just as the drawing from the archive woke my memory, the encounter with the wild vines woke my senses. Once your senses are attuned and awakened to a particular pattern, texture, colour, it is hard to switch them off again. In car parks, in empty meadows near supermarkets, Fabio and I could not stop seeing grapevines running wild across former peasant landscapes that had become abandoned suburban land. I tell this story to show you how your senses can be transformed by moving back and forth between archives, talking to experts, and re-entering landscapes and using your curiosity. In the end, you have to learn to notice what is in front of you, to see traces of centuries of peasant vine/tree care in a grungy parking lot. Perhaps you might learn to notice histories of human care and of plant disease in the landscapes that you move through in your day-to-day life. It is not only Italian landscapes that have deep histories of human/plant encounters.

Sometimes we anthropologists and social scientists are reluctant to trust our senses. We might think that our job is to focus only on the stories people tell us, rather than also trusting our own capacity to notice details about the world, and to tell stories that these details inspire. Certainly, I do plenty of listening to other peoples' stories. I learned to recognize ancient chestnut trees by talking to smallholders and biologists. Learning from others, however, does not absolve me from continuing to notice, to speculate, to wonder, to try to detect patterns across the landscape, and to tell stories about these patterns. This does not just apply to anthropologists. All of us can learn to trust our senses and our capacity to speculate about the forces that shaped a particular tree, a branch, a river bank, or a mountainside.

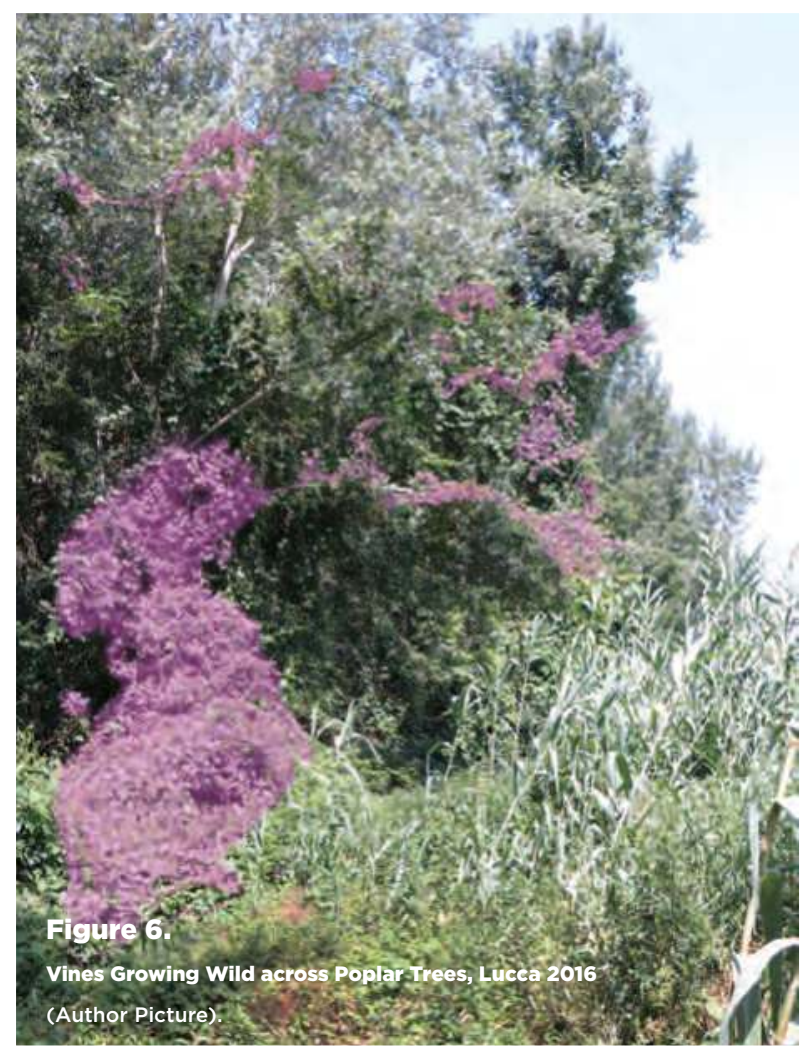

In telling you a little bit about the how histories shape the forms of trees in Italy, I hope I have inspired you to notice the shape-changing capacities of trees in your own daily lives.

If you look closely, traces of former human cultivation and care are everywhere around you, from the most apparently mundane street trees to the remnants of ancient cultiva- 
tion that stay on in the interstices of modern cities. At the University of California, Santa Cruz, where I teach, the campus is laden with histories of predatory capitalist logging in the late nineteenth century. Coastal live oaks at the edges of meadows are likely holdovers from the oak savannahs produced by controlled burning by Amah Mutsun Native American people. ${ }^{6}$ Perhaps similar histories of First Nations care are present in the forms of trees and pastures in and around Calgary.

\section{conclusion}

In this essay I have described how we might come to be partially attuned to the strangeness of long-lived beings that live at a different pace from us. To become attuned to the temporal rhythms of trees is to notice their gestures as they sense processes invisible to us. The form of branches and roots tells us of encounters with invisible nutrients and longago events. Think of trees as moving across the landscape, too slowly for us to notice. Dropping seeds, sending up new shoots. Gradually forests grow and change. People in Italy cared for individual trees for many centuries. I find it hopeful that humans do not always manage for the urgencies of the short term. Consider this ancient chestnut tree, high up in the Italian Apennine mountains, grafted perhaps six hundred years ago by peasant cultivators. In the mountains of the Mediterranean, the most ancient trees are grafted chestnut trees like this one. Without human care, this tree would not be here. The bulges, loops, and whirls that cover the trunk are the echo of the moment, half a millennium ago, when a peasant aligned the cambium layers of scion and rootstock into an unstable graft. Without repeated pruning of new shoots from the rootstock, the "wild" shoots take over and the cultivated variety dies. This ancient tree therefore shows not only past cultivation but ongoing care. I recount this story not only for its beauty and strangeness but because I think it helps us think about how to respond to the multiple crises and urgencies of our times. Slow and long-lived beings, in this case chestnut trees, have demonstrably been able to compel humans to take care of them for a very long time. The morphology of trees places a call upon us, to respond, to be responsible, and to care for them. Perhaps we can plan for the long term by attending to the shapes of trees.

Perhaps we can come to be passionately concerned with the strange, slow-lived beings that surround us, from trees to rivers to stones. These beings compel us, they call us to account, and they transform us, as when I come to notice grapevines running wild across abandoned fields. The stories we tell about the past and possible futures are a response to these beings. Such stories help us step aside from the stories of progress and environmental apocalypse that we too often are pulled into. Learning to notice the slow rhythms of trees presses me to tell stories about the past and the future. This is a demanding relationship, where storytelling is a matter of responding 
and of being responsible. The story has to be as right as I can get it. I have to respond to the obligation of the encounter, to the humans and non-humans who brought me there. These are the stories that I feel I have to tell, even while I know that each story is partial, limited, provisional.

It seems fitting to end with some element of doubt. I can tell stories about this tree, but I never fully know what it is or might become. As a forester, I know that trees often surprise you. A tree stump may send out new branches, or it may die. This ancient tree is hovering on the verge of life and death. At various times in the past it was a food source for peasants, a source of tannin for a nearby factory, an object of care for environmentalists concerned with local heritage. This tree is all and none of these things, it is still growing after the projects of all these humans have disappeared, it might grow on into another era. I find it helpful to remain passionately empirical, to remember that all of my perceptions, descriptions, and stories fail to fully capture what I describe. I remind myself that other stories and futures are possible.

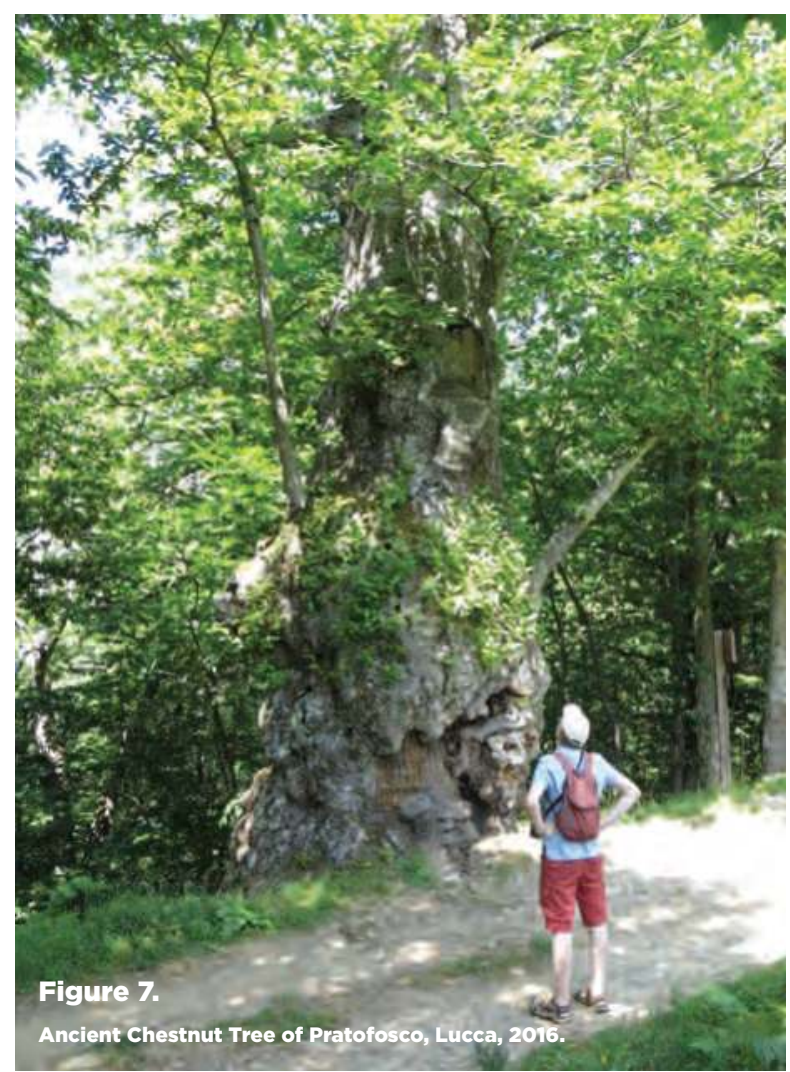




\section{notes}

1 "Peasant" is one of the most vexed words in the English language. I use the term to refer to the subsistence farmers who might have described themselves as "contadini." Present-day chestnut farmers might call themselves direct cultivators-"coltivatori diretti."

2. For a more complete description of this work, see Mathews, "Ghostly Forms and Forest Histories."

3. Mathews, Instituting Nature; Mathews, "Ghostly Forms and Forest Histories."

4. Giannini and Gabbrielli, "Evolution of Multifunctional Land-Use Systems”; Squatriti, Landscape and Change in Early Medieval Italy.

5. Sereni, Storia del Paesaggio Agrario Italiano.

6. Commissione delle Acque e Strade, "Disegno dello Sbocco del Rio di Vorno in Ozzeri." This drawing is undated, but was likely produced as part of repair works after a major flood in 1826.

7. Lightfoot et al., "Anthropogenic Burning."

\section{bibliography}

Commissione delle Acque e Strade. Archivio di Stato, Lucca, 1701-1800. "Disegno dello Sbocco del Rio di Vorno in Ozzeri." V. Mappe, Sezzione XXIX, n. 2, N. 29.

Giannini, R., and A. Gabbrielli. "Evolution of Multifunctional Land-Use Systems in Mountain Areas in Italy." Italian Journal of Forest and Mountain Environments 68, no. 5 (2013): 259-68.

Lightfoot, K. G., R. Q. Cuthrell, C. M. Boone, R. Byrne, A. S. Chavez, L. Collins, A. Cowart, R. R. Evett, P. V. A. Fine, D. Gifford-Gonzalez, M. G. Hylkema, V. Lopez, T. M. Misiewicz, and R. E. B. Reid. "Anthropogenic Burning on the Central California Coast in Late Holocene and Early Historical Times: Findings, Implications, and Future Directions." California Archaeology 5, no. 2 (2013): 371-90.

Mathews, A. S. "Ghostly Forms and Forest Histories." In Arts of Living on a Damaged Planet: Ghosts and Monsters of the Anthropocene, edited by Anna Lowenhaupt Tsing, Elaine Gan, Heather Anne Swanson, and Nils Bubandt, 145-56. Minneapolis: University of Minnesota Press, 2017.

_. Instituting Nature: Authority, Expertise, and Power in Mexican Forests. Cambridge, MA: MIT Press, 2011.

Sereni, E. Storia del Paesaggio Agrario Italiano. Roma-Bari: Editori Laterza, 1996 [1961].

Squatriti, P. Landscape and Change in Early Medieval Italy: Chestnuts Economy and Culture. Cambridge: Cambridge University Press, 2013. 


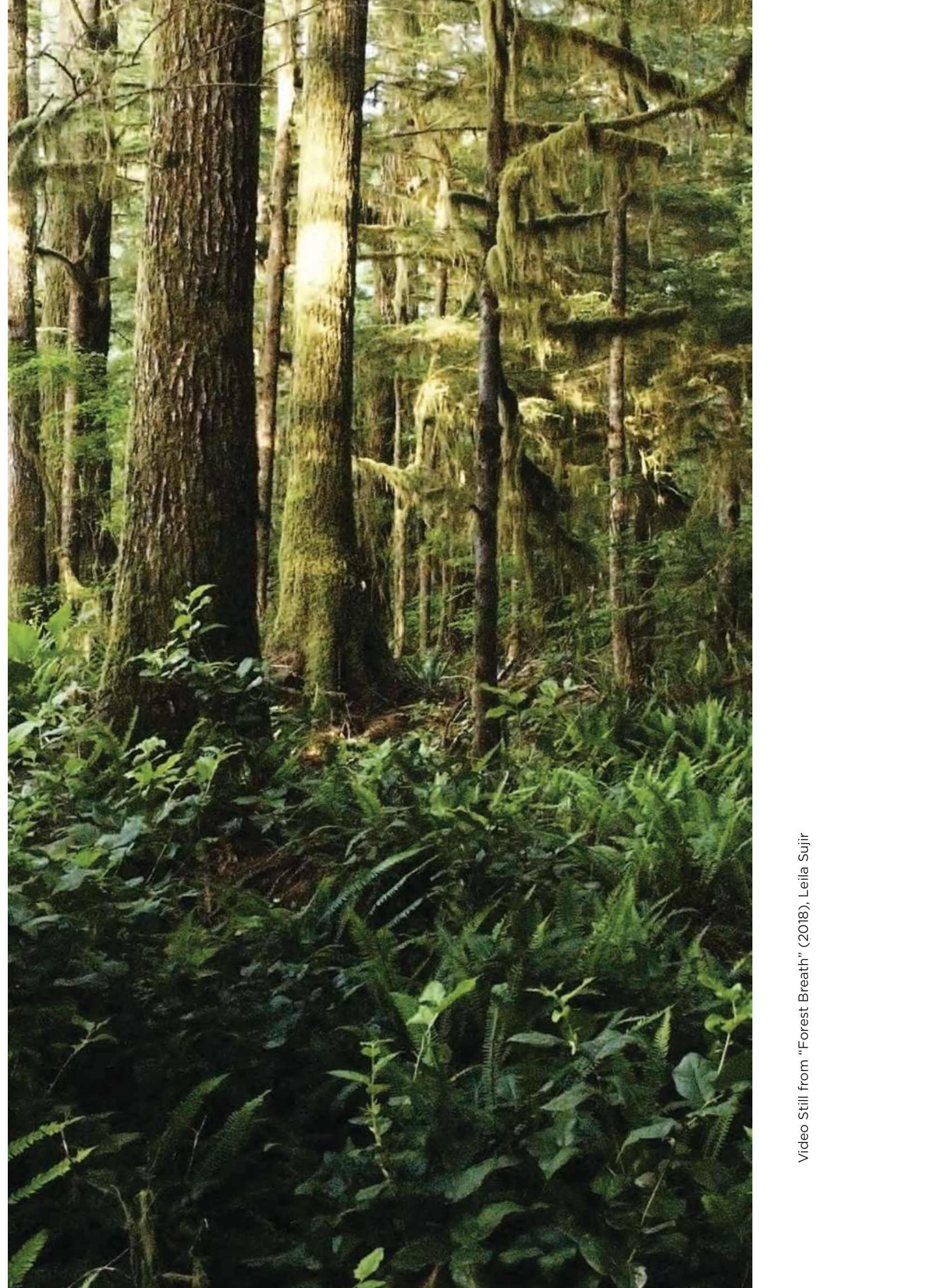




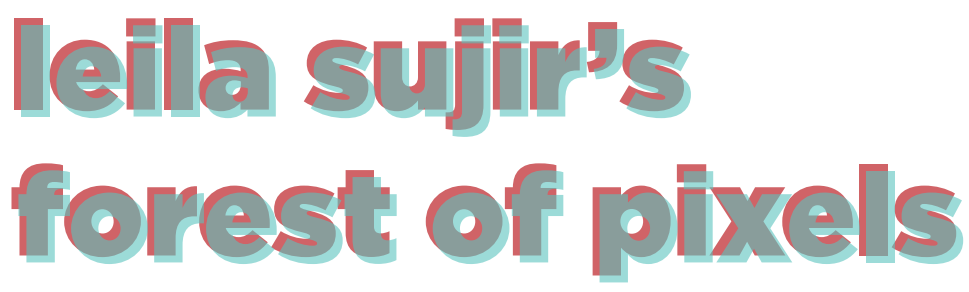

\section{nancy tousley}

Standing among the giant trees, stepping forward to watch gently bobbing ferns on the forest floor or water droplets falling from leaves, gazing ahead into the deep space of the woods: this is the experience of Leila Sujir's Forest Breath (2016-2018). As if the screen separating the viewer from the image has magically evaporated, the stereoscopic 3D video reaches into the viewer's space as she moves forward and from side to side of the image. The video space, a luminous volume, fills, expands, and empties. The ancient forest appears to breathe. A reversal of the time-honoured photographic spectacle of a tiny human standing next to a gigantic towering tree, this pixel-engendered journey into an old-growth forest is ground-level and intimate. It offers the experience of a wondrous living place, one that the curious embodied viewer is invited to enter imaginatively as if through an open portal. Sujir's aim is to walk you into a rainforest environment of trees that are hundreds of years old so as to say, "You are here."

Forest Breath draws on aspects of film, video, photography, and painting to create a virtual reality delivered via stereoscopic 3D video projections into a large lightbox. To see the $3 \mathrm{D}$ effects requires wearing optical polarized glasses, like the ones used to view commercial 3D films. Inside the box, which measures $283 \mathrm{~cm} \times 164 \mathrm{~cm} \times 62.5 \mathrm{~cm}\left(9^{\prime} \times 5^{\prime} \times 2^{\prime}\right)$, four forest views bloom, hold, and fade to a silvery green blur for two to three minutes each on a 10-minute rotational cycle. Emily Carr or nineteenth-century photographers 
like Carleton Watkins and Eadweard Muybridge would recognize some of the compositional strategies, though none worked at such a large scale. But even if Forest Breath is a major work in its own right, it represents only about one-third-Sujir describes it as a vertical slice-of what will be a mammoth stereoscopic 3D video installation, Forest!, curated by Haema Sivanesan for the Art Gallery of Greater Victoria.

Scheduled to open at the Art Gallery of Greater Victoria (AGGV) in 2024, Forest! has grown into an expanded media work with artistic, technological, social, and ecological dimensions. Forest Breath was made for the group exhibition Supernatural: Art, Technology and the Forest, which Sivanesan curated at the AGGV in 2018, as part sketch, part progress report, part rehearsal for what is to come. The exhibition was accompanied by Forest Breath: A Portrait in Progress, a one-day guided forest walk and a community screening in Port Renfrew, in an elementary school gymnasium, of a 16-foot expanse of raw uncut 3D video, recorded in 2016. The completed Forest! project will consist of a stereoscopic 3D video installation, two storeys high, that viewers will be able to walk into; a 10-day field school conducted on Vancouver Island in the rainforest near Port Renfrew; and a 360-degree video podcast for those who cannot attend in person. Concurrently, Sujir is making Forest Aerial, a 2D short film for XL Outer Worlds, a festival of expanded cinema curated by Janine Marchessault celebrating the fiftieth anniversary of IMAX, to be held in Toronto in the fall of 2019.

Sujir, an intermedia and video artist based in Montreal, where she is chair of Studio Arts at Concordia University, has worked with stereoscopic 3D video for more than a dozen years. Based on the mid-nineteenth-century stereoscope, it is an old technology expanded by new technological developments. Photographers of the American West, such as Watkins, produced stereo views of their photographs to be looked at through a stereoscope in the comfort of a Victorian parlour. "The mind feels its way into the very depths of the picture," wrote Oliver Wendell Holmes in 1859. "The scraggy branches of a tree in the foreground run out at us as if they would scratch our eyes out."1 Stereographs like these, the first attempt at virtual reality, are forerunners of the far more sophisticated and enveloping stereoscopic 3D video. Sujir speaks of the quality of its space as "elastic and dream-like ... ephemeral, yet capable of extending a sensation of volume, physicality, and presence to the viewer."

In her earlier work, Sujir used this elastic, doubled space to address immigration, migration, disorientation and loss, culture, and memory. Born in Hyderabad, India, in 1951, and a Canadian since childhood, she has often drawn as an artist on the culture and experi- 
116

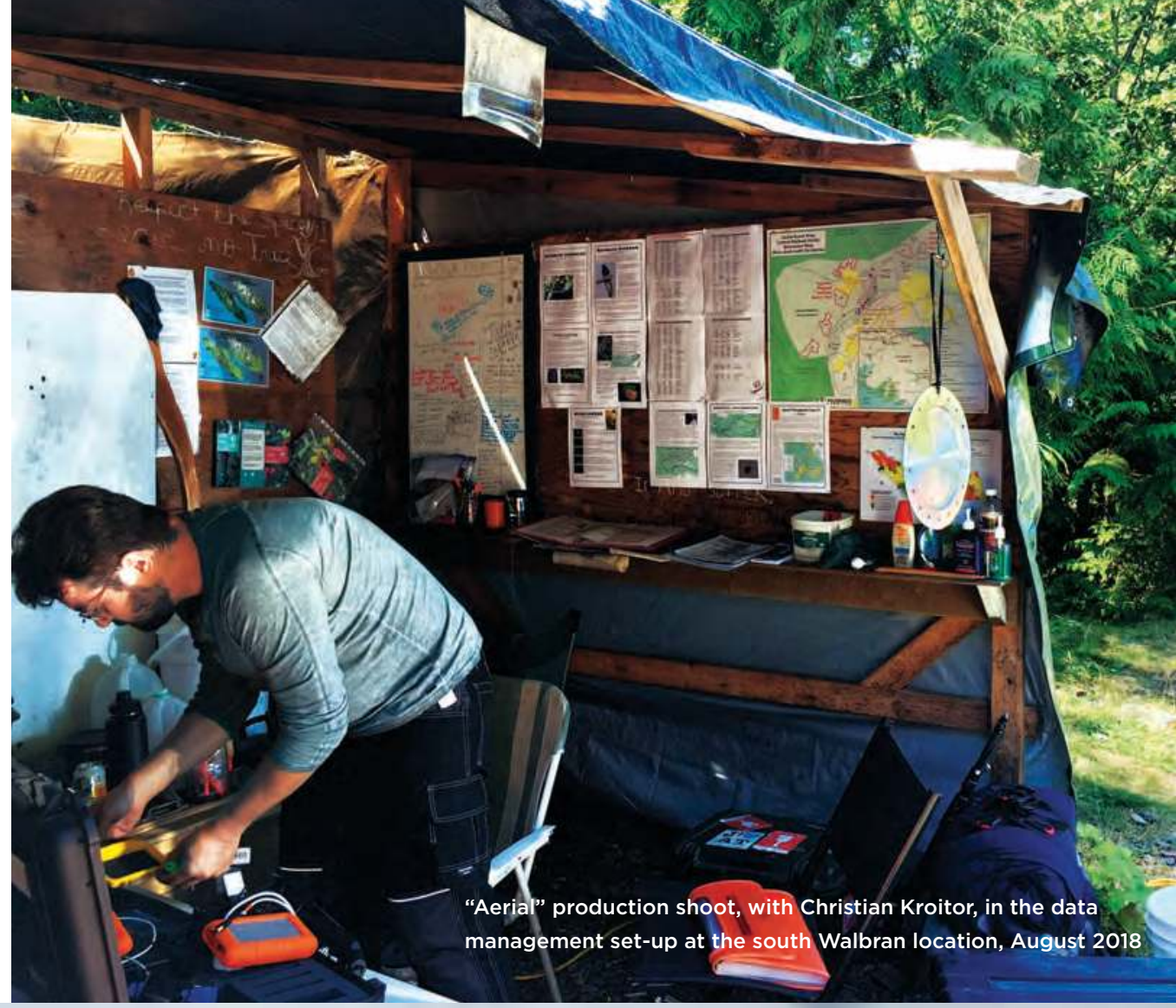

Old growth production shoot "Forest!" with artist director Leila Sujir at left, cinematographer Christian Kroitor at right, Big Lonely Doug location near Port Renfrew, June 2016, photo credit Christian Kroitor

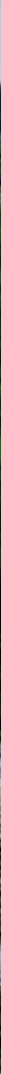


ences of the Sujir family. Her father Raghu, an airline pilot, died in a plane crash in Canada when he was in his mid-thirties. Her mother, Ruth Horricks-Sujir, who was from Calgary, Alberta, died on her daughter's birthday just short of a year before the artist began work on Forest! Biographical content is not visible in this work, as it is in others, but it is present nonetheless in the powerful connection between the artist and her subject. When Sujir was twenty-four, she thought she might die of cancer. As she recovered from surgery, her mother took her for walks in the rainforest near Tofino, on the west coast of Vancouver Island. Since then, she has thought of the rainforest as a space of healing, wonder, and contemplation: "The forest was where I found wonder and learned how to be alive again."

Sivanesan's invitation was for Sujir to make a major work for solo exhibition at the AGGV, for the newly renovated and expanded building slated to open in 2024. Sujir could have begun work by doing research at the provincial archives or going into the art gallery collections. Instead, following her intuition, she went directly to the forest without a shooting script. Her first concern was to work on creating space, that of the forest reconstituted within the elastic space of stereoscopic 3D, with which she would construct a walking viewer. To do this she reversed the usual technical steps. The filmmaking technique of pull focus is used during a shoot to change the focus within a shot from one object to another. Pull parallax is a special effects technique used in post-production. Pulling the parallax deepens or expands the space of a film or video image by making the foreground seem to move at a greater speed than the background. Working with cinematographer Chris Kroitor, grandson of IMAX co-founder Roman Kroitor, Sujir used pull parallax to video the forest and "pull" the moving image from relative flatness to extended 3D.

As a result, a viewer who walks toward Forest Breath feels the space of the video expand as it seems to move out toward her, producing a deeper and more immersive virtual reality. However, the effect does not work with a seated audience. Conditions set up by artworks can prescribe the way a viewer addresses them: Forest Breath constructs a mobile embodied viewer who interacts with its three-dimensionality.

In June 2016, Sujir shot stereoscopic 3D video at four locations in ancient forests on Vancouver Island: the Central Walbran Valley, located outside of Carmanah Walbran Provincial Park; Avatar Grove and Big Lonely Doug, northwest of Port Renfrew, along the Gordon River; and Red Creek Fir to the east. Sujir and Kroitor had to exercise ingenuity from the start, not only to reach remote forest areas, which had not yet been mapped, but also to shoot 3D stereoscopic video without a full crew and rigging. They 


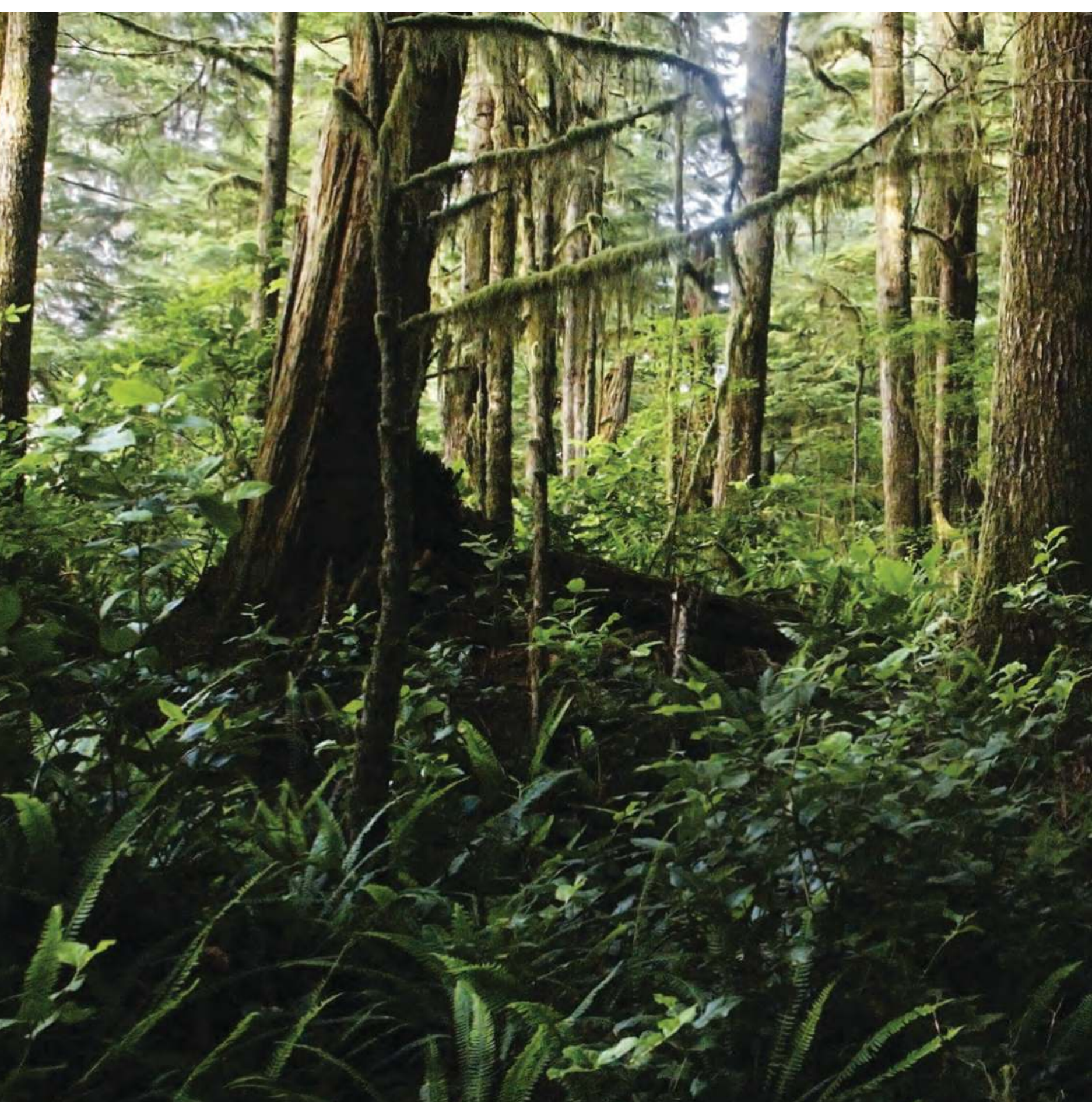




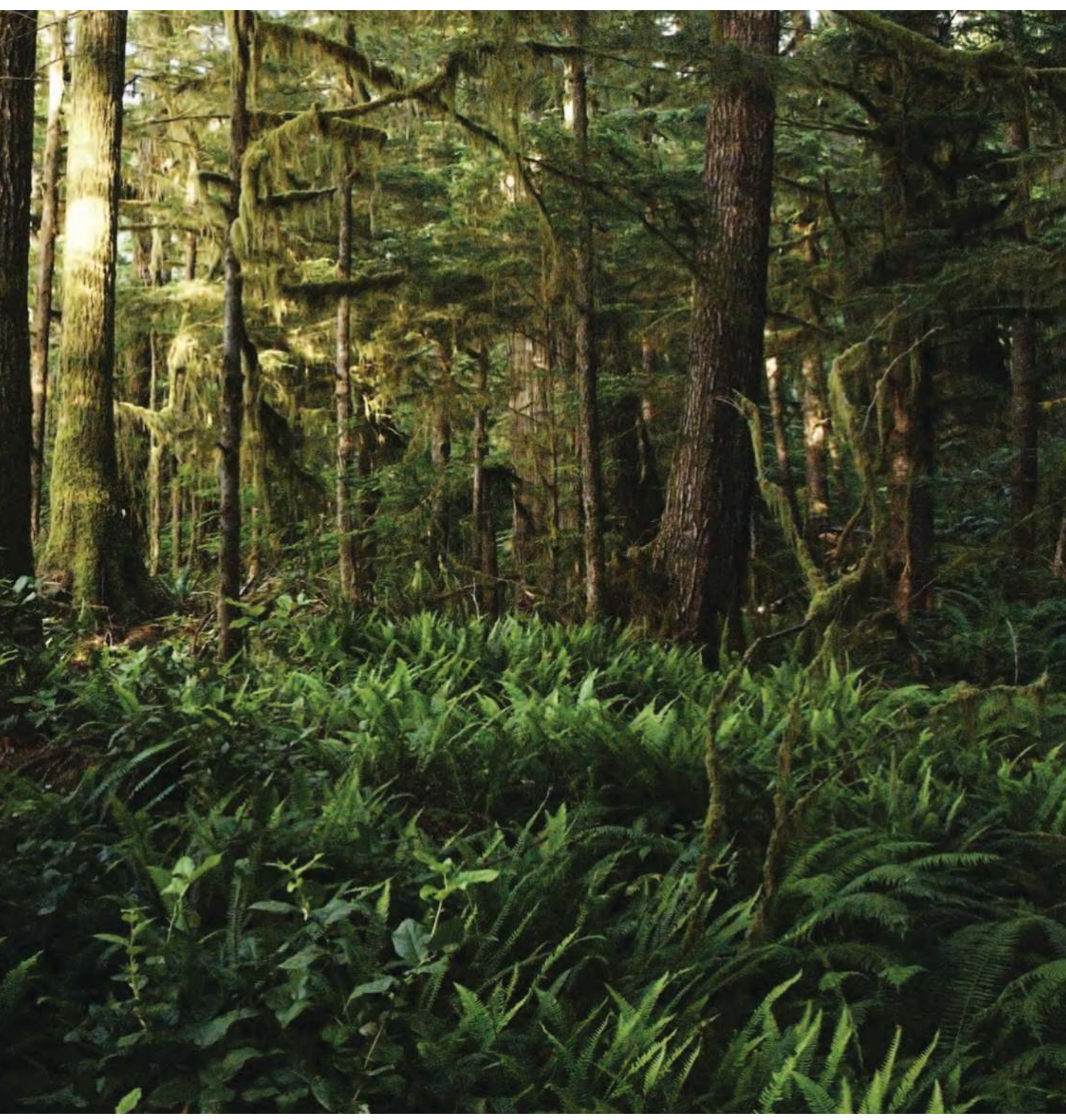

Video Still from "Forest Breath" (2018), Leila Sujir 
made the experimental shoots in 2016 with improvised equipment: two Sony F65 digital cameras that shoot $8 \mathrm{~K}$ ( 8,000 pixels, which is four times HD), mounted on an IMAX mirror rig. The two cameras recorded slightly different views that converged on the mirror to produce a 3D stereoscopic effect. Technical director Jorge Zavagno joined the shoot in 2018 for Forest Aerial, which took place at Emerald Pool, in the Central Walbran. There they shot with a RED camera, a large-format, ultra-high definition, digital motion picture camera that is physically small. Mounted on a drone, the RED camera was flown along the forest floor and up the trunks of trees, emulating the flight of a hummingbird. A soundtrack added in post-production will introduce the bird's hum with sounds played by a musician on a trumpet.

The story does not stop here. Forest Breath was an experimental art project that developed into a research project. Forest! quickly turned into a project not only with artistic and technological importance but also with social and ecological implications, making it exemplary of process in which research grows into art making. The long lead time provided by the AGGV and Sivanesan, the artist's curatorial collaborator, was part of what made this possible. As well, Sivanesan introduced her to members of the Pacheedaht First Nation, while Sujir's brother Jay introduced her to forest ecologist Andy Mackinnon, who in turn introduced her in Port Renfrew to the Friends of Carmanah Walbran, TJ Watt with the Ancient Forest Alliance, Handsome Dan with the Chamber of Commerce, and Jack Julseth with Wild Renfrew, a resort that promotes ecotourism. Sujir's meetings with community members and others set off a chain of interactions that took the project forward as if it were gathering its own momentum.

Vancouver Island harbours what the Ancient Forest Alliance calls "the grandest old growth forests in Canada," ${ }^{2}$ which are endangered by the rapid, continued cutting of old-growth trees. Sujir's first contact among BC environmentalists, forest ecologist Andy MacKinnon, advised her to start in the unprotected old-growth forests of the Central Walbran Valley because "they might not be there when you come back." The forestry company TealJones has proposed logging at eight sites in the valley, located on Crown land that is the unceded traditional territory of the Pacheedaht First Nation. One proposal has been approved, although logging had not yet begun at this writing. In February 2017, Sujir met Sarah Turner, a new professor in Geography, Planning, and Environment at Concordia, who was involved as a high-school student in the "War in the Woods," massive protests against clear-cutting by Macmillan-Bloedel in the Walbran Valley in the 1990s. One outcome was the creation of the Carmanah Walbran Provincial Park, but twenty-five years on, BC's ancient forests remain in crisis. According to the Sierra Club BC, the province has since lost 30 per cent of its remaining old-growth forests. 


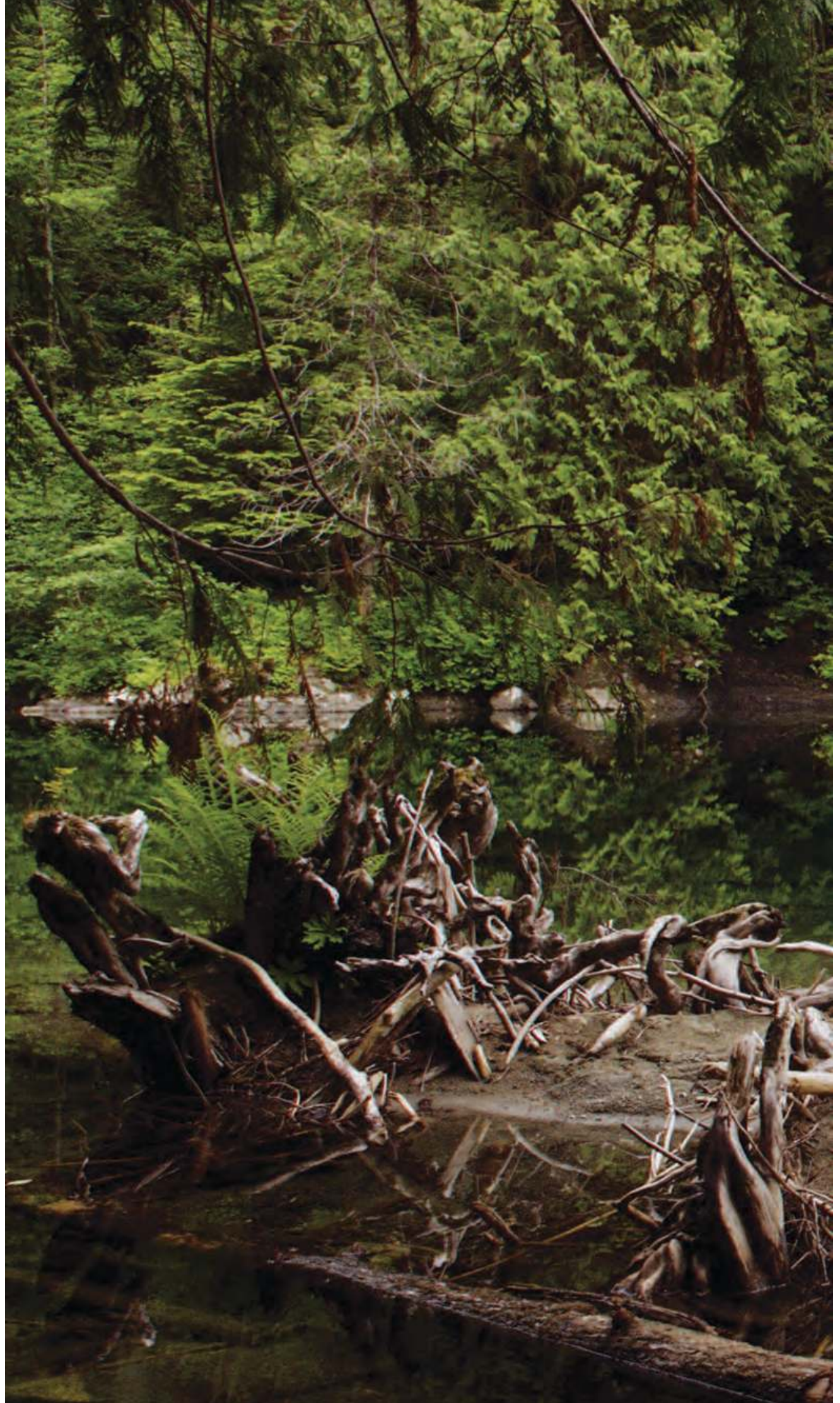



That February, Sujir also attended a meeting at which a logger's union representative read aloud a resolution to stop cutting old-growth trees. This marked a significant change from the conflict between environmentalists and loggers in the "War in the Woods." In May 2017, Sujir met Sarah Turner's mother, ethnobotanist Nancy Turner, who teaches at the University of Victoria, and attended her symposium, Indigenous Peoples' Land Rights and the Roles of Ethnobotany and Ethnoecology. At the symposium, the artist gained introduction to Indigenous communities on Vancouver Island's west coast and to the concept of the "tribal park," land use that allows for cultural practices such as "culturally modified trees." Next she met Suzanne Simard, a forestry ecologist who teaches at the University of British Columbia, whom she had been aware of since June 2016. Simard is known for her research on how trees communicate and share resources through underground networks of fungi and roots that are connected to a hub or mother tree, the oldest and tallest in the forest. They met in July 2017, in the Harrop Procter area of $\mathrm{BC}$, at a site where Simard collects research data on carbon exchange among trees as the means of communication. There Sujir realized that, indeed, the place to talk about the forest was in the forest.

Turner, Simard, members of Indigenous communities, loggers, ecologists, environmentalist groups, city and provincial officials, and others with a vested interest in the health and survival of old-growth forests have been invited to participate in the 2023 Forest! field school. Sujir's and Turner's Concordia students who attend will receive three course credits. The issues are complex and political. Sujir's intention is to make an artwork that will bring the discussion of all these issues into the public arena where interaction and discussion can lead to larger social change. Forest! is a catalyst for conversation, one that Sujir feels confident has already started.

\section{notes}

1. Oliver Wendell Holmes, "The Stereoscope and the Stereograph."

2. Ancient Forest Alliance, "Massive Cutting."

\section{bilbliography}

Ancient Forest Alliance."Massive Cutting of Canada's Grandest Old-Growth Forests Coordinated by BC Government's Logging Agency." Media release, May 18, 2018.

https://www.ancientforestalliance.org/media-release-massive-cutting-of-canadaaes-grandest-oldgrowth-forests-coordinated-by-bc-governmentaes-logging-agency-near-record-sized-douglasfirs-found-in-nahmint-valley-on-van/.

Holmes, Oliver Wendell. "The Stereoscope and the Stereograph.” The Atlantic (June 1859). https://www. theatlantic.com/magazine/archive/1859/06/the-stereoscope-and-the-stereograph/303361/, accessed January 2019. 


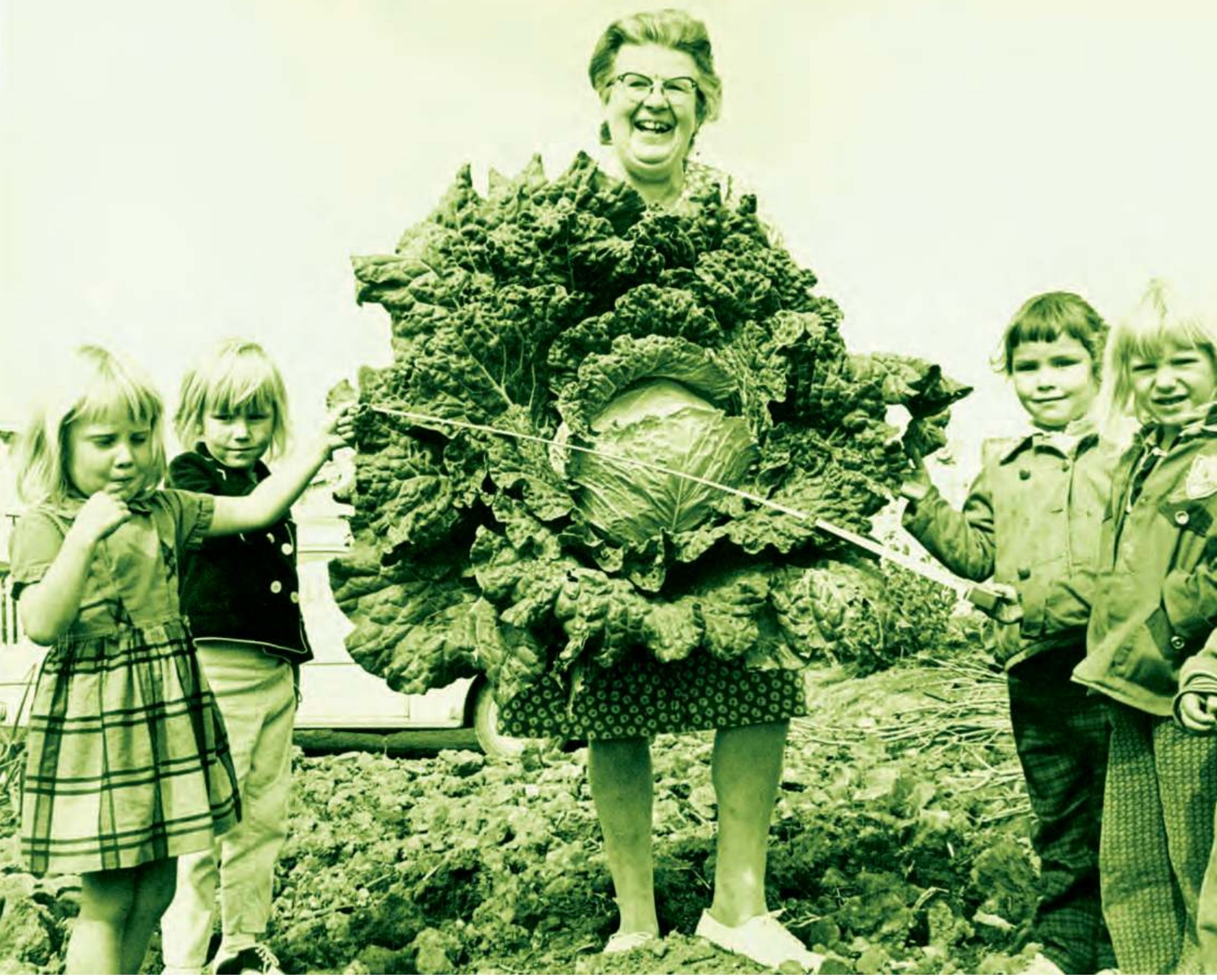

Mrs. George Catt holding the 20 pound cabbage she grew in her garden, Calgary, Alberta, 1965. Glenbow Archives, PA-1599-278-12. 


\section{contributors}

Nikki Anguish is a horticulturalist with a professional focus in arboriculture. As an urban forestry superintendent with Calgary Parks, she has managed the Civic Tree Nursery and worked on the Re-Tree project responsible for the initial response, recovery, and subsequent reforestation of Calgary's urban canopy after the snowstorm of 2014 dubbed "Snowtember" decimated the urban forest. Having grown up in small-town Saskatchewan, she has always had a passion for trees; she is fortunate to be able to use her passion to benefit present and future Calgarians.

James F. Cahill Jr. is the head of the Cahill Lab of Experimental Plant Ecology at the University of Alberta. He maintains that plants do "behave" and lead anything but solitary and sedentary lives. He has a particular fondness for trying to understand how plants forage for resources, cope with enemies, and alter competitive strategies over ecological and evolutionary time scales. A key goal of this work is to understand how these social and behavioural interactions impact patterns of biodiversity, and the functioning of natural systems. He has appeared on Nature (PBS) and The Nature of Things (CBC) in recent years, showing viewers that plants are a lot more like animals than we ever imagined.

Jim Ellis is a professor of English and director of the Calgary Institute for the Humanities. $\mathrm{He}$ is the author of Sexuality and Citizenship (2003) and Derek Jarman's Angelic Conversations (2009), and the editor of the previous volumes in the ClH's Community Seminar series, Calgary, City of Animals (University of Calgary Press, 2017) and Water Rites: Reimagining Water in the West (University of Calgary Press, 2018). 
Erina Harris is a Canadian poet. She is the author of The Stag Head Spoke (2014). She is a former Calgary Institute of the Humanities Frances Spratt Graduate Fellow, and is currently conducting a SSHRC Postdoctoral Fellowship in Poetics and Pedagogy at the University of Alberta. She is at work editing the poetry manuscript Persephone's Abecedarium: An Alphabet Play (An Ecopoetical Adaptation of the "Hymn to Demeter").

M. N. Hutchinson has been a working photographer for over thirty years, with a commercial business that included album covers for A\&M Records and being a nationally recognized professional artist. His practice has been contrarily cross-media. He has exhibited photographs, printmaking, sculptural installations, audio, video, and performance works. He completed his MFA in New Media at the University of Calgary and has presented his work and theories in over twenty lectures and public presentations. He has been the recipient of several grants and awards both nationally and locally. He has also invested a considerable part of his career in the community, having been both a co-director of Truck Gallery and photography facilitator at the Banff Centre, as well as sitting on several boards.

Megan Ljubotina is an MSc student at the University of Alberta who is broadly interested in plant behaviour, and specifically in how plants forage for resources belowground. She is fascinated by how plants can take in information and respond to their environments in complex and unexpected ways. 
Alberta-born artist Attilla Richard Lukacs graduated from the Emily Carr Institute of Art and Design in Vancouver, British Columbia, in 1985. Lukacs became famous for his large, ambitious paintings depicting exaggerated masculine figures in the classical tradition. His range as an artist is evident in his stunning abstract paintings and collages as well as a collection of paintings of flowers and trees and numerous etchings.

Habba Mahal is an MSc student studying plant ecology at the University of Alberta in the Cahill Lab. She recently finished her BSc at the $U$ of A, with her undergraduate research on how plants react differently when exposed to the hormones released by the roots of kin plants versus stranger plants. Her graduate work delves deeper into plant behaviour by shifting the focus to plant decision making when faced with tough choices, such as helping kin plants or competing against them for nutrients. When not tending to the plants in her experiments, she can be found expanding her own mini plant-jungle at home and enjoying the great outdoors.

Andrew S. Mathews is an associate professor of Anthropology at the University of California Santa Cruz. His research focuses on the culture of forestry and conservation institutions, from state bureaucracies, to NGOs, to Indigenous communities. Mathews is the author of Instituting Nature: Authority, Expertise, and Power in Mexican Forests (MIT Press, 2011). He is committed to integrating natural and social science approaches to environmental problem solving. Mathews is currently working on the historical ecology, natural history, and climate politics of Italian forests. Because Mediterranean ecosystems have evolved to cope with dramatically variable climate, powerful disturbances, and intense human modification, they are good places to learn about climate change. 
Ciara Mckeown is a public art commissioner, curator, director, producer, and project manager who has worked with multiple arts organizations across Canada and the United States for over a decade. She has recently started her own practice writing, researching, and working with clients on public art planning. Ciara is an executive board member with Public Art Dialogue, and was co-organizer of "Public Art: New Ways of Thinking and Working," a symposium hosted by York University in May 2017. The first of its kind in Canada, the symposium invited cross-disciplinary perspectives and research to critically examine the current state of Canadian contemporary public art practices. Ciara holds an MA from New York University and a BA from McGill University.

Wes Olson worked for several years as a wildlife technician for the Yukon Government and then, after a stint at the Banff School of Fine Arts in 1981, began a career with Parks Canada as a National Park Warden in Banff, Waterton Lakes, Elk Island, Prince Albert, and Grasslands National Parks. He has the unique ability to combine his extensive scientific knowledge about bison with his talents using graphite, watercolour, oil painting, and mixed medium artwork to capture the buffalo and other wildlife in their natural environments. With photographer Johane Janelle, he is co-author of the books Portraits of the Bison: An Illustrated Guide to Bison Society (2005) and A Field Guide to Plains Bison (2011). 
Laura St. Pierre is a visual artist based in Saskatoon. Her installations, photographs, and video works have been exhibited throughout Canada and abroad. Since completing an MFA at Concordia University in Montreal, she has received numerous grants and awards from provincial funding bodies and the Canada Council for the Arts. Recent exhibitions include Winter Garden at VivianeArt (Calgary) as part of the Exposure Photography Festival; The Museum of Future History at the Dunlop Art Gallery (Regina), the Maison des Artistes (Winnipeg), and Foire papier (Montreal); "La vie fragile” at Galerie LUZ du Belgo (Montreal); and Spectral Garden // at PAVED Arts (Saskatoon).

Nancy Tousley, recipient of a Governor General's Award for Visual and Media Arts for outstanding contribution in 2011, is a senior art critic, arts journalist, and independent curator. Her work has been recognized with many prestigious awards, including the Board of Governors of the Alberta College of Art and Design Award of Excellence (1997), the Ontario Association of Art Galleries award for best curatorial writing on contemporary art (1999 and 2001), the Canadian Museums Association's award for outstanding achievement in arts journalism (2002), and the medal of the Royal Canadian Academy of Arts (2009). She was named a Fellow of the Glenbow Museum in 2018. 
Patrícia Vieira is an associate professor and researcher at the Centre for Social Studies, University of Coimbra / Georgetown University. Her latest books are States of Grace: Utopia in Brazilian Culture (SUNY University Press, 2018) and the co-edited volume The Language of Plants: Science, Philosophy, Literature (University of Minnesota Press, 2017). Many of her studies contribute to the debate on the complex relationship between humans and non-human beings. For more information, check www.patriciavieira.net.

Jennifer Wanner is a multidisciplinary visual artist based in Calgary, Alberta, who has exhibited in Poland and throughout Canada at galleries such as the Glenbow (Calgary) and the Dunlop Art Gallery (Regina). Her work explores how art-historical constructs and scientific objective means of observing the natural world have shaped our Western concept of nature. She holds a BFA from the University of Calgary and ACAD, as well as an MFA from Western University. Her work is in the collection of the Alberta Foundation for the Arts and was included in the 2013 Alberta Biennial of Contemporary Art. She is represented by the Paul Kuhn Gallery.

Katherine Ylitalo is an independent curator, writer, and educator with extensive museum experience in western Canada, and special interest in contemporary art and gardens. A graduate of Stanford University, she has taught at colleges and universities in Ontario, Nova Scotia, Saskatchewan, and Alberta. Currently she works at the Founders' Gallery, University of Calgary at The Military Museums of Calgary and is curator at Bow Valley College. A Master Gardener, garden historian, and horticulturalist, she has helped to steward the MacDonald Butterfly Garden at the Walter Phillips Gallery at the Banff Centre since 2008. 

UNIVERSITY OF CALGARY

University of Calgary Press press.ucalgary.ca

Intertwined Histories: Plants in Their Social Contexts Edited by Jim Ellis 978-1-77385-090-0 (pb)

Water Rites: Reimagining Water in the West Edited by Jim Ellis 978-1-55238-997-3 (pb)

Writing Alberta: Building on a Literary Identity Edited by George Melnyk and

Donna Coates 978-1-55238-890-7 (pb)

The Frontier of Patriotism: Alberta and the First World War Edited by Adriana A. Davies and

Jeff Keshen

978-1-55238-834-1 (pb)

So Far and Yet So Close: Frontier Cattle Ranching in Western Prairie Canada and the Northern Territory of Australia

Warren M. Elofson

978-1-55238-794-8 (pb)

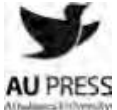

Athabasca University Press aupress.ca

Fish Wars and Trout Travesties: Saving Southern Alberta's Coldwater Streams in the 1920s

George Colpitts 978-1-927356-71-5 (pb)

The Medium Is the Monster: Canadian Adaptations of Frankenstein and the Discourse of Technology

Mark A. McCutcheon

978-1-77199-236-7 (cl)

978-1-77199-224-4 (pb)

Public Deliberation on Climate Change:

Lessons from Alberta Climate Dialogue

Edited by Lorelei L. Hanson 978-1-77199-215-2 (pb)

Visiting With the Ancestors: Blackfoot Shirts in Museum Spaces Laura Peers and Alison K. Brown 978-1-77199-037-O (pb)

Alberta Oil and the Decline of Democracy in Canada

Edited by Meenal Shrivastava and

Lorna Stefanick

978-1-77199-029-5 (pb)
(1) UNIVERsity of ALberta PRESS

University of Alberta Press uap.ualberta.ca

Feminist Acts:

Branching Out Magazine and the Making of Canadian Feminism

Tessa Jordan

978-1-77212-484-2 (pb)

Keetsahnak / Our Missing and Murdered Indigenous Sisters

Kim Anderson, Maria Campbell and Christi Belcourt, Editors

978-1-77212-367-8 (pb)

Trudeau's Tango:

Alberta Meets Pierre Elliott Trudeau, 1968-1972

Darryl Raymaker

978-1-77212-265-7 (pb)

Seeking Order in Anarchy: Multilateralism as State Strategy

Robert W. Murray, Editor

978-1-77212-139-1 (pb)

Upgrading Oilsands Bitumen and Heavy Oil

Murray R. Gray

978-1-77212-035-6 (hc) 


\section{intertwined histories}

plants in their social contexts

\section{How do we understand the boundaries of individual creatures? \\ What are the systems of interdependency that bind all living creatures together?}

Plants were among the the first to colonize the planet. They created the soil and the atmosphere that made life possible for animals. They are some of the largest and oldest life forms on Earth. In spite of their primacy, Western cultures have traditionally regarded plants as the lowest life forms, lacking mobility, sensation, and communication. But recent research argues that plants move and respond to their environment, communicate with each other, and form partnerships with other species.

Art, poetry, and essays by cultural anthropologists, experimental plant biologists, philosophers, botanists and foresters expose the complex interactions of the vibrant living world around us and give us a lens through which we can explore our intertwined histories.

Jim Ellis is Professor of English and Director of the Calgary Institute for the Humanities at the University of Calgary. He has written widely on art, literature, and film. 